\title{
Clinical guidelines for the management of patients with transposition of the great arteries with intact ventricular septum
}

\section{The Task Force on Transposition of the Great Arteries of the European Association for Cardio-Thoracic Surgery (EACTS) and the Association for European Paediatric and Congenital Cardiology (AEPC)}

Authors/Task Force Members: George E. Sarris* (Chairperson) (Greece), Christian Balmer (Switzerland), Pipina Bonou (Greece), Juan V. Comas (Spain), Eduardo da Cruz (USA), Luca Di Chiara (Italy), Roberto M. Di Donato (United Arab Emirates), José Fragata (Portugal), Tuula Eero Jokinen (Finland), George Kirvassilis (USA), Irene Lytrivi (USA), Milan Milojevic (Netherlands), Gurleen Sharland (UK), Matthias Siepe (Germany), Joerg Stein (Austria), Emanuela Valsangiacomo Büchel (Switzerland) and Pascal R. Vouhé (France)

EACTS Clinical Guidelines Committee Members: Miguel Sousa-Uva (Chairperson) (Portugal), Umberto Benedetto (UK), Giuseppe Cardillo (Italy), Manuel Castella (Spain), Martin Czerny (Germany), Joel Dunning (UK), Mark Hazekamp (Netherlands), Stuart Head (Netherlands), Neil J. Howell (UK), Matthias Thielmann (Germany) and Tómas Gudbjartsson (Iceland)

Keywords: Transposition of the great arteries (TGA); Arterial switch operation (ASO); Jatene operation

First published online: 2 March 2017

Table of Contents

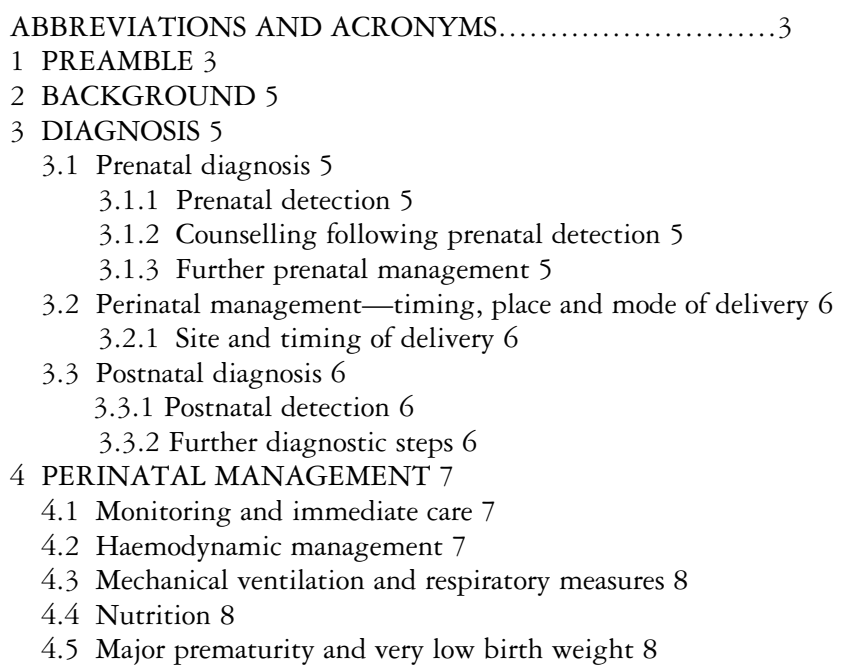

Corresponding author. Athens Heart Surgery Institute, Leoforos Kifissias 2, Amaroussion, 15125 Athens, Greece. Tel: +30-6932-601020; fax: +30-210-6836013; e-mail: gsarris@mac.com (G.E. Sarris).

Disclosure: The members of the Task Force have provided disclosure statements of all relationships that might be perceived as real or potential sources of conflicts of interest. These disclosure forms are kept on file at the headquarters of the EACTS/AEPC. The Committee report received its entire financial support from the EACTS and AEPC, without any involvement of the pharmaceutical, device or surgical industries 


\section{Table of Contents continued}

\section{SURGERY FOR TRANSPOSITION OF THE GREAT ARTERIES WITH INTACT VENTRICULAR SEPTUM 9}

5.1 Timing for surgery of TGA IVS 9

5.2 Adequacy of left ventricular myocardial mass 9

5.2.1 Left ventricular mass regression 9

5.2.2 Assessment of left ventricular preparedness 10

5.3 Training of the left ventricle for a delayed arterial switch operation 10

5.3.1 Introduction and pathophysiological issues 10

5.3.2 Indications for a two-stage arterial switch operation 10

5.3.3 Types of left ventricular training and technical aspects 10

5.3.3.1 Hypoxic (pre-ASO) left ventricular training 10

5.3.3.2 Normoxic (post-ASO) left ventricular training 11

5.3.4 Results of left ventricular training for a delayed arterial switch operation 11

5.3.5 Optimal time interval between stages 11

5.4 Surgical techniques and intraoperative surgical management 12

5.4.1 Intraoperative parameters and cardiopulmonary bypass 12

5.4.2 Coronary transfer 13

5.4.3 Right ventricular outflow tract reconstruction 14

5.4.4 Atrial septal defect in TGA IVS 14

6 PERIOPERATIVE AND POSTOPERATIVE MANAGEMENT 15

6.1 Anaesthetic management 15

6.1.1 Monitoring 15

6.1.2 Induction and maintenance of anaesthesia 16

6.2 Pre-cardiopulmonary bypass management 16

6.3 Cardiopulmonary bypass and anaesthesia 16

6.4 Separation from cardiopulmonary bypass 17

6.5 Transfer to the intensive care unit 17

6.5.1 Postoperative management in the intensive care unit 18

6.5.1.1 Transition and handover from the operating room 18

6.5.1.2 Haemodynamic and tissue perfusion monitoring 18

6.5.1.3 Ancillary evaluation 18

6.5.1.4 Haemodynamic management 18

6.5.1.5 Management of rhythm and conduction disorders 18

6.5.1.6 Low cardiac output syndrome 19

6.5.1.7 Extracorporeal life support 19

6.5.1.8 Sedation and analgesia 19

6.5.1.9 Ventilation and airway management 20

6.5.1.10 Fluid and electrolyte management 20

6.5.1.11 Renal management 20

6.5.1.12 Feeding and nutrition 20

7 SPECIAL TOPICS 20

7.1 Atrial switch-is there a role for it? 20

7.1.1 Introduction 20

7.1.2 Current role of atrial switches 21

7.1.3 Who still knows how-and is able-to perform this operation? 21

7.1.4 Treatment for late failure of the systemic right ventricle 21

7.1.4.1 Medical therapy for TGA patients with systemic right ventricular failure 21

7.1.4.2 Cardiac devices for TGA patients with systemic right ventricular failure 21

7.1.4.3 Surgery for patients with TGA with right ventricular/ tricuspid valve dysfunction 21

7.1.4.4 Methods for conversion of atrial switch to an ASO 21

7.1.4.5 Indications and timing for conversion of atrial switch to an ASO 21

7.1.4.6 Pulmonary artery banding—operative and postoperative management 22

7.1.4.7 Interim follow-up during left ventricular training 22

7.1.4.8 Anatomical correction-operative and postoperative management 22

7.1.4.9 Results for anatomic conversion of TGA after the Mustard or Senning operation 22

7.1.4.10 Heart transplant 22

7.2 Cardiology follow-up protocols 23

7.3 Arrhythmias 24

8 REOPERATIONS AND INTERVENTIONS FOR MANAGEMENT OF LATE COMPLICATIONS 24

8.1 Introduction 24

8.2 Reoperations for neopulmonary outflow tract lesions 24

8.2.1 Relief of neopulmonary outflow tract obstruction 24

8.2.1.1 Neopulmonary outflow tract obstruction: prevalence and incidence 24

8.2.1.2 Neopulmonary outflow tract obstruction: patient-related risk factors 24

8.2.1.3 Neopulmonary outflow tract obstruction: surgery-related risk factors 25 


\section{Table of Contents continued}

8.2.1.4 Neopulmonary outflow tract obstruction: indications for treatment 25

8.2.1.5 Neopulmonary outflow tract obstruction: intervention 25

8.2.2 Treatment of neopulmonary valve regurgitation 25

8.2.2.1 Neopulmonary valve regurgitation: prevalence and incidence 25

8.2.2.2 Neopulmonary valve regurgitation: potential risk factors 25

8.2.2.3 Neopulmonary valve regurgitation: indications for treatment 25

8.3 Reoperations for left ventricular outflow tract lesions 26

8.3.1 Treatment of neoaortic valve regurgitation 26

8.3.1.1 Neoaortic regurgitation and root dilatation: prevalence and incidence 26

8.3.1.2 Neoaortic regurgitation and root dilatation: patient-related risk factors 26

8.3.1.3 Neoaortic regurgitation and root dilatation: surgery-related risk factors 26

8.3.1.4 Neoaortic root dilation and neoaortic valve regurgitation: treatment 26

8.3.2 Relief of neoaortic outflow tract obstruction 27

8.4 Reoperations for coronary lesions 27

8.4.1 Mechanisms for long-term declining coronary function 27

8.4.2 Coronary lesions: prevalence, incidence and diagnosis 27

8.4.3 Coronary lesions: patient-related risk factors 27

8.4.4 Coronary lesions: surgery-related risk factors 28

8.4.5 Residual/recurrent coronary lesions: indications and management 28

8.4.5.1 Surgical approaches 28

8.4.5.2 Percutaneous transluminal coronary angioplasty in infants and young children 28

8.5 Other reoperations for late complications 29

8.5.1 Treatment of tracheobronchial compression 29

8.5.2 Treatment of persistent pulmonary hypertension 29

8.5.3 Treatment of transposition of the great arteries with aortopulmonary collaterals 29

8.5.4 Treatment of residual mitral regurgitation 29

\begin{tabular}{|c|c|}
\hline AEPC & $\begin{array}{l}\text { Association for European Paediatric and Congenital } \\
\text { Cardiology }\end{array}$ \\
\hline ASD & atrial septal defect \\
\hline ASO & arterial switch operation \\
\hline BAS & balloon atrial septostomy \\
\hline CMR & cardiovascular magnetic resonance \\
\hline $\mathrm{CO}_{2}$ & carbon dioxide \\
\hline $\mathrm{CPB}$ & cardiopulmonary bypass \\
\hline CT & computed tomography \\
\hline CVP & central venous pressure \\
\hline DHCA & deep hypothermic circulatory arrest \\
\hline EACTS & European Association for Cardio-Thoracic Surgery \\
\hline ECG & electrocardiogram \\
\hline ECLS & extracorporeal life support \\
\hline FFP & fresh frozen plasma \\
\hline $\mathrm{FiO}_{2}$ & fraction of inspired oxygen \\
\hline ICU & intensive care unit \\
\hline IV & intravenous \\
\hline IVS & intact ventricular septum \\
\hline JET & junctional ectopic tachycardia \\
\hline LCOS & low cardiac output syndrome \\
\hline LVOT & left ventricular outflow tract \\
\hline MRI & magnetic resonance imaging \\
\hline NO & nitric oxide \\
\hline NIRS & near-infrared spectroscopy \\
\hline $\mathrm{O}_{2}$ & oxygen \\
\hline $\mathrm{PaCO}_{2}$ & partial pressure of arterial carbon dioxide \\
\hline $\mathrm{PaO}_{2}$ & partial pressure of arterial oxygen \\
\hline PGE1 & prostaglandin E1 \\
\hline pRIFLE & $\begin{array}{l}\text { Pediatric Risk, Injury, Failure, Loss, End-Stage Renal } \\
\text { Disease }\end{array}$ \\
\hline PTFE & polytetrafluoroethylene \\
\hline 14 & pulmonary vascular resistance \\
\hline
\end{tabular}

$\begin{array}{ll}\mathrm{RBC} & \text { red blood cell } \\ \mathrm{RVOT} & \text { right ventricular outflow tract } \\ \mathrm{SaO}_{2} & \text { arterial oxygen saturation } \\ \mathrm{SvO}_{2} & \text { venous oxygen saturation } \\ \mathrm{TGA} & \text { transposition of the great arteries } \\ \mathrm{TOE} & \text { transoesophageal echocardiogram } \\ \text { VAD } & \text { ventricular assist device } \\ \text { VSD } & \text { ventricular septal defect }\end{array}$

\section{Preamble}

Guidelines summarize and evaluate all available evidence with the aim of assisting physicians in selecting the best management strategy for an individual patient suffering from a given condition, taking into account the impact on outcome and the risk-benefit ratio of diagnostic or therapeutic means. Guidelines are no substitutes for textbooks, primary literature sources, or clinical evaluation and judgment. Guidelines and recommendations should help physicians to make decisions in their daily practice. However, the ultimate specific decisions regarding the care of an individual patient must be made by his/her responsible physician(s).

A large number of guidelines have been issued in recent years by many societies and organizations. Because of the impact of guidelines on clinical practice, quality criteria for their development have 
been established to make the formulation of guidelines transparent to the user.

We followed the recommendations for formulating guidelines issued by the European Association for Cardio-Thoracic Surgery (EACTS) [1].

Members of this Committee were selected by the EACTS Congenital Domain and the Association for European Paediatric and Congenital Cardiology (AEPC) to represent all specialities involved with the medical and surgical care of patients with transposition of the great arteries (TGA). The following complex transposition cases remain outside the scope of this article: TGA with aortic coarctation or arch hypoplasia, TGA with ventricular septal defect (VSD) with or without left ventricular outflow tract (LVOT) obstruction, TGA or malposition of the great arteries associated with double-outlet right ventricle or in anatomical or functionally univentricular hearts, and congenitally corrected transposition. In brief, experts in the field were selected and undertook a comprehensive review of the published evidence for management of the various clinically important aspects of this common congenital cardiac anomaly. A critical evaluation of diagnostic and therapeutic procedures was performed. The level of evidence and the strength of recommendation of particular management options were weighed and graded according to predefined scales, as depicted in Tables 1 and 2.

A uniform wording of the stated recommendations to reflect the strength of evidence has been used, in accordance with EACTS policy, as recently published [1].
Disclosure: The members of the Task Force have provided disclosure statements of all relationships that might be perceived as real or potential sources of conflicts of interest. These disclosure forms are kept on file at the headquarters of the EACTS/AEPC. The Committee report received its entire financial support from the EACTS and AEPC, without any involvement of the pharmaceutical, device or surgical industries.

The Task Force selected by the EACTS and AEPC is responsible for the endorsement process of these joint guidelines. The finalized document has been approved by all the experts involved in the Committee.

The document was revised, and finally approved, by both the EACTS and the AEPC and subsequently submitted for publication simultaneously to the European Journal of Cardio-Thoracic Surgery and Cardiology in the Young.

Limitations: Practice guidelines are to be evidence based, but, in the field of congenital heart disease, most studies involve relatively small patient numbers for any given condition, especially when variants and coexisting lesions are considered. Therefore, there is a paucity of robust data such as prospective randomized trials; consequently, it is frequently impossible to use categories for strength of endorsement that have been used in guidelines documents pertaining to other disciplines. Thus, the vast majority of recommendations in this document are based on expert consensus (level of evidence $C$ ) rather than on solid data (level of evidence $\mathrm{A}$ or $\mathrm{B}$ ).

Table 1. Classes of recommendations

\begin{tabular}{ll}
$\begin{array}{l}\text { Classes of } \\
\text { recommendations }\end{array}$ & Definition \\
\hline Class I & $\begin{array}{l}\text { Evidence and/or general agreement that a given treatment or procedure is beneficial, useful, } \\
\text { effective } \\
\text { Conflicting evidence and/or a divergence of opinion about the usefulness/efficacy of the given } \\
\text { treatment or procedure } \\
\text { Class II }\end{array}$ \\
Class IIa & $\begin{array}{l}\text { Usefulness/efficacy is less well established by evidencelopinion } \\
\text { Evidence or general agreement that the given treatment or procedure is not useful/effective, and } \\
\text { Class lIb } \\
\text { Class III }\end{array}$
\end{tabular}

Table 2. Levels of evidence

\begin{tabular}{ll} 
Level of evidence A & $\begin{array}{c}\text { Data derived from multiple randomized clinical trials or meta-analyses } \\
\text { Data derived from a single randomized clinical trial or large non-randomized } \\
\text { studies } \\
\text { Consensus of opinion of the experts and/or small studies, retrospective studies, } \\
\text { Legistries }\end{array}$ \\
\hline
\end{tabular}




\section{Background}

Transposition of the great arteries is the most common cyanotic congenital heart defect [2]. It accounts for approximately $5 \%$ of congenital heart disease cases and is characterized by ventriculoarterial discordance: the left ventricle gives rise to the pulmonary artery and the right ventricle, to the aorta. There is atrioventricular concordance. If no significant additional cardiac lesions are present, it is referred to as TGA with intact ventricular septum (TGA IVS). The lesion is categorized as complex TGA when it has associated cardiac anomalies including VSD (which occurs in up to $45 \%$ of cases), LVOT obstruction (25\%) and coarctation of the aorta (5\%). In general, TGA is not familial. There is no known association with syndromes or chromosomal abnormalities. There is a 2:1 male preponderance.

The anatomical configuration of this anomaly establishes a potentially fatal parallel circulation that results in deep hypoxaemia from lack of mixing, with resulting lactic acidosis and demise. Prompt, adequate preoperative intervention and stabilization, followed by surgical repair and expert postoperative management, favour an excellent outcome, with short-term survival probability around 97-100\% in selected centres [3-7]. The arterial switch operation (ASO), first described by Adib Jatene in 1976 [8], is currently the procedure of choice when the anatomical conditions and the timeline are appropriate; it is performed in the first month of life. Other alternatives, such as the atrial switch and the two-stage ASO, are reserved for the specific scenarios discussed below. Despite the medical and surgical advances in the management of TGA and the low mortality rate, patients require expert diagnostic evaluation, preferably prenatally, and meticulous multidisciplinary management in the perinatal period, preoperatively, intraoperatively and postoperatively.

\section{Diagnosis}

\subsection{Prenatal diagnosis}

3.1.1 Prenatal detection. The diagnosis of TGA can be made accurately before birth if the foetal heart is screened at the time of the obstetric anomaly scan. Some studies have shown that the type of repair likely to be required after birth can be well predicted [9-12]. Due to the fact that the previously frequently used four-chamber view in TGA IVS shows no abnormality, the overall proportion of cases of TGA in foetal series has been low compared with postnatal series [13-15]. The inclusion of the outflow-tract views at the time of the obstetric foetal anomaly scan results in significant improvement in prenatal detection of the transposition [16,17]. Recent publications have reported improved prenatal detection rates for TGA of up to $50 \%$ [2, 18-20]. It is now generally more widely recommended that, in addition to the four-chamber view, the views of the cardiac outflow tracts also be included as part of the obstetric screening scan [21-23]. A formal programme for education and training regarding the foetal heart is required as part of this process, to ensure that sonographers are taught and can maintain the skills of foetal heart examination [24-28].

3.1.2 Counselling following prenatal detection. If transposition is detected or even suspected from the obstetric anomaly scan, referral should be made to a specialist who is experienced in the diagnosis and management of congenital heart disease in the foetus. This referral should be made as soon as possible after detection of a possible transposition, to have the diagnosis confirmed and to allow the parents to be counselled appropriately [29, 30].

Following the diagnosis of TGA, the parents need to be informed of the diagnosis, associations, further management during pregnancy and birth, management after birth and the prognosis for their baby. They also need to be made aware of features that may complicate the management. The parents should be given all the information regarding their baby's heart condition in a way that they understand and be allowed sufficient time to ask questions. Written information and drawings illustrating the problem should be provided. The parents should be given the opportunity to speak with a paediatric cardiac surgeon as well as having the option to speak with other parents who have had a child with transposition. Contact details of parent support groups, both locally and nationally, can be provided to help them.

3.1.3 Further prenatal management. Because many forms of congenital heart disease are associated with extracardiac abnormalities, including karyotype abnormalities, foetal karyotyping is generally recommended after prenatal diagnosis [31-34]. However, cases of TGA are rarely associated with chromosomal anomalies. It is important to liaise with foetal medicine specialists in order to exclude any associated extracardiac abnormalities. Foetal karyotyping is not generally indicated or recommended in TGA IVS, but the option of karyotyping can be discussed on an individual basis. Following the initial diagnosis and counselling, further foetal cardiology assessment will be required later in the pregnancy. The number and timing of further scans may vary depending on local practices, but they should include an assessment in the few weeks prior to delivery to look for high-risk features [35-37]. 


\begin{tabular}{|c|c|c|}
\hline Recommendation & Class $^{a}$ & Level $^{\mathrm{b}}$ \\
\hline $\begin{array}{l}\text { It is recommended that the obstetric anomaly scan } \\
\text { be performed at } 18-22 \text { weeks of gestation }\end{array}$ & I & $\mathrm{C}$ \\
\hline $\begin{array}{l}\text { To increase prenatal detection, it is recommended } \\
\text { that outflow tract views, in addition to four-chamber } \\
\text { views, be included in obstetric anomaly scans }\end{array}$ & I & $\mathrm{C}$ \\
\hline $\begin{array}{l}\text { It is recommended that the diagnosis be confirmed } \\
\text { by a foetal cardiology specialist and that parental } \\
\text { counselling should also be provided by a foetal } \\
\text { cardiology specialist and other related health } \\
\text { professionals (foetal medicine specialists, } \\
\text { obstetricians, paediatric cardiac surgeons and } \\
\text { neonatologists) }\end{array}$ & I & $\mathrm{C}$ \\
\hline $\begin{array}{l}\text { It is recommended that a detailed foetal anomaly } \\
\text { scan be performed by a foetal medicine specialist }\end{array}$ & I & $\mathrm{C}$ \\
\hline $\begin{array}{l}\text { Because the risk for foetal karyotype abnormality is } \\
\text { low in cases of TGA IVS, karyotyping may be } \\
\text { considered on an individual basis where appropriate }\end{array}$ & $\mathrm{IIb}$ & $\mathrm{C}$ \\
\hline $\begin{array}{l}\text { After foetal diagnosis, follow-up to term is } \\
\text { recommended for early detection of the } \\
\text { development of high-risk features, which may } \\
\text { require immediate intervention following delivery }\end{array}$ & I & $\mathrm{C}$ \\
\hline
\end{tabular}

${ }^{\mathrm{a}}$ Class of recommendation.

${ }^{\mathrm{b}}$ Level of evidence.

Recommendations for prenatal detection

\subsection{Perinatal management_-timing, place and mode of delivery}

Studies comparing the outcome of babies with TGA diagnosed prenatally with those diagnosed postnatally suggest that the rates of preoperative and postoperative mortality [9, 20, 38, 39] and morbidity [19, 40-43] are lower for babies diagnosed prenatally.

3.2.1 Site and timing of delivery. Because babies with TGA require early treatment after birth, it is generally recommended that delivery takes place at or near a tertiary-care paediatric cardiology and paediatric cardiac surgery centre $[44,45]$. Adhering to this practice enables the neonate to be in optimal condition and avoids neonatal retrieval transportrelated complications and costs [46]. Although the delivery must be scheduled before the due date, the majority of women can have a vaginal delivery, which is generally recommended [47]. However, a planned caesarean delivery may be indicated if high-risk maternal or foetal features are identified.

\begin{tabular}{lll} 
Recommendation & Class $^{\mathrm{a}}$ Level $^{\mathrm{b}}$ \\
\hline $\begin{array}{l}\text { It is recommended that delivery takes place at or } \\
\text { near a tertiary-care paediatric cardiology and }\end{array}$ & $\mathrm{C}$ \\
paediatric cardiac surgery centre & \\
Vaginal delivery at term is recommended in most & $\mathrm{I}$ & $\mathrm{C}$ \\
cases, whereas caesarean delivery is recommended & \\
when high-risk features are identified & \\
\hline${ }^{\mathrm{a} C l a s s}$ of recommendation. & \\
${ }^{\mathrm{b}}$ Level of evidence. \\
Recommendations for perinatal management
\end{tabular}

\subsection{Postnatal diagnosis}

3.3.1 Postnatal detection. The newborn with TGA and inadequate intercirculatory mixing will be symptomatic from birth. Severe cyanosis is an early, almost universal clinical finding, which at least during the first hours after birth, may be the only sign. Screening for arterial oxygen saturation $\left(\mathrm{SaO}_{2}\right)$ is indicated for early identification of initially asymptomatic patients with TGA, when the pre- or post-ductal value or both are $<95 \%$ [48].

3.3.2 Further diagnostic steps. Once cyanotic congenital heart disease is suspected, transthoracic echocardiography should be performed immediately, because duration of deep cyanosis and tissue hypoxia are important additional factors in determining ventricular function, acidosis and eventually multiple organ failure.

The results observed on chest radiographs can be normal, but the following abnormal features can also be observed: oval or egg-on-side cardiac shape (due to the narrow mediastinum), mild cardiomegaly and increased pulmonary vascular markings. The electrocardiogram (ECG) may be normal, with the typical neonatal findings of right-axis deviation and right ventricular hypertrophy. Echocardiography is the modality of choice for a definitive diagnosis.

At the time of echocardiography, one should pay particular attention to the root of the great arteries and to the coronary arteries or concomitant features such as VSD, LVOT obstruction, coarctation and mitral valve anomalies. In particular, the diameters of the main pulmonary artery and the aorta have to be measured; the location of the valve commissures and also the origin and course of the coronary arteries must be described carefully before surgery.

It has been shown that echocardiography facilitates accurate evaluation of the coronary artery pattern and exclusion of other relevant malformations [49, 50]. In addition, echocardiography facilitates imaging for

\begin{tabular}{|c|c|c|c|}
\hline Recommendation & Class $^{a}$ & Level $^{\mathrm{b}}$ & $\operatorname{Ref}^{c}$ \\
\hline $\begin{array}{l}\text { Neonatal pulse oximetry screening is } \\
\text { crucial for timely diagnosis of TGA }\end{array}$ & I & C & 51 \\
\hline $\begin{array}{l}\text { Echocardiography is the modality of choice } \\
\text { for diagnosing TGA postnatally and } \\
\text { allows accurate evaluation of the coronary } \\
\text { artery pattern and exclusion of other } \\
\text { relevant malformations in most cases }\end{array}$ & I & B & 49,50 \\
\hline $\begin{array}{l}\text { Performance of BAS should be considered, } \\
\text { under echocardiographic guidance }\end{array}$ & IIa & B & $52-54$ \\
\hline
\end{tabular}

BAS: balloon atrial septostomy; TGA: transposition of the great arteries. ${ }^{a}$ Class of recommendation.

${ }^{\mathrm{b}}$ Level of evidence.

${ }^{c}$ References

Recommendations for postnatal diagnosis 
the safe performance of balloon atrial septostomy (BAS) (also known as the Rashkind procedure). Because BAS can be safely performed under echocardiographic guidance, preoperative diagnostic cardiac catheterization should be considered only in selected cases for diagnosis of complex lesions or if institutional experience does not permit performance of atrial septostomy under echocardiographic guidance.

\section{Perinatal management}

Significant regional differences exist in the organization of care for newborns with TGA. In most instances, especially in the absence of prenatal diagnosis, the newborn with TGA will need to be stabilized in a neonatal intensive care unit (ICU) and subsequently transported to a tertiary-care centre, where definitive surgical care is available. Although elective intubation of infants on prostaglandin $E_{1}$ (PGE1) prior to transport has been common practice in many institutions, several studies have shown that the rate of complications is significantly higher in infants who need intubation $[55,56]$. Occasionally, BAS may be available locally and may be performed prior to transport.

\subsection{Monitoring and immediate care}

Preoperative monitoring of patients with TGA in the ICU includes mostly noninvasive technologies associated with the clinical evaluation of vital signs and peripheral perfusion and cardiovascular examination (although invasive strategies may be required): pre- and post-ductal pulse oximetry, continuous ECG, noninvasive blood pressure monitoring, respiratory rate and pattern monitoring. Inspired end-tidal capnography may be used and reserved for ventilated patients. In addition to vital signs, urine output must be monitored closely, but the insertion of a Foley catheter is not justified unless the patient is haemodynamically compromised. Tissue perfusion monitoring may be followed by serial testing for blood lactate levels and near-infrared spectroscopy (NIRS) in the decompensated phase. Neonates with TGA might have umbilical venous, and eventually umbilical arterial, lines inserted promptly after birth, which facilitates safe administration of drugs, including-but not exclusively limited to-PGE1; surveillance of invasive haemodynamic parameters, as needed; fluid administration and acid-base follow-up and management. The use of other central lines should be minimized in the preoperative period unless the patient remains critically ill. To assess mixed venous saturations, sampling in the innominate vein is required to avoid overestimates because of the atrial level mixing. Fluids ought to be administered without restrictions, and the indications do not vary with standard neonatal recommendations.

\subsection{Haemodynamic management}

The initial management of newborns with TGA should focus on stabilization, optimization of mixing of systemic and pulmonary circulations (management of hypoxia) and oxygen delivery, maintenance of adequate systemic perfusion and correction of acidosis.

The immediate priority after birth and throughout the first few hours of life is to determine whether the mixing between systemic and pulmonary circulations is adequate. Immediately after birth, an intravenous (IV) infusion of PGE1 is recommended to maintain ductal patency until the comprehensive series of postnatal echocardiograms is complete and all sites of intercirculatory mixing have been evaluated. PGE1 has been used in various dosing regimens: a higher dose of up to $0.1 \mu \mathrm{g} / \mathrm{kg} / \mathrm{min}$ may be necessary when the ductus needs to be reopened. To maintain patency, starting doses vary from 0.0125 to $0.05 \mu \mathrm{g} / \mathrm{kg} / \mathrm{min}$, and patients can be weaned, starting $2-4 \mathrm{~h}$ following initiation, provided that oxygen $\left(\mathrm{O}_{2}\right)$ saturations and tissue perfusion remain acceptable. Nevertheless, the use of PGE1 may not suffice, because ductal shunting is often inadequate in the presence of a restrictive interatrial communication. These patients warrant an emergent atrial septostomy. Throughout the performance of the atrial septostomy, or in those patients needing longer-term ventilation, sedation and analgesia are occasionally required. The usual combination of drugs includes nonopioids (i.e. paracetamol), opioids (low-dose morphine or fentanyl) and benzodiazepines. Dexmedetomidine has emerged as a useful and safe drug with anxiolytic properties and no significant respiratory depressive effect [57].

Patients presenting with deep hypoxaemia, acidosis and in shock must benefit from the emergent measures recommended in neonatal advanced life-support algorithms. Concomitantly, an infusion of PGE1 should be emergently started at high doses $(0.1 \mu \mathrm{g} / \mathrm{kg} / \mathrm{min})$ while preparing for the atrial septostomy.

Once adequate mixing has been achieved at the atrial level, discontinuation of PGE1 is often possible, unless there is an associated left-heart obstruction (i.e. coarctation of the aorta). Notwithstanding this attempt, successful discontinuation of the drug is unpredictable $[58,59]$. Because of the risk of rebound hypoxaemia after abrupt discontinuation of PGE1, it is recommended that, after septostomy, patients should be weaned from PGE1 rather than stopped. Patients remaining on PGE1 must be observed for potential side and adverse effects. The risk of apnoea may be attenuated by the administration of caffeine or with 
stimulation tools like a high-flow nasal cannula or continuous positive airway pressure [60]. Furthermore, persistent left-to-right shunting across the ductus arteriosus may cause pulmonary oedema, which may affect patient stability and require escalation of therapy and airway support. Pragmatically, it may be adequate to adopt a permissive attitude with regards to the degree of cyanosis rather than exposing patients to the deleterious effects of excessive blood flow to maintain a higher arterial $\mathrm{O}_{2}$ saturation level.

Further haemodynamic measures to support decompensated patients include colloids or crystalloids for volume expansion, use of $\mathrm{O}_{2}$ and correction of metabolic acidosis.

A few neonates may remain significantly cyanotic and acidotic even after the atrial septostomy. In such circumstances, echocardiography should be performed to confirm the unrestrictive nature of the atrial septal defect (ASD) as well as of the patent ductus arteriosus and to determine the presence and degree of pulmonary hypertension. The diagnosis of pulmonary hypertension is usually confirmed using echocardiography. Although cut-off values are difficult to define, the rate of diagnosed pulmonary hypertension varies in the available literature. The incidence of persistent pulmonary hypertension in neonates with TGA is $12.5 \%$, and it occurs more frequently in cases of TGA IVS [61, 62].

Mortality is high in this group of neonates and mid-term postoperative outcomes are negatively affected [61, 63]. Given that it is a serious condition with a high mortality rate, different treatment strategies have been used with variable success, including sedation, paralysis and hyperventilation [64], inhaled nitric oxide (NO) [65], sildenafil, bosentan [66] and extracorporeal life support (ECLS), alone or in combination $[67,68]$. Because the existing literature consists mainly of case reports, management should include the stepwise introduction of the abovementioned treatment modalities and close monitoring of the clinical response (improved oxygenation). Such patients may require the resumption of PGE1 because the ductus arteriosus may be useful as a "pop-off and ultimately improve systemic tissue perfusion.

\subsection{Mechanical ventilation and respiratory measures}

Systemic $\mathrm{SaO}_{2}$ saturation in TGA depends on the relative proportions and $\mathrm{O}_{2}$ saturation levels of the two sources of the systemic circulation, i.e. fully saturated pulmonary venous blood that is shunted from the pulmonary to the systemic circulation ('effective' systemic flow) and the systemic mixed venous blood that recirculates through the systemic vascular bed. The degree of intercirculatory mixing is dictated by the number, size and site of anatomical communications between the two circuits. The haemoglobin level is also important, and a level of around $15 \mathrm{~g} / \mathrm{dl}$ is considered optimal. Systemic and pulmonary vascular resistances (PVR) add to the complex interplay of the preceding factors $[69,70]$. Preoperative manipulation of mixing and the other contributing factors should result in an $\mathrm{O}_{2}$ saturation level of $75-85 \%$ of the arterial blood gas. In preterm newborns, the lower end of the acceptable range can be as low as $70 \%$. One important point is that the accuracy of pulse oximetry values $<80 \%$ is limited in neonates [71] and frequent monitoring of arterial blood gases may be warranted.

Neonates with profound hypoxaemia (partial pressure of arterial oxygen $<25 \mathrm{mmHg}$ and/or $\mathrm{SaO}_{2}<60 \%$ ) require urgent attention [35].

Conservative measures to increase systemic $\mathrm{O}_{2}$ saturation levels and adequate tissue oxygen delivery include (i) continuous PGE1 infusion to maintain ductal patency and emergent BAS to increase intercirculatory mixing; (ii) mild hyperventilation and increased fraction of inspired oxygen $\left(\mathrm{FiO}_{2}\right)$ to lower PVR and increase pulmonary blood flow; (iii) transfusion to treat relative anaemia and increase $\mathrm{O}_{2}$-carrying capacity; (iv) sedation and paralysis to decrease $\mathrm{O}_{2}$ consumption; and (v) possibly inotropic support to increase cardiac output and $\mathrm{O}_{2}$ delivery [72].

\subsection{Nutrition}

Infants with TGA and adequate intercirculatory mixing, without PGE1 infusion (e.g. after septostomy), should be fed enterally and encouraged to bottle-feed and breast-feed [73-75]. There is still great controversy surrounding the best approach to enteral nutrition for infants with cyanotic congenital heart defects, especially during the time when they are prostaglandin-dependent [73]. Based on limited evidence in favour or against the practice of feeding infants enterally while they are on PGE1 [74, 76, 77], haemodynamically stable newborns with TGA should be fed enterally as soon as it is deemed feasible preoperatively, even while they are on PGE1. Breast milk and breast-feeding are preferred. Trophic enteral feeding may be considered in some patients in order to reduce the risk of translocation.

\subsection{Major prematurity and very low birth weight}

The incidence of low birth weight among newborns with TGA is reported to be $3.05 \%$ [78], which compares favourably with the reported $15 \%$ overall incidence of prematurity or low birth weight in neonates with congenital heart disease [79]. Although it is clear that low birth weight and prematurity are different factors, they often coexist. Low birth weight 
$(\leq 2.5 \mathrm{~kg})$, very low birth weight $(\leq 1.5 \mathrm{~kg})$ and, less so, prematurity [80] present technical and physiological challenges to complete repair in the neonate. Additional comorbidities from other organ systems (central nervous system, renal, gastrointestinal) increase the morbidity and mortality rates of these infants both short and long term [81]. More specifically, in transposition, large, multi-institutional studies in Europe and North America have demonstrated increased mortality rates after an ASO in infants weighing $<2.5 \mathrm{~kg}[82,83]$. However, it has been shown that delaying repair to allow for weight gain confers higher preoperative morbidity and early mortality without any associated benefit $[84,85]$. Furthermore, delaying intervention for TGA IVS results in deconditioning of the left ventricle, rendering the patient a potentially poor candidate for a primary ASO. Centres have reported early repair [86], primary repair as late as age 3 months, late single-stage repair with postoperative mechanical circulatory support and two-stage repair (i.e. pulmonary artery banding with or without aortopulmonary shunt placement followed by an ASO in 7-14 days) [86, 87] with acceptable results.

\begin{tabular}{|c|c|c|}
\hline Recommendation & Class $^{a}$ & Level $^{\mathrm{b}}$ \\
\hline $\begin{array}{l}\text { Immediately after birth, IV infusion of PGEI is } \\
\text { recommended to maintain ductal patency until } \\
\text { the comprehensive series of postnatal } \\
\text { echocardiograms is complete and all sites of } \\
\text { intercirculatory mixing have been evaluated }\end{array}$ & I & $\mathrm{C}$ \\
\hline $\begin{array}{l}\text { Avoidance of elective intubation of infants on PGE1 } \\
\text { during transport is recommended. The decision to } \\
\text { intubate prior to transport must be individualized }\end{array}$ & I & $\mathrm{C}$ \\
\hline $\begin{array}{l}\text { An individualized management strategy for low } \\
\text { birth weight and premature infants is } \\
\text { recommended, taking into account patient and } \\
\text { institutional factors. Management options include } \\
\text { primary repair as late as } 3 \text { months of age, late } \\
\text { single-stage repair with postoperative VAD or } \\
\text { ECLS support and two-stage repair }\end{array}$ & I & $\mathrm{C}$ \\
\hline $\begin{array}{l}\text { A primary ASO may be considered the preferred } \\
\text { management strategy for low-birth-weight and } \\
\text { premature infants and can be performed with } \\
\text { acceptable but increased early and mid-term risk }\end{array}$ & $\mathrm{IIb}$ & $\mathrm{C}$ \\
\hline
\end{tabular}

ASO: arterial switch operation; ECLS: extracorporeal life support; IV: intravenous; PGE1: prostaglandin E1; VAD: ventricular assist device. ${ }^{\mathrm{a}}$ Class of recommendation.

${ }^{\mathrm{b}}$ Level of evidence.

Recommendations for perinatal management in a neonatal intensive care unit

\section{Surgery for Transposition of The Great Arteries With Intact Ventricular Septum}

\subsection{Timing for surgery of TGA IVS}

The ASO for TGA IVS in newborns was introduced in the early 1980s. The assumption was that the neonatal left ventricle would be suited for systemic work after having withstood systemic pressure throughout foetal life $[88,89]$. The neonatal ASO has since become the preferred approach for repair of TGA IVS and is currently achievable with an average surgical mortality rate of 2-5\% [90].

At birth, the left ventricular muscle mass is equivalent to that of the right ventricle. Subsequently, as a result of the rapid postnatal decrease in PVR, the left ventricle soon becomes 'deconditioned', losing muscle mass and the ability to function at systemic workloads [91, 92]. Currently, the optimal timing for an ASO in babies with TGA IVS is established from the first few days to 3 weeks of life [93].

In Europe, 25-30\% of patients with TGA IVS have undergone a routine ASO within the first week of life [90]. It is worth noting that an ASO in the first few hours of life may obviate the need for BAS $[94,95]$. This very early approach, however, remains controversial.

Also, the upper age limit for a primary ASO in TGA IVS cannot be determined. Most surgeons undertake a primary ASO in babies up to 4 weeks of age, whereas the choice of a primary ASO beyond 1 month of age is controversial [90]. In fact, several groups have electively adopted a primary ASO in late presenters (up to 8 weeks of age), planning postoperative mechanical support, if necessary [93, 96-99], and accepting prolonged duration of postoperative ventilation and hospital stay [100]. A few outliers undergoing an ASO at up to 9 months of age have been reported [100, 101]. However, for infants older than 2 months, left ventricular mass and mass/end-diastolic volume ratio should, preferably, orient towards a rapid two-stage ASO.

\begin{tabular}{|c|c|c|c|}
\hline Recommendation & Class $^{a}$ & Level $^{\mathrm{b}}$ & $\operatorname{Ref}^{c}$ \\
\hline $\begin{array}{l}\text { It is recommended that a primary ASO } \\
\text { in neonates with TGA IVS be } \\
\text { performed from the first few days to } \\
3 \text { weeks of life }\end{array}$ & I & $\mathrm{B}$ & $90-95$ \\
\hline $\begin{array}{l}\text { A primary ASO should be considered } \\
\text { up until } 60 \text { days (with ECLS back-up) }\end{array}$ & IIa & B & $7,97-100$ \\
\hline
\end{tabular}

ASO: arterial switch operation; ECLS: extracorporeal life support; IVS: intact ventricular septum; TGA: transposition of the great arteries. ${ }^{a}$ Class of recommendation.

${ }^{\mathrm{b}}$ Level of evidence.

${ }^{\mathrm{c}}$ References.

Recommendations for timing of the ASO

\subsection{Adequacy of left ventricular myocardial mass}

5.2.1 Left ventricular mass regression. Upon completion of a postnatal fall of pulmonary 
arteriolar resistance (around the fourth week of life), left ventricular mass in TGA IVS starts decaying $[92,102]$, although with some degree of reversibility $[103,104]$.

In addition, isolated pulmonary outflow obstruction in TGA IVS, whether anatomical [96] or dynamic [105, 106], may trigger left ventricular myocardial hypertrophy and potentially allow an ASO to be performed. Furthermore, a moderately restrictive ASD and a sizeable $(\geq 5 \mathrm{~mm})$ patent arterial duct may both preserve adequate left ventricular preload and pressure and partly explain the positive outcomes in some late presenters [100]. Finally, genetically predetermined factors might also account for the involution of PVR and left ventricular performance [96].

5.2.2 Assessment of left ventricular preparedness. Left ventricular 'preparedness' for an ASO is commonly judged on measurable parameters (e.g. left ventricular geometry, wall thickness and function on echocardiogram) and on additional evidence of pressure and volume loading related to the size of the duct and an ASD [91, 100, 105, 107-110]. The ventricular septum is forged by unequal ventricular pressures and progressively shifts towards the pulmonary ventricle, assuming a banana-shaped appearance on an echocardiogram $[111,112]$. The Marie Lannelongue group introduced echo-based markers to judge preparedness [105]. On the contrary, the Great Ormond Street group found that, in the late ASO group, conventional measures of left ventricular pressure and function were not predictive of mortality or of the need for mechanical support [99]. Alternatively, left ventricular preparedness may be assessed by a 'provocative' pulmonary artery banding: If tolerated by the left ventricle for up to $15-30 \mathrm{~min}$, a primary ASO is undertaken [113].

\subsection{Training of the left ventricle for a delayed arterial switch operation}

5.3.1 Introduction and pathophysiological issues. In 1977, Yacoub et al. [114] devised a two-stage approach for an ASO in older patients with TGA IVS that included a preparatory pulmonary artery banding together with a systemic-to-pulmonary shunt for left ventricular training, followed by an ASO several months later. However, this policy did not become widely adopted for frequent, intractable, postoperative, left ventricular dysfunction, probably because of the advanced age at pulmonary banding $[115,116]$. In 1989, Jonas et al. [117] introduced the so-called rapid two-stage ASO, showing that left ventricular hypertrophy is elicited as early as $1-2$ weeks after the imposition of a pressure load in younger patients beyond neonatal age.

An $85 \%$ increase in left ventricular mass within 5-7 days of applying a pulmonary artery band was demonstrated in infants with TGA IVS [117, 118]. Remarkably, both the capacity and the rapidity of left ventricular hypertrophy decrease with aging. The age limit at which the potential for myocyte hyperplasia in the human infant is lost is allegedly 3-6 months after birth [102].

5.3.2 Indications for a two-stage arterial switch operation. Categorical indications for left ventricular training include a combination of the following noninvasive criteria:

1. Indexed left ventricular mass $<35 \mathrm{~g} / \mathrm{m}^{2}$.

2. Age well above 3 weeks.

3. Ventricular septal profile, with a banana-like left ventricular shape on 2D echocardiograms.

4. Absence of a patent arterial duct or LVOT obstruction [105].

Haemodynamic data may also be used, especially if BAS is achieved using heart catheterization rather than 2D echocardiographic guidance. Aortic and systemic venous oxygen saturations, right atrial pressure and the left/right ventricular pressure ratio may then be obtained [119]. In general, a left/right ventricular pressure ratio $<0.6$ is an indication for a staged ASO [113, 120].

\subsubsection{Types of left ventricular training and technical aspects}

5.3.3.1 Hypoxic (pre-ASO) left ventricular training. Hypoxic left ventricular training, often preceded by BAS, implies a two-stage ASO with preliminary imposition of either pressure or volume overload or, more commonly, combinations of both. Whichever of the three methods described below is used, a tolerable level of systemic $\mathrm{O}_{2}$ saturation and an adequate left ventricular preload must be sought.

1. Pulmonary artery banding combined with a systemic-pulmonary shunt (usually a modified Blalock-Taussig anastomosis) followed by an ASO after an interval that depends on the patient's age [i.e. 1-2 weeks in young infants (rapid two-stage ASO) [105, 117], or several months in older infants/children] [114, 120122]. A moderate degree of both pressure and volume overload provides the most effective stimulus for ventricular hypertrophy, and a small-to-moderate ASD is advantageous to ensure the necessary volume preload for the left ventricle [123]. Through either a sternotomy or a thoracotomy, a systemic-pulmonary shunt is placed first, using a polytetrafluoroethylene (PTFE) vascular graft (size $3.5 \mathrm{~mm}$ ). After opening the shunt, under an $\mathrm{FiO}_{2}$ of $30 \%$, the 
pulmonary artery band is placed and, while directly monitoring the left ventricular pressure, sequentially tightened to obtain a left/ right ventricular systolic pressure ratio of 0.7. Simultaneous 2D echocardiographic guidance provides information on the tightness of the banding: the occurrence of ventricular failure suggests that the banding is too tight. Postoperatively, patients are weaned from inotropes and mechanical ventilation, based upon echocardiographic documentation of sustained good left ventricular function $[105,122]$. In older patients, sequential tightening over several months may be necessary [124]. In the presence of a wide ASD for intercirculatory mixing, the single best predictor of $\mathrm{SaO}_{2}$ is the magnitude of pulmonary blood flow. Acute reduction of total pulmonary blood flow, as happens following pulmonary artery banding, drastically cuts both effective pulmonary and systemic flows [69]. If no additional source of pulmonary blood flow is contemplated, the degree of banding must be mild enough to allow sufficient effective pulmonary blood flow. In these cases, a slower myocardial hypertrophic response should be expected.

2. Pulmonary artery banding combined with induced patency of the arterial duct, obtained either by prostaglandin infusion or by ductal stenting, depending on the anticipated duration of the interim period.

3. Induced patency of the arterial duct alone, obtained using either prostaglandin infusion or ductal stenting [125]. In this case it may be advisable NOT to pursue a wide ASD, to assure adequate preload of the left ventricle [126]. Simple ductal stenting, or supposedly prolonged prostaglandin infusion, may also rapidly train the involuted left ventricle of late presenters within days to a few weeks [99, $123,126]$. It can be a less morbid method of left ventricular training because it avoids haemodynamic stress, pulmonary artery distortion and neoaortic valve regurgitation. The use of moderate-sized ( 3.5 or $4 \mathrm{~mm}$ ) coronary stents was suggested to avoid post-procedure heart failure [125].

\subsubsection{Normoxic (post-ASO) left ventricular} training. Normoxic left ventricular training is adopted after an ASO presenting intraoperative left ventricular failure unrelated to a coronary problem. It may be achieved pharmacologically or by mechanical circulatory support (see section 6.5.1).

5.3.4 Results of left ventricular training for a delayed arterial switch operation. The reported risk of mortality after Stage I is very low and easily avoided by emergency takedown of the pulmonary artery banding $[105,111]$. The initial postoperative course of these patients, however, is often characterized by significant morbidity associated with low-output syndrome of variable severity and significant metabolic acidosis [127-129]. A less tight pulmonary banding, with a left/right ventricular peak pressure ratio at 0.65 , prevents left ventricular dysfunction while endorsing ventricular remodelling [105, 123].

The left/right ventricular pressure ratio increases from 0.5 before pulmonary banding to 1.0 before the ASO. Most of the increase in left ventricular mass $(95 \%)$ occurs in the first week, with the most rapid rate of hypertrophy by Day 2 and an exponential fall in the growth rate thereafter. The left ventricular volume also progressively increases, but not as rapidly as the left ventricular mass, with a consequent gradual rise in left ventricular mass/volume ratio without acute dilation. The left ventricular ejection fraction is significantly reduced at $12 \mathrm{~h}$ after banding but returns to basal levels by 3.5 days after banding as compensatory hypertrophy takes place $[111,118]$.

The early mortality rate after a rapid two-stage ASO is between 0 and $6 \%$, and the postoperative course can be smoother than in a single-stage ASO due to the excellent left ventricular mass developed [105, 111, 117, 123]. The late follow-up of the two-stage approach has revealed impaired left ventricular systolic performance [127], increased incidence of neoaortic regurgitation [128] and right ventricular outflow tract (RVOT) obstruction [119]. Nonetheless, most of these patients enjoy an excellent clinical condition and physical ability [105].

5.3.5 Optimal time interval between stages. The key tool for surgical decision making after Stage I is $2 \mathrm{D}$ echocardiography $[105,111,117]$. Clinical and haemodynamic parameters are also important [129]. Proposed criteria for a safe second-stage ASO include left-to-right ventricular pressure ratio $>0.85$, left ventricular end-diastolic volume $>90 \%$ of normal, left ventricular ejection fraction $>0.5$, posterior wall thickness $>4 \mathrm{~mm}$ and a predictive wall stress $<120 \times 10^{3}$ dynes $/ \mathrm{cm}^{2}$ [130]. At Marie Lannelongue, the ASO was performed when the left ventricular mass had reached $50 \mathrm{~g} / \mathrm{m}^{2}$ [105].

The median interval between Stages I and II is 10 days (range 5 days to 6 weeks) [105, 111, 118]. Provided that adequate left ventricular mass and volume are rapidly achieved, the early Stage II ASO has the advantage of avoiding pericardial adhesions. 


\begin{tabular}{|c|c|c|c|}
\hline Recommendation & Class $^{a}$ & Level $^{\mathrm{b}}$ & $\operatorname{Ref}^{c}$ \\
\hline \multicolumn{4}{|c|}{$\begin{array}{l}\text { Post-banding left ventricular preparedness: the following should be } \\
\text { considered as adequate: }\end{array}$} \\
\hline $\begin{array}{l}\text { Indexed left ventricular mass } \\
\geq 50 \mathrm{~g} / \mathrm{m}^{2}, \text { left } / \text { right ventricular } \\
\text { pressure ratio } \geq 0.85, \text { left } \\
\text { ventricular } \\
\text { end-diastolic volume }>90 \% \text { of } \\
\text { normal, left ventricular ejection } \\
\text { fraction } \geq 0.5 \text {, posterior wall } \\
\text { thickness } \geq 4 \mathrm{~mm} \text { and predictive } \\
\text { wall stress }<120 \times 10^{3} \text { dynes } / \mathrm{cm}^{2}\end{array}$ & IIa & $\mathrm{C}$ & 105,130 \\
\hline $\begin{array}{l}\text { Ventricular septal profile (septal } \\
\text { alignment or left-to-right bulging } \\
\text { of ventricular septum on } 2 \mathrm{D} \\
\text { echocardiography }\end{array}$ & I & $\mathrm{B}$ & 10,130 \\
\hline $\begin{array}{l}\text { Left ventricular training in late } \\
\text { presenters }\end{array}$ & & & \\
\hline $\begin{array}{l}\text { The staged ASO (rather than a } \\
\text { postprimary ASO plus mechanical } \\
\text { circulatory support) should be } \\
\text { considered in late presenters with } \\
\text { TGA IVS }\end{array}$ & IIa & $\mathrm{C}$ & 105 \\
\hline $\begin{array}{l}\text { Precautions in left ventricular } \\
\text { training }\end{array}$ & & & \\
\hline $\begin{array}{l}\text { Only a moderate degree of pressure } \\
\text { overload (by avoiding an overtight } \\
\text { pulmonary artery banding) } \\
\text { should be considered as the target. } \\
\text { A post-banding left/right } \\
\text { ventricular pressure ratio } \\
\text { of } 0.65-0.70 \text { should be considered }\end{array}$ & IIa & $\mathrm{C}$ & $\begin{array}{l}105,114 \\
117,120- \\
122\end{array}$ \\
\hline $\begin{array}{l}\text { Only a moderate degree of } \\
\text { volume overload (by avoiding } \\
\text { oversized systemic-pulmonary } \\
\text { shunt) } \\
\text { should be considered as the target. } \\
\text { A size } 3.0-3.5 \mathrm{~mm} \text { PTFE shunt, } \\
\text { according to the patients weight } \\
(<3 \text { or } \geq 3 \mathrm{~kg} \text { ), should be } \\
\text { considered }\end{array}$ & IIa & $\mathrm{C}$ & $\begin{array}{l}105,114 \\
117,120- \\
122\end{array}$ \\
\hline $\begin{array}{l}\text { Creation of a small-to-moderate } \\
(4-5 \mathrm{~mm}) \text { atrial septal } \\
\text { communication should be } \\
\text { considered }\end{array}$ & IIa & $\mathrm{C}$ & 123 \\
\hline
\end{tabular}

ASO: arterial switch operation; BAS: balloon atrial septostomy; IVS: intact ventricular septum; PTFE: polytetrafluoroethylene; TGA: transposition of the great arteries.

${ }^{a}$ Class of recommendation.

${ }^{\mathrm{b}}$ Level of evidence.

${ }^{\mathrm{c}}$ References.

Recommendations for left ventricular training

\subsection{Surgical techniques and intraoperative surgical management}

5.4.1 Intraoperative parameters and cardiopulmonary bypass. Cardiopulmonary bypass (CPB) policy regarding temperature, flow, the use of vasodilators and $\mathrm{pH}$ status management varies widely without a clear consensus among the members of the surgical community and with little evidence to justify endorsing one approach over another. Compared with low flow bypass, a deep hypothermic circulatory arrest (DHCA) strategy in infancy is associated with worse neuro-developmental outcomes. DHCA should, therefore, be avoided whenever possible, due to both early and late unfavourable impacts $[131,132]$.

Cannulation for $\mathrm{CPB}$ varies according to preference. The ascending aorta is typically cannulated just proximally to the innominate artery, and venous return occurs through a single atrial basket. Direct or indirect bicaval cannulation is a valid alternative, making intracardiac procedures more flexible without circulatory arrest. No evidence favours any of the methods. A properly placed systemic vent enhances visibility.

Myocardial protection strategies vary widely, from cold crystalloid to multidose cold blood cardioplegia, used antegradely through the aortic root and then directly through the coronary ostia. Recently, warm bypass strategies and warm blood cardioplegia were introduced with claimed advantages; however, none of the myocardial protection methods has yet been shown to be preferable.

Weaning off bypass should be straightforward unless there is ischaemia (related to any coronary transfer occurrence), left ventricular dysfunction due to ischaemia or ventricle detraining. Less commonly, problems with RVOT reconstruction or transient pulmonary hypertension may create weaning difficulties but are easily recognized.

Immediate postoperative targets are a stable ECG, with no electrical instability (suggesting ischaemia), left atrial pressure $5-15 \mathrm{mmHg}$, with evidence of good tissue perfusion and urine output $>1 \mathrm{ml} / \mathrm{kg} / \mathrm{h}$. High lactate levels and ongoing acidosis are poor prognostic markers and require active corrective measures [133, 134].

There is no direct evidence to suggest that routine use of milrinone (a phosphodiesterase inhibitor) following an ASO improves outcome but it is recommended from extrapolation to its use for other infant cardiac procedures. It is recommended that milrinone be started for any patient with signs or symptoms of low cardiac output and with at least a left atrial pressure $>15 \mathrm{mmHg}$. The recommended loading dose of milrinone is $50 \mu \mathrm{g} / \mathrm{kg}$ over 30-60 min, followed by an infusion of $0.375-0.750 \mu \mathrm{g} / \mathrm{kg} / \mathrm{min}$. If hypotension develops, blood pressure support with other inotropic/vasopressor agents (epinephrine or dopamine) may be necessary [135].

Bleeding is a well-known problem after an ASO in neonates. Perfect suture lines are essential to prevent bleeding, but the use of antifibrinolytic drugs is common. Formerly, aprotinin in different doses and regimens proved to be effective and safe for 
kidney function [136]. Both epsilon-aminocaproic acid and tranexamic acid were introduced; tranexamic acid has the same level of safety and similar level of efficacy as epsilon-aminocaproic acid and is associated with improved outcomes. The use of prophylactic antifibrinolytic agents for ASOs should be considered [137]. The use of recombinant factor VII (rVII) was recently introduced and might be a valuable addition in cases with severe bleeding. However, scientific proof for the use of rVII is lacking.

Acute renal failure is prevalent after an ASO. However, prophylactic use of a peritoneal dialysis catheter is not recommended [131].

Delayed sternal closure after an ASO has been a routine technique for many surgical groups over the years. Studies do not support the hypothesis that elective delayed sternal closure will reduce the morbidity after an ASO in neonates but they do confirm the safety and efficacy of the procedure.

5.4.2 Coronary transfer. All coronary artery patterns are theoretically transferable [89, 138]. Coronary artery patterns have been identified as a risk factor for mortality in ASOs [90, 139-146]. Different techniques have been used for coronary transfer: the button technique in which coronary ostia are transferred to punch holes, and tissue is removed from the neoaortic root, to accommodate the ostia; the slit technique in which slit openings that may be linear or U-shaped are created in the neoaorta; and the trap-door technique in which L-shaped incisions are created, leaving a hinged flap, with an angle that seems to favour coronary transfer and improves landing. None of these techniques was demonstrated as being superior [147, 148]; however, the trap-door technique is recognized for reducing angulation for all cases, particularly for double-loop patterns.

In some specific cases, pericardium hoods allow for more flexibility and safer transfer [149, 150].

Large coronary buttons should be harvested, often requiring removal of most of the respective sinus of Valsalva. For eccentrically situated ostia, the nearest aortic valve commissure may need to be taken down and later resuspended in the neopulmonary root. The proximal segments of the coronary artery should be mobilized adequately to allow kink-free, tension-free and torsion-free translocation.

The coronary ostia are to be transferred to the respective facing sinuses, preferably laterally, and should not be compressed by the facing neopulmonary trunk, upon distension. The location on the sinuses is dictated by anatomical details, namely commissural placement. In most cases, surgeons prefer to place the left coronary button rather low, whereas the right coronary button needs to be placed higher. In some cases, namely posteriorly looping patterns, the right coronary artery button in pattern $\mathrm{D}$ is better implanted into a higher position, above the sinotubular junction and the main vessel suture line.

A single-ostium coronary pattern is a specific transfer challenge. It may or may not be associated with an intramural course of the proximal coronary artery, which may involve a commissural area. The two standardized techniques are the Yacoub technique [151] and the Imai technique [152]. In the Yacoub technique, the single coronary ostium is harvested with a large aortic cuff, mobilizing the adjacent commissure if necessary. The ostium is then anastomosed to the posteriorly facing neoaorta, along its superior border, the pouch being completed by the distal end of the aorta, which is cut obliquely, leaving a long anterior lip. Alternatively, a pericardial patch can be used to augment the aortic suture line to accommodate the pouch. In this case, the ostium is not rotated more than $90^{\circ}$, allowing no torsion. This method of transfer is applied to a singleostium Yacoub type B classification and also to a Yacoub type $\mathrm{C}$ in which the two coronary ostia are very close to each other and truly impossible to split apart. Alternatively, the Imai technique can be used: the ostium, or closely lying ostia, is left untouched without harvesting or without any rotation; the aortic wall above the ostium is excised to within 1-2 mm of the ostium; and a window opening is created to the adjacent neoaortic root. A small semilunar patch of pericardium or adjacent aortic tissue as a rotated flap of the non-coronary sinus is sutured to the inferior edges of the coronary button, creating a wide pouch. The reconstruction is completed by the ascending aortic suture line to the superior end of the pouch [152]. None of these alternative methods was found to be superior; however, their use is recommended for single or 'too-close' ostia transfer [153-159].

An intramural course often occurs in the presence of a single ostium but may occur with other complex patterns, also involving one or two main coronary arteries. Whenever it is detected, an intramural course should be addressed by unroofing, even when a commissure is involved. In this case the commissural area must be repaired. After unroofing, the coronary ostia are to be transferred normally using a trap-door technique [144, 160, 161].

Transferring coronary arteries in the presence of non-facing great arteries, i.e. in pure side-byside vessel arrangements, is extremely challenging. Individualized techniques are recommended, i.e. using extensive proximal coronary artery mobilization, trap doors and even pericardium tube extensions, for anterior loops with distant lateralized 
vessels. The use of autologous pericardial hoods is sometimes useful to accommodate unexpected anatomical problems.

For experienced surgeons, all coronary artery patterns are said to be transferrable. However, there may be occasions in which the only safe option is to opt for the atrial switch. These cases are exceptional and are not recommended by any level of evidence or recommendation.

5.4.3 Right ventricular outflow tract reconstruction. The reconstruction of the neopulmonary trunk connecting the former aorta to the pulmonary bifurcation depends on the construction of a tension-free anastomosis, in order not to create any coronary compression and trying to minimize the risk of tension-induced late RVOT stenosis. This goal requires several manoeuvres: full mobilization of pulmonary arterial branches as far as the origin of the first pulmonary branching into the lung hilum; reconstruction of pulmonary tissue defects related to excision of the Valsalva sinuses area; and anterior or more lateral pulmonary bifurcation displacement, which is achieved mainly by the Lecompte manoeuvre.

The Lecompte manoeuvre [162], by which the pulmonary bifurcation is brought anterior to the aorta, should be performed routinely [163-169] whenever the aorta and pulmonary arterial trunks are orientated totally, or predominantly, anteriorlyposteriorly.

Whenever great vessels are located side by side, and depending on special orientations, the Lecompte manoeuvre may or may not be performed $[161,167$, $170,171]$. In cases where it is not performed, it is necessary to shift the pulmonary artery bifurcation, which is done by sliding the anastomosis to one of the pulmonary branches.

The pulmonary artery tissue defects related to coronary transfer must be filled in. Several patch materials and patching techniques may be used [163, 166, 168, 170, 172-174]; however, autologous pericardial patch material is used most widely [163, 166, 174]. Most surgeons use fresh pericardium $[167,173]$, because the use of materials pretreated with glutaraldehyde, irrespective of its concentrations, is associated with the development of RVOT stenosis postoperatively [174].

The so-called trousers patch reconstruction technique is generally used [163, 167, 173], because it apparently produces less residual RVOT obstruction [163].

In the so-called button hole technique for coronary harvest and transfer, the neopulmonary trunk may reconstructed using direct anastomosis [165, 173]; the punch holes should be filled in with patch material.
No evidence has been produced regarding the use of any particular suture material. Resection of a small segment of ascending aorta before aortic reanastomosis in order to allow a more tensionfree pulmonary reconstruction has been proposed [169].

No evidence regarding the use of glue, systematically or sporadically, to prevent bleeding, is available, although its use has become generalized.

5.4.4 Atrial septal defect in TGA IVS. Patients under consideration for an ASO always have an ASD: a secundum ASD, a patent foramen ovale or an ASD after septostomy. This defect is normally closed, either directly or by patch. As part of the procedure, a residual defect may be left intentionally, to make the postoperative course smoother, particularly in patients in whom PVR might fluctuate and prompt a haemodynamic crisis. However, there is insufficient evidence to make a recommendation in favour or against this practice.

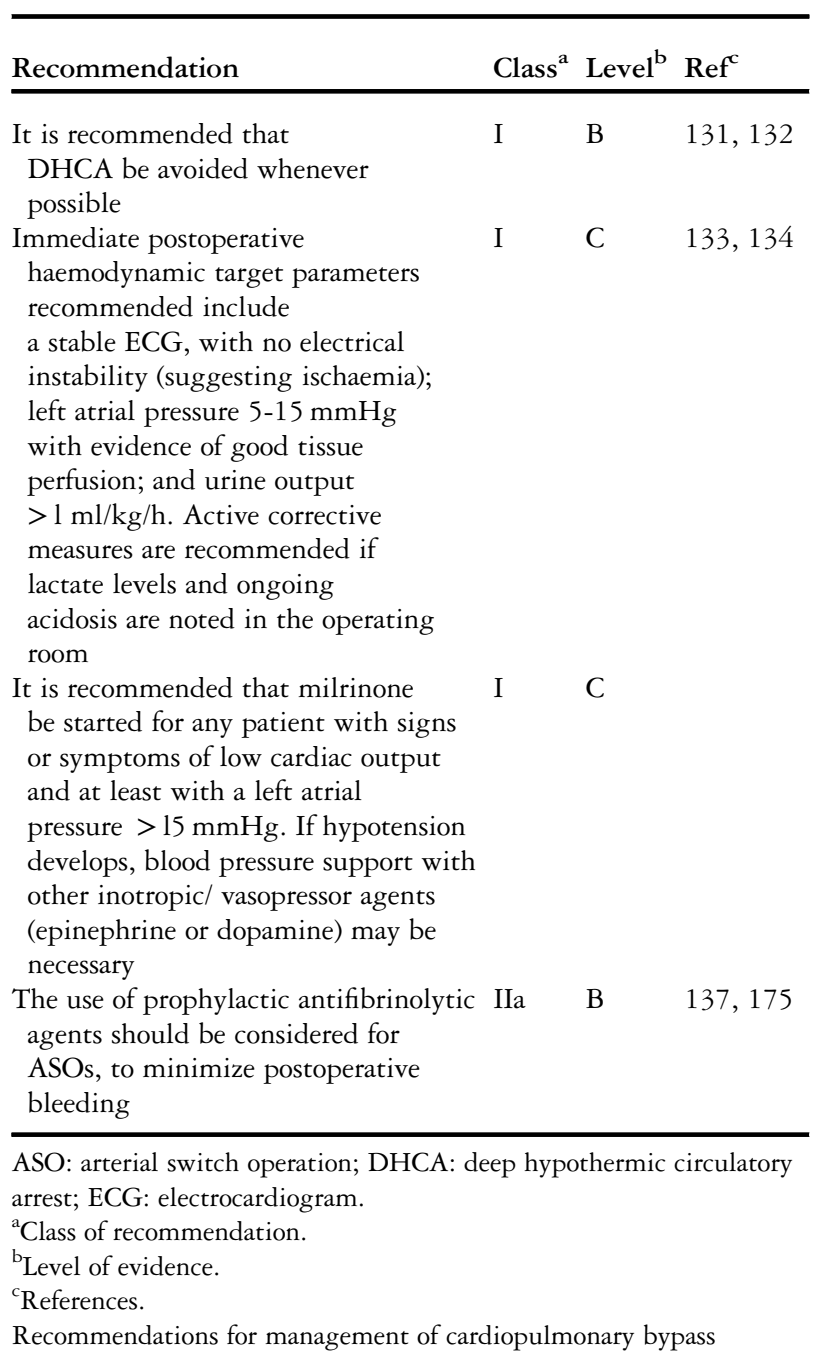




\begin{tabular}{|c|c|c|c|}
\hline Recommendation & Class $^{\mathrm{a}}$ & Level $^{\mathrm{b}}$ & $\operatorname{Ref}^{c}$ \\
\hline $\begin{array}{l}\text { Delayed sternal closure after an ASO } \\
\text { should be considered in selected cases } \\
\text { of significant postoperative tissue } \\
\text { oedema }\end{array}$ & IIa & $\mathrm{C}$ & \\
\hline $\begin{array}{l}\text { Although all coronary artery patterns } \\
\text { are theoretically transferable, some } \\
\text { are more difficult to transfer than } \\
\text { others and have been identified as risk } \\
\text { factors for mortality in an ASO (e.g. } \\
\text { double looping, side-by-side vessels } \\
\text { and single ostium, particularly with } \\
\text { intramural course). Therefore, } \\
\text { meticulous attention to } \\
\text { individualized surgical technique is } \\
\text { recommended to avoid kinking, } \\
\text { torsion or stretching }\end{array}$ & I & $\mathrm{B}$ & $\begin{array}{c}90,139- \\
146,153\end{array}$ \\
\hline $\begin{array}{l}\text { Coronary transfer, after the harvest of } \\
\text { large buttons and adequate } \\
\text { mobilization of the proximal coronary } \\
\text { artery segments, is recommended }\end{array}$ & I & $\mathrm{C}$ & \\
\hline $\begin{array}{l}\text { Of the various equally effective } \\
\text { coronary-transfer techniques, trap } \\
\text { doors are recognized for reducing } \\
\text { angulation for all cases; their } \\
\text { generalized use should be considered }\end{array}$ & IIa & $\mathrm{C}$ & \\
\hline $\begin{array}{l}\text { In posterior-looping coronary patterns, } \\
\text { as in the circumflex originating } \\
\text { from the right coronary artery } \\
\text { (pattern D), implantation into a } \\
\text { higher position, above the sinotubular } \\
\text { junction and possibly above the main } \\
\text { vessel suture line, is recommended }\end{array}$ & I & $\mathrm{C}$ & \\
\hline $\begin{array}{l}\text { It is recommended that an intramural } \\
\text { coronary course be addressed by } \\
\text { unroofing, followed by transfer of the } \\
\text { coronary ostia }\end{array}$ & I & $\mathrm{C}$ & \\
\hline $\begin{array}{l}\text { Whenever the aorta and pulmonary } \\
\text { arterial trunks are orientated totally or } \\
\text { predominantly anteriorly-posteriorly, } \\
\text { the Lecompte manoeuvre is indicated }\end{array}$ & I & $\mathrm{C}$ & \\
\hline $\begin{array}{l}\text { Whenever the great vessels are located } \\
\text { side by side, and depending on special } \\
\text { orientations, avoidance of the } \\
\text { Lecompte manoeuvre should be } \\
\text { considered. In cases when it will } \\
\text { not be performed, consideration } \\
\text { should be given to shifting the } \\
\text { pulmonary artery bifurcation by } \\
\text { sliding the anastomosis to one of the } \\
\text { pulmonary branches }\end{array}$ & IIa & $\mathrm{C}$ & \\
\hline $\begin{array}{l}\text { Neopulmonary root reconstruction } \\
\text { using fresh rather than } \\
\text { glutaraldehyde-treated pericardium } \\
\text { should be considered }\end{array}$ & IIa & $\mathrm{C}$ & \\
\hline $\begin{array}{l}\text { In an effort to reduce development of } \\
\text { RVOT obstruction, neopulmonary } \\
\text { root reconstruction using the trousers } \\
\text { patch technique should be considered }\end{array}$ & IIa & $\mathrm{C}$ & \\
\hline
\end{tabular}

ASO: arterial switch operation; RVOT: right ventricular outflow tract.

${ }^{\mathrm{a}}$ Class of recommendation.

${ }^{\mathrm{b}}$ Level of evidence.

${ }^{\mathrm{c}}$ References.

Recommendations on surgical technique

\section{Perioperative and postoperative management}

\subsection{Anaesthetic management}

Pertinent preoperative and perioperative issues that require special attention include the following:

1. Cyanosis, which may delay induction of anaesthesia with inhaled anaesthetics: neonates with a high haematocrit and excessive viscosity may have impaired microvascular perfusion, outweighing the advantages of increased oxygen-carrying capacity. Reduction of red blood cell (RBC) volume is not recommended in this situation.

2. Elevated PVR: special attention must be paid to patients with high PVR who present as 'poor mixers' and require urgent surgery with a suboptimal acid-base balance.

3. Coexisting diseases: these could preclude the use of monitoring options [transoesophageal echocardiogram (TOE)].

4. Family rapport and parent informed consent: to help the family develop a sense of trust and a positive hospital experience, it is important to discuss with them line placement, prolonged ventilation and instrumentation issues.

6.1.1 Monitoring. Noninvasive monitoring for an ASO should include pulse oximetry (usually two sites, pre- and post-ductal, are used), five-lead ECG, end-tidal capnography, oxygen and anaesthetic gas analysis, automated blood-pressure-measurement cuff, multiple-site (rectal, tympanic or posterior pharyngeal) temperature measurement, volumetric urine collection and a precordial stethoscope during induction. In the presence of cyanosis, pulse oximetry overestimates $\mathrm{SaO}_{2}$ and is exacerbated with further decrease of partial pressure of arterial oxygen $\left(\mathrm{PaO}_{2}\right)$ [176]. The partial pressure of end-tidal $\mathrm{CO}_{2}$ value is less reflective of partial pressure of arterial carbon dioxide $\left(\mathrm{PaCO}_{2}\right)$ because of ventilation perfusion mismatching [177]. Rectal and tympanic temperature readings overestimate brain temperature [178]. NIRS has been used routinely to evaluate both cerebral (forehead) [179] and tissue (renal) perfusion. Although more data in humans are needed, the use of noninvasive monitoring is likely to improve perioperative management in patients undergoing an ASO [180]. These technologies are useful indicators of trends in oxygenation [181].

Invasive monitoring includes placement of an arterial line and catheterization of a central vein for central venous pressure (CVP) measurement.

Transoesophageal echocardiogram is an invaluable perioperative tool for monitoring ventricular performance and evaluating surgical results. Attention 
should be paid to complications that could occur during the use of TOE, especially haemodynamic compromise from left atrial compression.

Blood-gas analysis, along with the ability to perform onsite thromboelastography and platelet count, is as important as haemodynamic monitoring for this procedure.

6.1.2 Induction and maintenance of anaesthesia. No studies support the use of any particular anaesthetic agents for induction and maintenance of anaesthesia. Patients usually present with established IV access. In such cases, an opioid-based anaesthetic is supported. All other IV induction agents could be used at judicious doses, once their primary effects on the myocardium and vascular system are carefully evaluated. In cases of the inhalation-induction technique, administration of sevoflurane, the preferred anaesthetic agent, should be done with care and not in 'high' inspired concentrations, which could lead to relative bradycardia and decreased systemic vascular resistance.

All inhaled anaesthetic agents are thought to offer a degree of ischaemic preconditioning not only to the myocardium but also to the brain [182] and kidney [183].

Administration of amnesia-inducing agents is frequently minimized, because the importance of perioperative recall in this age group is frequently underestimated. Benzodiazepines given intravenously or a volatile anaesthetic agent administered through a vaporizer on $\mathrm{CPB}$ should be considered.

\subsection{Pre-cardiopulmonary bypass management}

The duration of the pre-CPB period varies and requires the vigilance and intense involvement of the anaesthesiologist, particularly in periods when distractions are unavoidable (such as during line placement). It is important to realize that pre-CPB is the period when the parallel connection of the systemic and pulmonary circulations takes place, whereby adequate mixing is achieved by obtaining appropriate volume status. Systemic oxygenation is highly dependent on increased venous oxygen saturation $\left(\mathrm{SvO}_{2}\right)$ and improves with volume administration. Some anaesthesiologists have a lower threshold for use of inotropic support during this period, because of its favourable potential impact on cardiac output and therefore oxygenation improvement. There are not enough data to support such a choice. The importance of optimizing PVR and ensuring adequate mixing should not be underestimated. In cases of late TGA corrections, decreased left ventricular performance is also important. Finally, during the pre-CPB period, attention should be paid to careful surgical manipulation of the aorta and vena cava because missteps at this point could precipitate arrhythmias, hypotension and blood loss, leading to further systemic desaturation.

\subsection{Cardiopulmonary bypass and anaesthesia}

The initiation of CPB introduces major changes in the pharmacokinetics and pharmacodynamics of administered agents. These changes, which are magnified by the volume of distribution changes in the neonate, require additional attention directed towards achieving adequate depth of anaesthesia [184] and enhancement of the effects of the administered vasoactive agents. Parameters of $\mathrm{CPB}$ management that require special anaesthesiological consideration include the following:

1. Haematocrit and blood product utilization on bypass. Use of blood products for an ASO is unavoidable and practice is institution specific. The majority of centres would add either whole blood or packed RBCs with fresh frozen plasma (FFP) to ensure a haematocrit $\geq 25 \%$, especially during the cooling and rewarming phases when hypoxic and ischaemic brain injuries are most likely to occur [185]. The risk-benefit ratios favour the greater haematocrit approach up to $30 \%$, which represents a shift from previous practice trends [186]. We propose the use of fresh blood up to 5 days old, because, compared with stored RBCs, fresh RBCs are more metabolically balanced, have a higher $\mathrm{pH}$, contain less potassium and reduced concentrations of lactate [187], lead to fewer pulmonary complications and renal dysfunction and have lower infection rates [188].

2. Vascular tone. When an $\alpha$-stat technique is used, catecholamine production and a relative alkaline environment lead to elevated systemic vascular resistance and not to homogeneous tissue and organ perfusion. The use of vasodilators, mainly $\alpha$-receptor antagonists, is widely advocated. Phentolamine at $0.1-0.2 \mathrm{mg} / \mathrm{kg}$, phenoxybenzamine, sodium nitroprusside and nitroglycerine offer vasodilating effects.

3. Systemic inflammatory response. Treatments intended to reduce the systemic inflammatory response to $\mathrm{CPB}$ and operative trauma in general include the use of steroids. The use of steroids has been questioned. Although many groups use steroids preoperatively in order to mitigate the inflammatory effects of $\mathrm{CPB}$ while providing myocardial protection [189], various publications show that there are not enough evidence-based data to justify this practice $[190$, 191]. A multicentre observational analysis performed in the USA and published in 2012 did not find any benefit associated with 
methylprednisolone in neonates undergoing heart surgery and suggested that increased infection occurred in certain subgroups [192]. Another recent systematic review of randomized controlled trials showed that, despite the demonstrated attenuation of CPB-induced inflammatory response following the administration of steroids and other potential clinical advantages (lower mortality rate and significant reduction of renal-function deterioration), a large prospective randomized study is still needed to verify clearly the effects of steroid prophylaxis in paediatric patients [193]. Studies of newer anti-inflammatory treatment modalities are under way, including the use of monoclonal antibodies for inflammatory products (i.e. complement, tumour necrosis factor and endotoxins), and these may offer advantages in the future. Currently, adequate heparinization, along with the use of coated circuits [194, 195], is recommended, because it offers evidencebased elimination of thrombin production, minimizing the degree of systemic inflammatory reaction [196]. Finally, it should be noted that the use of opioids (fentanyl at doses higher than $25 \mu \mathrm{g} / \mathrm{kg}$ ) decreases stress response, modifies inflammation and stabilizes haemodynamics [197]. The use of conventional and modified ultrafiltration techniques provides evidence of reduction of bypass-related perioperative morbidity. Both improve myocardial function, decrease tissue oedema and minimize ventilatory support times. Modified ultrafiltration does not necessitate the addition of crystalloids or colloids, as does conventional ultrafiltration, uses only the patient's blood volume, but requires extra vigilance to avoid volume depletion and temperature alterations [198].

4. Glucose control. Although still controversial, glucose control should be kept in mind, to avoid extremes of blood-sugar levels. In the Boston Circulatory Arrest Study, intraoperative [199] and initial postoperative [200] hyperglycaemia did not predict worse neuro-developmental outcomes.

\subsection{Separation from cardiopulmonary bypass}

Issues pertinent to ASOs that play important roles during separation from CPB are as follows:

1. Myocardial ischaemia resulting from either air emboli or stenotic coronary anastomoses. After the surgical coronary anastomotic result is evaluated, increasing the coronary perfusion pressure should resolve myocardial ischaemia. Elevated RV afterload after the Lecompte manoeuvre could be another cause of coronary ischaemia.

2. Labile pulmonary artery pressure and elevated PVR that require interventions.

3. Poor left ventricular performance, especially in late correction of TGA, requiring use of inotropic support (milrinone, epinephrine, dopamine or dobutamine) or mechanical circulatory support.

\subsection{Transfer to the intensive care unit}

Monitoring of $\mathrm{O}_{2}$ saturation; ECG; and end-tidal carbon dioxide $\left(\mathrm{CO}_{2}\right)$, arterial, central venous and atrial pressures (if available), should be continuous when the patient is transferred from one area of the hospital to another.

Resuscitation drugs, airway equipment, blood products and fluids for intravascular volume replacement should also be available. Patients are transferred on high $\mathrm{FiO}_{2}$, with a manual resuscitator or preferably a Jackson-Rees circuit, which provides better clinical information for chest and lung compliance. For patients on NO, ensuring continuous administration of $\mathrm{NO}$ is required. Various battery charges should be checked as well as pacing availability. Once adequate depth of anaesthesia is assured, the endotracheal tube should be suctioned before arrival in the ICU.

Finally, but most importantly, communication and rapport with the ICU staff should be a top priority well before the patient is moved to the ICU. We recommend that ICU nursing staff be in the operating room before the patient is moved.

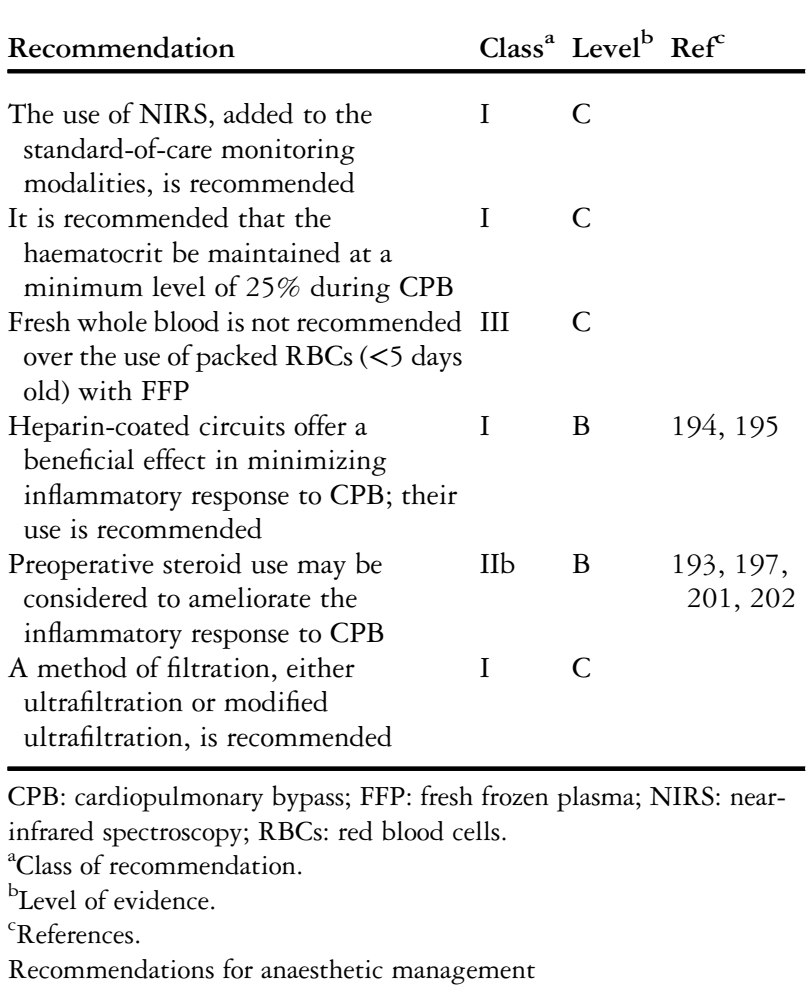


6.5.1 Postoperative management in the intensive care unit. Postoperative management of patients with TGA focuses on the optimization of cardiac output [avoidance and treatment of low cardiac output syndrome (LCOS)], tissue perfusion and respiratory status, and on mitigation of the stress response and inflammatory processes triggered by CPB. Early goals of management also include control of coagulopathy; management of vascular tone, anomalies and capillary leak; and prevention and management of total body volume overload.

6.5.1.1 Transition and handover from the operating room. Intensive-care management starts with an adequate, standardized and safe transfer from the operating room. Prior to transfer, a World Health Organization Surgical Safety Checklist should be applied [203]. The objectives are to have a face-toface handover of information in a systematic, concise, cohesive and safe manner. The anaesthesiologist is responsible for the care of the patient until the report process is complete. The assessment of the patient by the cardiac ICU nurses and physicians must occur after the report process is complete [204-209].

6.5.1.2 Haemodynamic and tissue perfusion monitoring. After the ASO, patients require noninvasive and invasive monitoring. Basic monitoring strategies include continuous ECG; respiratory rate; noninvasive blood pressure cuff; core and peripheral temperatures; systemic oximetry and invasive arterial blood pressure; CVP; inspired end-tidal capnography; and, infrequently, continuous left atrial pressure. The acid-base status, mixed venous $\mathrm{O}_{2}$ saturations and serum lactate levels are excellent markers of $\mathrm{O}_{2}$ delivery [210]. Patients may also be monitored with NIRS, which is a good surrogate marker of mixed venous oxygen saturation and hence a good continuous monitor of cardiac output and $\mathrm{O}_{2}$ delivery $[211,212]$. Alternative technologies include invasive continuous mixed venous saturation monitoring and devices based on arterial wave contour analysis. Urine output must be carefully monitored although it is a poor early indicator of low cardiac output and deficient oxygen delivery.

6.5.1.3 Ancillary evaluation. Baseline evaluation includes a chest radiograph, arterial blood gas with a lactate level, central mixed venous saturation if required (in unstable patients), basic electrolyte and renal function panels and coagulation screening. Patients with bleeding may need more frequent evaluation of coagulation and possibly thromboelastograms, which would direct a goal-orientated therapy. Echocardiography is indicated for all unstable patients. Awareness of signs of coronary insufficiency is of utmost importance. An immediate postoperative ECG is routinely obtained and compared with preoperative evaluations. In the event of electrocardiographic or clinical evidence of ischaemia, nitroglycerine may be started; an echocardiograph, emergency catheterization and immediate surgical revision should be considered.

6.5.1.4 Haemodynamic management. Proper haemodynamic support must be based on comprehensive haemodynamic and pathophysiological appraisals [213-215].

The most important take-home message is that the ultimate objective is to provide adequate tissue perfusion. Mean arterial pressures of $35-45 \mathrm{mmHg}$ are acceptable for newborns following an ASO. Left atrial pressures, when monitored, should be maintained in the $8-10 \mathrm{mmHg}$ range because volume boluses to increase this pressure are not well tolerated by the non-compliant left ventricle. The presence of right ventricular hypertension is unusual, and its presence should be promptly investigated using echocardiography. Residual intracardiac shunts or branch pulmonary artery stenosis following the Lecompte manoeuvre have both been implicated in elevated right ventricular pressures $[7,216]$. Neonates undergoing an ASO receive milrinone $(0.5-1.0 \mu \mathrm{g} / \mathrm{kg} / \mathrm{min})$ and low-dose dopamine $(3-5 \mu \mathrm{g} / \mathrm{kg} / \mathrm{min})$ or low-dose adrenaline $(0.01-$ $0.05 \mu \mathrm{g} / \mathrm{kg} / \mathrm{min}$ ) to augment ventricular function if needed. Calcium chloride (10\%) infusions at $5-15 \mathrm{mg} / \mathrm{kg} / \mathrm{h}$ may also be helpful. Systemic afterload reduction can also be achieved with numerous drugs that add to the vasodilatory effect of milrinone; these may be alpha-blockers (phentolamine, phenoxybenzamine) or sodium nitroprusside. Vascular tone may be an issue in patients who present with significant inflammatory reactions. Vasopressin, low-dose norepinephrine and phenylephrine at low doses are useful to antagonize such vasodilation, optimize target organ perfusion and eventually optimize urine output, while reducing fluid overload [217].

6.5.1.5 Management of rhythm and conduction disorders. Following an ASO, neonates may be vulnerable to arrhythmias, which may relate to various factors [218]. Arrhythmias are associated with increased mortality rates; therefore, anticipating risk factors and preventing arrhythmias remain important objectives during the postoperative course [218, 219]. Many arrhythmias are easily solved. In patients undergoing an ASO, indwelling lines may cause arrhythmias triggered by irritation of the myocardium when their tip is in an intracardiac position, and in this case, they require removal [218, 220]. Usually automatic tachycardia and re-entry tachycardia may not be well tolerated in the early postoperative phase, particularly in patients with marginal haemodynamics. For patients with 
arrhythmias, priority should be given to immediate resuscitation efforts if they are haemodynamically unstable; parallel steps focus on the correction of electrolyte and acid-base disturbances, optimization of ventilation, repositioning of intrathoracic linesgeneral, simple measures that may resolve the arrhythmias. If these measures fail, prompt antiarrhythmic therapy should be initiated. One of the most common arrhythmias after an ASO is junctional ectopic tachycardia (JET). In the management of JET, the following measures are recommended: controlled hypothermia, decrease of vasoactive drugs, optimization of electrolytes, use of dexmedetomidine or amiodarone and pacemaker strategies. Ideally, for safety reasons, antiarrhythmic drugs should be titrated as continuous infusions. Esmolol [221, 222], procainamide [223-225] and amiodarone [224, 226-229] are the most commonly used antiarrhythmic drugs in the neonatal period [224]. Other commonly used antiarrhythmic drugs used in the neonate after an ASO are sotalol [224, 230], propranolol [224], digoxin [231], adenosine and magnesium sulphate [218].

6.5.1.6 Low cardiac output syndrome. Low cardiac output syndrome is multifactorial, related to $\mathrm{CPB}$ and circulatory arrest or to myocardial preservation, mechanical disruption of the myocardium, postinflammatory effects of bypass, and coronary manipulation, among others [129, 232]. LCOS may be more likely to happen when surgical intervention is delayed. It is critical to anticipate subtle changes that may indicate the inception of LCOS, including urine output, clinical perception of peripheral perfusion, and trends in heart rate and pressures, but this awareness may be related to the caregivers' experience [233]. Persistent systemic hypotension in the setting of poor peripheral perfusion, elevated left atrial pressure, elevated serum lactate or decreased cerebral NIRS and other signs of left ventricular dysfunction should be promptly investigated. Any suspicion of coronary insufficiency should be addressed immediately, with possible re-exploration and revision. In the absence of coronary insufficiency, low cardiac output can be caused by primary myocardial dysfunction. Pharmacological support is therefore provided with vasoactive, inotropic and lusitropic drugs titrated to improve cardiac output with systemic afterload reduction and to enhance tissue perfusion markers.

6.5.1.7 Extracorporeal life support. In certain cases, mechanical circulatory support with ECLS or a ventricular assist device (VAD) may be indicated. In situations where adequate haemodynamics cannot be achieved or can be achieved only with high inotropic support (exposing the patient to significant myocardial oxygen consumption and progressive lactic acidosis and progressive alteration of tissue perfusion markers), a brief period of ECLS may help to bridge the patients to recovery. In such scenarios, it is vital to rule out residual defects that may need surgical revision prior to weaning the patient from the ECLS. The need for ECLS has been reported in around 20\% of infants undergoing an ASO beyond the sixth week of life [234].

6.5.1.8 Sedation and analgesia. All medications should be given following the principle of minimal effective dosing. Analgesic and sedative strategies should encompass the provision of baseline comfort and the limitations of haemodynamic side effects. No combinations have proven superior, but it is important to remain consistent. Universal pain and sedation scores (i.e. the COMFORT scale) are required and will be used to evaluate needs and drug titration [235]. Avoidance of prolonged use may help prevent subsequent withdrawal symptoms. Strategies to try to avoid withdrawal may include drug rotation, daily interruption of infusions and the use of long-acting agents; nonetheless, the most effective method is to avoid using opioids and benzodiazepines for more than 5 days [236].

The most commonly prescribed combinations include opioids and benzodiazepines. Morphine and fentanyl are the most frequently used opioids for maintenance and breakthrough analgesia. Continuous infusions may be better tolerated and allow easier titration to minimal effective doses. It is important to keep in mind that the combination with nonopioid analgesia (i.e. paracetamol) reduces the requirements for opioids. Midazolam, the most commonly used agent for sedation, provides effective sedation and amnesia. Dexmedetomidine is a newer agent that has been approved for use in the European Union since 2011; it produces stable sedation without respiratory depression and decreases the need for other sedatives or analgesics [237-240]. The use of muscular relaxants should be avoided in the postoperative course of an ASO. It may occasionally be needed to promote ventilator synchrony with specific modalities. It may also be useful to induce hypothermia as part of the management of LCOS or after cardiac arrest, or in the event of pulmonary hypertension crisis or JET. Ventilated neonates on muscle relaxants have a higher than average overall mortality rate compared with neonates managed without muscle relaxants [241]. Neuromuscular blockade should be administered only in patients who are deeply sedated with appropriate monitoring [236]. If necessary, its administration should be short-lived because it carries numerous inconveniences [242]. Vecuronium is used most commonly; rocuronium and cisatracurium are also used frequently. 


\subsubsection{Ventilation and airway management.} Mechanical ventilation targets the maintenance of homeostasis ( $\mathrm{pH} 7.35-7.45, \mathrm{PaCO}_{2} 35-45 \mathrm{mmHg}$, no hypoxaemia) while avoiding barotrauma. Ventilatory modalities and parameters need to be adapted to specific conditions such as pulmonary hypertension. Neonates with ongoing bleeding, unstable haemodynamics or rhythm abnormalities and those with delayed closure of the sternum should remain mechanically ventilated. All other patients should be weaned from mechanical ventilation over $12-24 \mathrm{~h}$ at the latest. Prevention of ventilatorassociated pneumonia is essential in neonates who remain ventilated after the ASO. The main clinical bundles in the prevention recommendations are head-of-bed positioning, closed suction, oral care and patient repositioning [243-246].

6.5.1.10 Fluid and electrolyte management. Fluid overload can have a profound influence on the initial postoperative course; therefore a methodical followup of fluid intake and output is essential. IV fluids with $10 \%$ dextrose are given at $50 \%$ maintenance $(2 \mathrm{ml} / \mathrm{kg} /$ day) for the first $24 \mathrm{~h}$ and then gradually used more liberally after that time. Hypotension due to hypovolaemia is treated with $5-10 \mathrm{ml} / \mathrm{kg}$ bolus infusions of $5 \%$ albumin, normal saline or FFP. Patients who are tenuous and anaemic ought to receive concentrated RBCs, and patients with persistent bleeding may require FFP, platelets and packed RBCs. On Day 2 postoperatively, fluids may be increased to $75 \%$ of requirements and then to $100 \%$ from Day 3 onwards.

6.5.1.11 Renal management. Transient renal insufficiency and acute kidney injury are fairly common and associated with increased morbidity and mortality [247-251]. This disturbance is not exclusive to unstable patients and is multifactorial. A methodical evaluation of patients with suboptimal urine output is necessary and may require the estimation of a Paediatric Risk, Injury, Failure, Loss, End-Stage Renal Disease (pRIFLE) score. Furosemide is started $8-12 \mathrm{~h}$ after surgery $(0.5-$ $1 \mathrm{mg} / \mathrm{kg}$ boluses every $6-24 \mathrm{~h}$ or continuous infusion at $0.05-0.3 \mathrm{mg} / \mathrm{kg} / \mathrm{h})$.

6.5.1.12 Feeding and nutrition. Enteral feeding is started when haemodynamics are stable. If enteral feeding cannot be started by Day 1 postoperatively, then total parenteral nutrition should be initiated. Mechanically ventilated patients can be fed via a nasogastric tube or a post-pyloric feeding tube if there is concern about gastrooesophageal reflux. If the patient is breathing spontaneously and has stable respiratory mechanics, one can try oral feedings. In addition, ranitidine should be used prophylactically in the postoperative period.

\begin{tabular}{|c|c|c|c|}
\hline Recommendation & Class $^{a}$ & Level $^{\mathrm{b}}$ & $\operatorname{Ref}^{c}$ \\
\hline $\begin{array}{l}\text { Compliance with a meticulous } \\
\text { checklist in the operating room and } \\
\text { an operating-room-to-intensive } \\
\text { care transfer algorithm are } \\
\text { recommended }\end{array}$ & I & $\mathrm{C}$ & 204-209 \\
\hline $\begin{array}{l}\text { It is recommended that, upon } \\
\text { suspicion of ischaemia (such as } \\
\text { ischaemic ECG changes or de novo } \\
\text { ventricular arrhythmias), } \\
\text { nitroglycerine may be used and, most } \\
\text { importantly, emergent diagnostic } \\
\text { strategies and possible surgical } \\
\text { reintervention be instituted promptly }\end{array}$ & I & $\mathrm{C}$ & 216 \\
\hline $\begin{array}{l}\text { It is recommended that } \\
\text { pharmacological support be } \\
\text { provided with vasoactive, inotropic } \\
\text { and lusitropic drugs, titrated to } \\
\text { improve cardiac output with } \\
\text { systemic afterload reduction; } \\
\text { milrinone together with a low dose } \\
\text { of dopamine or epinephrine is } \\
\text { recommended as the first-line drug } \\
\text { combination for postoperative } \\
\text { pharmacological support }\end{array}$ & I & $\mathrm{C}$ & $\begin{array}{l}135,216 \\
217,252 \\
253\end{array}$ \\
\hline $\begin{array}{l}\text { Early ECLS is indicated with lack of } \\
\text { responsiveness to medical therapy, } \\
\text { in the presence of worsening } \\
\text { markers of tissue perfusion }\end{array}$ & I & $\mathrm{C}$ & 216,234 \\
\hline $\begin{array}{l}\text { It is recommended that analgesic, } \\
\text { sedative and anxiolytic agents, } \\
\text { which are vital for favourable } \\
\text { patient progression, be } \\
\text { administered according to the } \\
\text { principle of minimal effective } \\
\text { dosing; prolonged use of muscle } \\
\text { relaxants should be avoided }\end{array}$ & I & $\mathrm{C}$ & \\
\hline $\begin{array}{l}\text { It is recommended that early } \\
\text { extubation be a priority of } \\
\text { postoperative management }\end{array}$ & I & $\mathrm{C}$ & \\
\hline
\end{tabular}

ECG: electrocardiogram; ECLS: extracorporeal life support.

${ }^{\mathrm{a} C}$ Class of recommendation.

${ }^{\mathrm{b}}$ Level of evidence.

${ }^{\mathrm{c}}$ References.

Recommendations for intensive care postoperative management

\section{Special topics}

\subsection{Atrial switch-is there a role for it?}

7.1.1 Introduction. Over the years, atrial switch procedures have almost entirely yielded to the ASO in TGA IVS and are currently limited to rare indications. The long-term outcome following atrial switch procedures is reported to be $80 \%$ survival at 25-30 years [254-258]. There is a significant late hazard function affecting this population, and sudden death occurs in $6-17 \%$ of patients [258]. Sudden death may relate to the occurrence of atrial arrhythmias [259] and loss of sinus rhythm [260]. Furthermore, the long-term outcome of these 
patients may entail a number of reoperations or interventional procedures in $10-20 \%$ of survivors, most commonly for baffle leak or obstruction [261] or tricuspid regurgitation [262].

7.1.2 Current role of atrial switches. Possible indications for atrial switch procedures in patients with TGA IVS are given in the 'Recommendations for atrial switch' (see section 7.1.4 'Treatment for late failure of the systemic right ventricle' section).

7.1.3 Who still knows how - and is able - to perform this operation? The currently limited application of the Senning and Mustard operations has deprived the younger generations of congenital heart surgeons of sufficient exposure to the many tips and pitfalls of the atrial switch procedures. Yet, mastering these techniques can be crucial for special circumstances. Exhaustive references dealing with the technical aspects of these procedures are available for both the Senning [263-265] and the Mustard [266] operations, which are still indicated in conditions outside the scope of these guidelines.

7.1.4 Treatment for late failure of the systemic right ventricle. The treatment for late failure of the systemic right ventricle after the Senning or Mustard operation is controversial. The following two options are available:

1. Medical management and/or cardiac devices eventually followed by heart transplant, or

2. Conversion (staged) to anatomical repair.

7.1.4.1 Medical therapy for TGA patients with systemic right ventricular failure. Conservative management should include meticulous echocardiographic follow-up, with exercise testing when appropriate, to detect early changes in ventricular/valvular function and decrements in the patient's functional status [262]. Mild systemic right ventricular dysfunction with mild-to-moderate tricuspid regurgitation can be treated conservatively with afterload reduction and control of arrhythmias $[262,267]$. Afterload reduction, using angiotensinconverting enzyme inhibitors, $\beta$-blockers and diuretics, has proved useful in this setting $[267,268]$.

7.1.4.2 Cardiac devices for TGA patients with systemic right ventricular failure. Pacemaker implantation can restore physiological cardiac rhythm, with $11 \%$ of pacemaker dependency reported in the adult population of TGA patients [269]. Electromechanical dyssynchrony, secondary to right bundle branch block or left ventricular pacing, may respond to cardiac resynchronization therapy [270, 271]. Implantable cardioverter defibrillators may help prevent sudden death [272]. The use of left VAD for RV failure following the Mustard operation has been described [273].

7.1.4.3 Surgery for patients with TGA with right ventricular/tricuspid valve dysfunction. For cases with progressive right ventricular and tricuspid valve dysfunction, surgical therapy is indicated.

1. Tricuspid valve surgery: tricuspid valve repair or replacement may improve right ventricular function, but only if surgery is performed before significant right ventricular dysfunction ensues [274]. It is unclear whether tricuspid valve replacement should be preferred to tricuspid valvuloplasty; however, surgical intervention is associated with a risk of early mortality (up to $10 \%)$ and the need for reoperation (in another $25 \%$ ) [275]. In general, tricuspid valve function and functional class improve significantly after surgery, and systemic right ventricular function is preserved [276].

2. Pulmonary artery banding and conversion to anatomical repair: in the presence of reversible right ventricular dysfunction associated with well-maintained left ventricular and mitral valve function, conversion to anatomic correction may be considered.

However, with the exception of cases with longstanding pulmonary hypertension (e.g. for residual pulmonary venous obstruction) or ventricular outflow tract obstruction, the left ventricle must be retrained by incremental pulmonary artery banding [277]. Gradual left ventricular training is vital because overzealous banding can induce left ventricular failure [278]. Interestingly, the increase in the left ventricular pressure may induce a rightward septal shift, with improved coaptation of the leaflets and consequent reduced regurgitation of the systemic atrioventricular valve. The result is reduced right ventricular volume load and improved function. Whether this approach can be considered a definitive palliation is not yet clear [262, 274, 275, 277]. Nonetheless, it can act as a bridge to transplant [278].

7.1.4.4 Methods for conversion of atrial switch to an ASO. Left ventricular training in children or older patients is a much slower process than it is in infants and is achievable by different strategies of incremental pulmonary artery banding:

1. Single, long-standing ( $\geq 1$ year) pulmonary artery banding, in which the patient gradually outgrows an initially loose band [278].

2. Multiple surgical procedures (2-3 stages) with progressive tightening of the band [278].

3. Application of a telemetric adjustable pulmonary artery band, undertaking a variety of cardiac fitness protocols [279, 280].

7.1.4.5 Indications and timing for conversion of atrial switch to an ASO. There is an age-dependent time limit for preparatory pulmonary artery banding to recondition the left ventricle $[102,122,274]$. 
Clinically, the response to left ventricular training appears inconsistent among adolescents and adults $[277,278,281]$. This response is a possible consequence of inadequate myocardial perfusion in the presence of suddenly increased cardiac work during pulmonary banding and induced myocardial hypertrophy [102, 278]. In older patients, failure to achieve adequate reconditioning of the left ventricle increases the risk of death and calls for timely transplant [122]. In general, however, strict contraindications for left ventricular reconditioning and/or ultimate anatomical correction do not exist [281].

7.1.4.6 Pulmonary artery banding-operative and postoperative management. The band is gradually tightened until a drop in the systemic blood pressure and a rise in the CVP are observed, together with a decrease in oxygen saturation or the development of rhythm disturbances; the band is then loosened slightly [262, 282]. This step usually corresponds to an increment in left ventricular pressure of $20-50 \mathrm{mmHg}$. TOE can identify any shift of the ventricular septum and reduction of tricuspid regurgitation and right ventricular dysfunction. Conversely, if TOE demonstrates any deterioration in left ventricular function or the manifestation of mitral regurgitation, the band should be loosened immediately [262].

7.1.4.7 Interim follow-up during left ventricular training. Left ventricular function and pressures are periodically reassessed (e.g. every 3 months) using echocardiography, magnetic resonance imaging (MRI) and cardiac catheterization. Criteria for left ventricular preparedness include ventricular ejection fraction of $\geq 55 \%$, less-than-mild mitral regurgitation, ventricular systolic pressure $\geq 80 \%$ of systemic blood pressure, ventricular end-diastolic pressure $\leq 10 \mathrm{mmHg}$, normal indexed ventricular mass $\left(\geq 60 \mathrm{~g} / \mathrm{m}^{2}\right)$ and normal wall thickness [262, 278]. If these criteria are not met, pulmonary artery banding is repeated. Roughly one to two band-tightening procedures over a 1-year period may be needed [262, $278,283]$. If left ventricular dysfunction is observed or if atrial arrhythmias progress, the banding is taken down.

Patients are listed for transplant when their condition deteriorates to end-stage heart failure [278].

7.1.4.8 Anatomical correction-operative and postoperative management. Along with take-down of atrial repair and conversion to anatomical correction [284], additional procedures may be needed to manage neoaortic insufficiency or atrial arrhythmias [277]. The immediate postoperative therapy must comprise aggressive reduction of both pre- and afterload (using phenoxybenzamine and nitroprusside) and adequate inotropic support (using dopamine, dobutamine and milrinone). Nitroglycerine therapy may help to prevent coronary vasospasm and to control pulmonary artery vasoreactivity. Fluid challenges are contraindicated. Patients stay paralyzed and ventilated for at least $24 \mathrm{~h}$, and chronic afterload reduction medication is started orally once the patient is extubated [277].

7.1.4.9 Results for anatomic conversion of TGA after the mustard or senning operation. The median duration of pulmonary artery banding for left ventricular training is 13 months (maximum duration up to 5 years). Approximately one-half of these patients survive after an ASO in New York Heart Association functional class I or II, whereas another one-quarter need a heart transplant [262, 277, 282, 285, 286]. Additional morbidity occurs in these patients due to progressive aortic insufficiency and arrhythmias [277, 278].

7.1.4.10 Heart transplant. Patients presenting with advanced right ventricular or biventricular failure, severe tricuspid or mitral dysfunction, pulmonary valve abnormalities precluding its use as a neoaortic valve, resilient arrhythmias or heart block, especially beyond adolescence, should not be offered left ventricle training measures with the ultimate intention of anatomical correction and should be enrolled in the heart transplant pathway [262]. Nowadays, heart transplant is a well-established treatment strategy [287] and is likely to be a superior option to anatomical conversion from a functional aspect. However, it is challenging for both patient and clinician and, even more importantly, has limited application due to the shortage of donor organs [276, 288]. Therefore, currently, the most reasonable approach for patients with late right ventricular failure after an atrial switch repair is probably to integrate left ventricular reconditioning and an anatomical correction protocol into a cardiac transplant programme that can serve as a bailout solution [278].

\begin{tabular}{|c|c|c|c|}
\hline Recommendation & Class $^{\mathrm{a}}$ & Level $^{\mathrm{b}}$ & $\operatorname{Ref}^{c}$ \\
\hline \multicolumn{4}{|c|}{ An atrial switch should be considered in the following cases: } \\
\hline $\begin{array}{l}\text { Complex coronary transfer or } \\
\text { coronary origin from the non-facing } \\
\text { sinus }\end{array}$ & IIa & $\mathrm{C}$ & $\begin{array}{r}289 \\
290\end{array}$ \\
\hline $\begin{array}{l}\text { Late referral, as an alternative to a } \\
\text { two-stage ASO, especially in older } \\
\text { infants and children }\end{array}$ & IIa & $\mathrm{C}$ & 291 \\
\hline $\begin{array}{l}\text { In developing countries where there } \\
\text { is no setup for complex neonatal } \\
\text { surgery }\end{array}$ & IIa & $\mathrm{C}$ & 291 \\
\hline $\begin{array}{l}\text { In TGA IVS with persistent pulmonary } \\
\text { hypertension }\end{array}$ & IIa & $\mathrm{C}$ & 68 \\
\hline
\end{tabular}

ASO: arterial switch operation; IVS: intact ventricular septum; TGA: transposition of the great arteries.

${ }^{\mathrm{a}}$ Class of recommendation.

${ }^{\mathrm{b}}$ Level of evidence.

${ }^{\mathrm{c}}$ References.

Recommendations for atrial switch 


\begin{tabular}{|c|c|c|c|}
\hline Recommendation & Class $^{\mathrm{a}}$ & Level $^{\mathrm{b}}$ & $\operatorname{Ref}^{c}$ \\
\hline \multicolumn{4}{|c|}{ Management of late right ventricular failure } \\
\hline $\begin{array}{l}\text { In the event of late failure of the } \\
\text { systemic right ventricle after an atrial } \\
\text { switch, palliative treatment may be } \\
\text { considered, using one or more of the } \\
\text { following options: medical } \\
\text { management, cardiac devices, } \\
\text { tricuspid valve surgery and pulmonary } \\
\text { artery banding }\end{array}$ & IIb & $\mathrm{C}$ & $\begin{array}{l}262,267 \\
270,273 \\
276\end{array}$ \\
\hline $\begin{array}{l}\text { In the event of late failure of the } \\
\text { systemic right ventricle after an } \\
\text { atrial switch, corrective } \\
\text { management, using staged } \\
\text { conversion to anatomical repair } \\
\text { (which may involve incremental } \\
\text { preparatory pulmonary artery } \\
\text { banding) should be considered }\end{array}$ & IIa & $\mathrm{C}$ & $277-279$ \\
\hline $\begin{array}{l}\text { Heart transplant should be considered } \\
\text { in cases of advanced cardiac failure or } \\
\text { if palliative or staged conversion } \\
\text { strategies are failing }\end{array}$ & IIa & $\mathrm{C}$ & 262,278 \\
\hline \multicolumn{4}{|l|}{ Criteria for left ventricular preparedness } \\
\hline $\begin{array}{l}\text { The following criteria should be met } \\
\text { for the left ventricle to be judged } \\
\text { adequately trained to permit late } \\
\text { arterial switch conversion: Ventricular } \\
\text { ejection fraction } \geq 55 \% \text { Less-than- } \\
\text { mild mitral regurgitation Ventricular } \\
\text { systolic pressure } \geq 80 \% \text { of systemic } \\
\text { blood pressure and suprasystemic } \\
\text { after isoproterenol Ventricular end- } \\
\text { diastolic pressure } \leq 10 \mathrm{mmHg}\end{array}$ & IIa & $\mathrm{C}$ & 262,278 \\
\hline $\begin{array}{l}\text { Normal indexed ventricular mass } \\
(\geq 60 \mathrm{~g} / \mathrm{m} 2) \text { and normal wall } \\
\text { thickness }\end{array}$ & & & \\
\hline
\end{tabular}

${ }^{\mathrm{a}}$ Class of recommendation.

${ }^{\mathrm{b}}$ Level of evidence.

${ }^{\mathrm{c}}$ References.

Recommendations for late left ventricular training

\subsection{Cardiology follow-up protocols}

Recommendations for follow-up of ASO patients are challenged by several factors: (i) current consensus on appropriate time interval and modality of surveillance imaging is still lacking; (ii) symptoms are rare and can be atypical, particularly in cases of coronary obstruction; (iii) a clear treatment strategy for sub-clinical anatomical or functional findings is not available; and (iv) during long-term follow-up, the effects of superimposed coronary artery disease on the operated coronary arteries are still unknown [148].

Nevertheless, according to the common standard of care, short-term follow-up during the first year after an ASO should include clinical visits at 1, 3, 6 and 12 months postoperatively. During mid- and long-term follow-up, children should be examined yearly and adults, every second year [292].

Each visit should include history taking, clinical examination, 12-lead ECG and transthoracic echocardiography. A 24-h ECG should be performed annually in small children, because it may indirectly detect myocardial ischaemia. Regular exercise testing should be used to screen for myocardial ischaemia as soon as the patient is old enough to cooperate.

Well-known sequelae after an ASO include obstruction of the coronary arteries with related myocardial ischaemia, left ventricular dysfunction, stenoses of the pulmonary artery side branches, RVOT obstruction, neoaortic valve insufficiency and dilatation of the aortic root $[145,293]$. Therefore, follow-up should be targeted to detect such lesions.

Supravalvular pulmonary stenosis, particularly in the side branches of the pulmonary arteries, occurs mainly early after an ASO. Transthoracic echocardiography is the modality of choice for detecting RVOT stenosis. Additional imaging is frequently required, typically cardiac MRI, which has the advantages of providing clear anatomical delineation of the pulmonary arteries and additional functional information; therefore, cardiac MRI is considered the modality of choice for determining the need for a catheter-guided intervention involving the pulmonary arteries [294, 295].

Neoaortic root dilatation and neoaortic valve regurgitation are the most frequently observed postoperative sequelae during long-term follow-up. Both findings can be detected and quantified using transthoracic echocardiography. However, exact quantification of the diameter of the aortic root and of regurgitant flow through the aortic valve, as well as of size and function of the left ventricle, may require examination by cardiac MRI [296].

Obstructed coronary arteries occur in $5-7 \%$ of survivors and remain the most common cause of morbidity and mortality after the ASO procedure [297, 298]. Invasive $\mathrm{X}$-ray coronary angiography is still considered the gold standard for evaluation of coronary patency or obstruction; however, modern ECG-triggered computed tomography (CT) angiography provides excellent spatial resolution, has been validated in large studies [299] and can be used for morphological assessment in young adults after an ASO [300].

In children, the use of coronary CT angiography is limited by the burden of radiation and the fast heart rate. Cardiac MRI is not validated for final evaluation of the coronary lumen but provides crucial functional information about myocardial perfusion (from first-pass perfusion images) and about the presence of myocardial scars (from late-enhancement images). In patients undergoing an ASO, cardiac MRI first pass has been shown to have slightly better diagnostic performance than positron emission tomography scans [301]. This technique has also been validated in children [302, 303]. Thus, the current recommendation is to perform noninvasive screening for myocardial ischaemia, with exercise testing (in older children and adults) and 24-h 
ECG (in younger children), in combination with cardiac MRI.

\subsection{Arrbythmias}

Postoperative early and late arrhythmias may have various causes but can also be related to subacute or acute myocardial ischaemia due to impaired coronary artery blood flow. Patients with certain unusual coronary patterns (including those with an intramural or single coronary artery) have a significantly increased mortality risk [139, 143, 154, 304, 305]. Arrhythmia problems encountered include:

1. Supraventricular tachycardia and sinus node dysfunction are rarely seen after an ASO but are common after senning or mustard procedures [306-308].

2. Sudden death: of all forms of congenital cardiac lesions, in the adult population, TGA is associated with one of the highest risks of sudden cardiac death [269]. For children, adverse prognostic indicators are right ventricular dysfunction and QRS prolongation [146, 309, 310].

Thus, unlike in TGA patients with atrial switch repairs, arrhythmias are uncommon after an ASO $(\leq 5 \%)$, possibly due to limited atrial manipulation [311]. Most patients who have had the ASO have, in fact, preserved sinus node function at long-term followup [311]. However, ASO patients are not completely free from arrhythmic complications. Longer aortic cross-clamp time and early age at time of operation have been identified as risk factors for rhythm disturbances among paediatric cardiac patients [312].

\begin{tabular}{|c|c|c|c|}
\hline Recommendation & Class $^{a}$ & Level $^{\mathrm{b}}$ & $\operatorname{Ref}^{\circ}$ \\
\hline $\begin{array}{l}\text { Routine annual follow-up visits should be } \\
\text { considered and should include history } \\
\text { taking, 12-lead ECG and echocardiograms }\end{array}$ & IIa & $\mathrm{C}$ & \\
\hline $\begin{array}{l}\text { CMR should be integrated in the routine } \\
\text { evaluation of all postoperative patients with } \\
\text { TGA with an individually tailored frequency }\end{array}$ & I & B & 295 \\
\hline $\begin{array}{l}\text { Routine 24-h Holter follow-up visits should be } \\
\text { considered-annually for patients }<5 \text { years old } \\
\text { and every second year for patients }>5 \text { years old }\end{array}$ & IIa & $\mathrm{C}$ & \\
\hline $\begin{array}{l}\text { Routine exercise testing at least every } 3 \text { years } \\
\text { should be considered for patients }>8 \text { years old }\end{array}$ & IIa & $\mathrm{C}$ & \\
\hline $\begin{array}{l}\text { Routine invasive electrophysiology } \\
\text { assessments are not indicated, because } \\
\text { inducible ventricular tachycardia is not a } \\
\text { predictor of future events in ASO patients }\end{array}$ & III & $\mathrm{C}$ & \\
\hline
\end{tabular}

ASO: arterial switch operation; CMR: cardiovascular magnetic resonance; ECG: electrocardiogram; TGA: transposition of the great arteries. ${ }^{\mathrm{a}}$ Class of recommendation.

${ }^{\mathrm{b}}$ Level of evidence.

${ }^{c}$ References.

Recommendations for cardiology follow-up and arrhythmias

\section{Reoperations and Interventions for Management of Late Complications}

\subsection{Introduction}

With the transition from atrial to arterial repair of TGA, complications requiring reoperation have shifted mainly from the inflow to the outflow of the ventricles [313, 314]. Most reoperations are performed during the first year after an ASO. This initial hazard phase is followed by a period of very low risk for reoperation, with a slightly ascending late hazard phase due to the increasing need for pulmonary artery and neoaortic valve surgery [313]. Most $(>80 \%)$ late reoperations are performed within the first 10 years after an ASO. Survival and functional outcome seem unaffected by the need for reintervention [293]. Freedom from reoperation after a neonatal ASO is about $80 \%$ at 20 years $[3,5,6$, $141,169,171,314]$. The overall catheter reintervention rate is approximately $18 \%$ at 10 years and $25 \%$ at 25 years post-ASO [141, 315]. Most reinterventions are carried out during childhood [4, $141,145]$. The risk for reintervention in adulthood is significantly higher for those having already had one reintervention during childhood [145].

\subsection{Reoperations for neopulmonary outflow tract lesions}

\subsubsection{Relief of neopulmonary outflow tract obstruction}

8.2.1.1 Neopulmonary outflow tract obstruction: prevalence and incidence. Neopulmonary outflow tract obstruction is the most frequent cause for reoperation [316-318]. Obstruction may occur at multiple levels following an ASO but most frequently involves the pulmonary arteries, with a reported incidence of $1-$ $42 \%$ [139, 166, 167, 173, 293]. Neopulmonary valve stenosis tends to develop primarily during the first year after repair [319], but there is a persistent constant low risk thereafter [313, 319].

8.2.1.2 Neopulmonary outflow tract obstruction: patient-related risk factors

1. Younger age at operation and lower birth weight [319-321].

2. Coronary artery pattern (e.g. left coronary artery arising from the right-facing sinus) [319-321].

3. Size mismatch between the great arteries and a smaller native aortic annulus [322].

4. Side-by-side relationship of the great arteries [320].

5. Coexisting aortic coarctation (with a small native aortic annulus) [320].

6. Rapid somatic growth [293, 323].

7. Remnant ductal tissue causing left pulmonary artery stenosis [324, 325].

8. Earlier institutional experience [320]. 
8.2.1.3 Neopulmonary outflow tract obstruction: surgery-related risk factors

1. Diffuse hypoplasia of the main pulmonary artery may be secondary to several mechanisms:

1. Inadequate mobilization of the branch pulmonary arteries [326, 327].

2. Technique used for reconstruction of the proximal pulmonary artery [324, 325, 328]. Distortion and stretching of the main and branch pulmonary arteries occur as a result of the Lecompte manoeuvre [329].

3. Posterior compression of the neopulmonary valve and main pulmonary artery by the neoaorta, also as a result of the Lecompte manoeuvre [330].

4. Pulmonary artery banding causing supravalvular stenosis [331, 332].

5. Growth failure of the valve annulus [318, 331].

6. Use of prosthetic material in reconstruction of the neopulmonary sinuses [320].

2. Discrete, circumferential narrowing at the suture line, leading to inadequate growth of the pulmonary anastomotic site resulting in a more discrete type of stenosis [293, 319].

8.2.1.4 Neopulmonary outflow tract obstruction: indications for treatment. Reoperation or intervention is indicated when a gradient $>50 \mathrm{mmHg}$ at any level in the neopulmonary outflow tract is detected on routine echo Doppler evaluation [293]. Supravalvular pulmonary stenosis should be relieved early because it may be associated with growth failure of the valve annulus [333, 334] and may induce asymmetrical distribution of pulmonary flow [330].

8.2.1.5 Neopulmonary outflow tract obstruction: intervention. Some patients who have had an ASO may need a reintervention to alleviate pulmonary branch artery stenosis. Although the arterial diameter could be increased in some cases using balloon dilation, the improvements did not last, and a high recurrence rate was observed. These unfavourable results led to the use of stents, which were significantly more effective [335]. The risks of early dissection and vessel rupture are known and manageable. More recently, a potentially more serious complication has been describedcreation of an aortopulmonary window. This complication cannot be avoided entirely because overdilation is necessary to achieve long-term success, but cardiologists should be aware of it [336, 337].

\begin{tabular}{|c|c|c|c|}
\hline Recommendation & Class $^{\mathrm{a}}$ & Level $^{\mathrm{b}}$ & $\operatorname{Ref}^{\mathrm{c}}$ \\
\hline \multicolumn{4}{|c|}{ Indications for reintervention for RVOT obstruction } \\
\hline $\begin{array}{l}\text { Reoperation or intervention should be } \\
\text { considered if evidence of significant } \\
\text { obstruction (gradient }>50 \mathrm{mmHg} \text { ) is } \\
\text { detected during routine echo Doppler } \\
\text { evaluation }\end{array}$ & IIa & $\mathrm{B}$ & 293 \\
\hline \multicolumn{4}{|l|}{ Suggested treatment } \\
\hline $\begin{array}{l}\text { Surgical patch angioplasty is the most } \\
\text { effective treatment and should be } \\
\text { considered as the treatment of choice }\end{array}$ & IIa & $\mathrm{C}$ & $\begin{array}{r}320 \\
327\end{array}$ \\
\hline $\begin{array}{l}\text { Balloon dilation of pulmonary stenoses } \\
\text { should be considered only if obstruction is } \\
\text { confined to the valvular level }\end{array}$ & IIa & $\mathrm{C}$ & \\
\hline $\begin{array}{l}\text { Catheter reintervention is not indicated for } \\
\text { supravalvular pulmonary stenosis }\end{array}$ & III & $\mathrm{C}$ & \\
\hline $\begin{array}{l}\text { Stenting of branch pulmonary artery } \\
\text { (bifurcation) stenoses may be considered }\end{array}$ & $\mathrm{IIb}$ & $\mathrm{C}$ & \\
\hline
\end{tabular}

RVOT: right ventricular outflow tract.

${ }^{\mathrm{a}}$ Class of recommendation.

${ }^{\mathrm{b}}$ Level of evidence.

${ }^{\mathrm{c}}$ References.

Recommendations for late neopulmonary outflow tract obstruction

\subsubsection{Treatment of neopulmonary valve regurgitation}

8.2.2.1 Neopulmonary valve regurgitation: prevalence and incidence. Neopulmonary valve regurgitation occurs after an ASO with an incidence varying from $9 \%$ to $80 \%$ [338, 339]. At least moderate neopulmonary valve regurgitation was present in $6.6 \%$ of the cases in the series of Khairy et al. [141].

8.2.2.2 Neopulmonary valve regurgitation: potential risk factors

1. Valve distortion secondary to anterior displacement of the neopulmonary arterial root by a redundant posterior neoaorta.

2. Valve misalignment during patch reconstruction of the neopulmonary artery root.

3. Loss of the sinotubular junction of the neopulmonary artery root following single-patch reconstruction of the coronary defects.

4. Partial commissural detachment to harvest a paracommissural or intramural coronary artery.

8.2.2.3 Neopulmonary valve regurgitation: indications for treatment. Reported cases of treated neopulmonary valve regurgitation are sporadic and usually embedded in large series of late results from ASOs [141, 340]. An increasing number of such cases are anticipated as the ASO population gets older. Indications for neopulmonary valve surgery probably replicate those for any long-standing pulmonaryvalve regurgitation affecting right ventricular function [341]. Surgical pulmonary valvuloplasty is attempted with increasing frequency [141]. 
However, pulmonary valve replacement still is often required with a preference for biological prostheses to allow later transcatheter implantation of other prostheses [342, 343], although some concern has been raised about potential coronary compression [344].

\begin{tabular}{|c|c|c|c|}
\hline Recommendation & Class $^{a}$ & Level $^{\mathrm{b}}$ & $\operatorname{Ref}^{c}$ \\
\hline \multicolumn{4}{|l|}{ Indications for reoperation } \\
\hline $\begin{array}{l}\text { Reoperation on the pulmonary valve } \\
\text { should be considered in cases with } \\
\text { significant right ventricular dilation } \\
\text { and dysfunction and tricuspid } \\
\text { insufficiency due to pulmonary } \\
\text { regurgitation }\end{array}$ & IIa & $\mathrm{C}$ & 341 \\
\hline \multicolumn{4}{|l|}{ Suggested treatment } \\
\hline $\begin{array}{l}\text { Pulmonary valve valvuloplasty } \\
\text { or replacement should be } \\
\text { considered }\end{array}$ & IIa & $\mathrm{C}$ & $\begin{array}{l}141 \\
342 \\
343\end{array}$ \\
\hline
\end{tabular}

${ }^{\mathrm{a}}$ Class of recommendation.

${ }^{\mathrm{b}}$ Level of evidence.

${ }^{c}$ References.

Recommendations for reoperations for late neopulmonary valve regurgitation

\subsection{Reoperations for left ventricular outflow tract lesions}

\subsubsection{Treatment of neoaortic valve regurgitation}

8.3.1.1 Neoaortic regurgitation and root dilatation: prevalence and incidence. After an ASO, the native pulmonary valve faces the high-pressure systemic circulation. It is still unclear whether it can maintain long-term competence [293, 321]. Neoaortic regurgitation is the second most common indication for reoperation after an ASO [169, 316], needed in $5-22 \%$ of cases [345-348]. It was more frequent in the early years of ASOs, occurring in up to $55 \%$ of patients undergoing a two-stage operation [349, $350]$. In the current era of neonatal ASOs, moderateto-severe neoaortic regurgitation is less frequent $(<7 \%)$ [346-348]; the need for reoperation at 15 years is $\leq 3 \%$ [316]. Of concern, however, is the high prevalence of trivial-to-mild neoaortic regurgitation and neoaortic root dilation, with some evidence of progression [316, 346, 350-352]. Aortic root dilation usually stabilizes over time [348, 353]. Fortunately, neoaortic valve intervention is associated with good outcomes [354, 355].

8.3.1.2 Neoaortic regurgitation and root dilatation: patient-related risk factors

1. Intrinsic weakness of native pulmonary artery and valve tissue in facing systemic pressure [169, 356-359], although others have refuted this hypothesis [360].
2. Previous pulmonary banding, distorting the native pulmonary artery root $[321,346,355]$.

3. The diameter of the neoaortic root appears positively related with mild-to-moderate neoaortic regurgitation [322, 361, 362]. Freedom from neoaortic root dilation at 1, 5, 10 and 15 years after an ASO is $84 \%, 67 \%, 47 \%$ and $32 \%$, respectively [361]. Others, however, observed that rapid dilation of the neoaorta is limited to the first year of life [353].

4. Non-facing commissures [363].

5. Abnormal coronary artery anatomy $[348,364]$.

6. Preoperative pulmonary valve regurgitation [352].

7. Acute angulation of the aortic arch following posterior translocation of the ascending aorta [365].

8. Impaired growth of the neoaorta [364].

8.3.1.3 Neoaortic regurgitation and root dilatation: surgery-related risk factors

1. The trap-door technique may cause distortion of the geometry of the sinotubular junction [364], although others have disputed this suggestion [366]. Very large buttons for translocation of the coronary arteries can also distort.

2. Aortic transection with disruption of vasa vasorum may alter the structure of the neoaorta $[347,367]$.

8.3.1.4 Neoaortic root dilation and neoaortic valve regurgitation: treatment. Surgery on the neoaortic root or valve is rare after an ASO and is needed mainly in children aged $>1$ year at the time of the ASO, particularly those undergoing conversion of an atrial switch [368]. The indications for aortic valve surgery are the same as those for adults with aortic regurgitation [369]. The indications and timing for repair of neoaortic root dilation are unclear [361]. Nevertheless, elective neoaortic root operations after an ASO have been reported for patients with neoaortic root z-scores of $\geq 3$ [348]. If neoaortic regurgitation occurs early, the patient should be closely monitored [321]. Importantly, the operation should be advised before the development of severe aortic regurgitation [169]. Surgical options adopted for neoaortic valve regurgitation with or without neoaortic root dilation include:

1. Valve-sparing aortic root repair, preventing the need for anticoagulation [354, 370].

2. Prosthetic valve replacement $[6,354,355,362$, 368, 371].

3. Bentall operation [6, 368].

4. Switch-back operation (Ross after an ASO) $[372,373]$. 
Class $^{\mathrm{a}}$ Level $^{\mathrm{b}}$ Ref $^{\mathrm{c}}$

Indications for reoperation

Reoperation should be considered in the IIa C 369

presence of symptoms attributable to

moderate or severe aortic insufficiency

Reoperation should be considered in the IIa C 369

presence of a left ventricular ejection

fraction $\leq 50 \%$ or an increased left

ventricular end-diastolic/systolic

dimension (normalized)

Reoperation should be considered in the IIa B 348

presence of aortic root diameter z-scores $\geq 3$

Suggested treatment

The type of aortic valve surgery (repair or IIa C 169 , replacement) should be considered on the

basis of the pathological condition of the

valve and the experience of the surgeon

${ }^{\mathrm{a}}$ Class of recommendation.

${ }^{\mathrm{b}}$ Level of evidence.

${ }^{c}$ References.

Recommendations for reoperations for late neoaortic valve regurgitation

8.3.2 Relief of neoartic outflow tract obstruction. Leftsided obstruction needing reoperation after an ASO is considerably less frequent than neopulmonary outflow tract obstruction, with freedom from reinterventions of up to $99 \%$ at 10 years after an ASO [320, 374, 375]. However, at least mild late neoaortic stenosis was found in 3.2\% of ASO patients [141]. Reintervention for leftsided obstruction after an ASO may consist of direct relief of the residual LVOT obstruction or of patch angioplasty of the ascending aorta [320]. Neoaortic valvular stenosis with a small annulus after an ASO can be managed using the Konno procedure $[375,376]$.

\subsection{Reoperations for coronary lesions}

Coronary obstructions may develop even after a successful ASO and can lead to coronary events [377]. Coronary events show a bimodal pattern with a rapidly declining early phase and a slowly increasing late phase [297]. The left main coronary artery is more frequently affected [6, 298].

8.4.1 Mechanisms for long-term declining coronary function. Progressive proximal eccentric intimal thickening occurs in up to $89 \%$ of the coronary arteries after an ASO [378]. The complexity of coronary patterns and the modality of coronary transfer could prompt flow abnormalities, leading to increased shear stress and progressive fibrocellular intimal thickening [293, 297, 378, 379]. Other suggested causes of progressive coronary occlusion include ostial fibrosis at the suture line, kinking or stretching with reactive injury from surgical manipulation [321, 380, 381]. A hypothetical compensatory mechanism is the greater capacity of collateralization, neovascularization and cellular proliferation of infants compared with adults [381]. In reality, however, infant coronary collateralization is unpredictable, and survival relies mostly on the number of arterial segments remaining patent [354]. As the ASO population approaches adulthood, superimposed variations in coronary artery anatomy will conceivably increase the risk factors for atherosclerotic disease and ischaemic events [321]. Therefore, these patients should undergo life-long close monitoring of myocardial perfusion [382].

8.4.2 Coronary lesions: prevalence, incidence and diagnosis. The known incidence of late coronary stenosis requiring reintervention varies from $<3 \%$ to $10 \%[141,143,297,313,383]$, and silent coronary obstructive lesions have a prevalence of 6-8\% [297, 380]. Some patients are symptom-free, without diagnostic evidence of myocardial ischaemia, until they experience sudden cardiac events [293, 297, 321, 384, 385]. Coronary lesions were detected after a mean interval of 33 months. Because the lesions are usually progressive, coronary evaluation should be repeated regularly during late follow-up [293].

Indications for selective coronary angiography or multislice CT angiography after an ASO include (i) the presence of electrocardiographic or echocardiographic signs suggestive of myocardial ischaemia at any time after the operation; (ii) the presence of unusual coronary patterns (e.g. coronary arteries coursing between the great arteries) or intraoperative difficulties in coronary transfer; and (iii) the use of a single-orifice technique for coronary reimplantation.

\subsubsection{Coronary lesions: patient-related risk factors}

1. Complex coronary anatomy. Early coronary lesions and coronary reoperation rates are more frequent in patients with complex or unusual coronary patterns $[142,173,297,321,377$, 382]. Intramural origin or single-ostium looping was found to increase the risk for morbidity and mortality [143]. Others did not find this correlation [144, 385].

2. Bicuspid neoaortic valve. This condition might cause commissural malalignment and neoaortic root dilation; both conditions increase the risk for suboptimal coronary transfer [386].

3. Relative position of the great arteries. Peculiar relationships between the reimplanted coronary arteries and the adjacent great arteries might lead to coronary compression [297, 380]. 
8.4.4 Coronary lesions: surgery-related risk factors. Technical details may impact on the need for reintervention after an ASO, and late coronary lesions may occur in all coronary patterns, even after the most straightforward initial operation [293].

Mechanical reasons for coronary obstruction include proximal coronary artery compression, kinking and stretching. Various technical factors have been suspected: inadequate coronary transfer, type of coronary artery button technique, excessive use of fibrin glue and abnormal early fibrosis [173, 293, 297, 298, 354].

8.4.5 Residual/recurrent coronary lesions: indications and management. Acute coronary insufficiency at the time of an ASO must be immediately addressed by revision of the anastomosis or by bypass grafting.

Reoperation in the event of late coronary insufficiency is indicated when myocardial ischaemia is demonstrated at myocardial imaging.

Different approaches have been used to manage post-ASO coronary lesions.

\subsubsection{Surgical approaches}

1. Coronary (ostial) patch angioplasty, using saphenous vein patch [293, 387, 388], autologous or heterologous pericardial patch [321, $383,387-391]$ or the proximal segment of the right internal thoracic artery [392]. Adequate enlargement of a proximal coronary obstruction is achieved using a patch from the aorta, across the stenotic lesion, down to a normal coronary artery, restoring normal coronary perfusion [387, 390, 393]. Surgical arterioplasty might be contraindicated only when the left main coronary artery bifurcation is involved in the stenotic process [389]. Coronary ostial patch angioplasty can be performed with low operative risk and high patency rate [384]. However, its long-term prognosis remains unknown.

2. Internal mammary artery grafting is technically feasible in most children, with satisfactory patency rates [173, 293, 354, 389, 394, 395]. Internal mammary grafting has been suggested only for more distal lesions, long and complete occlusions of the main stem or residual obstruction after primary surgical arterioplasty [389]. However, blood flow through a mammary bypass may be inadequate, particularly when a large myocardial area must be revascularized [394, 395].

\subsubsection{Percutaneous transluminal coronary angioplasty} in infants and young children. This procedure includes the possibility of inserting a coronary stent, as a firsttime intervention to alleviate coronary stenosis, or after a previous coronary patch angioplasty operation
[382, 396-398]. In these rare patients a policy of routine angiographic evaluation of the coronary arteries within the first $2-3$ years after repair is advisable [382].

\begin{tabular}{|c|c|c|c|}
\hline Recommendation & Class $^{\mathrm{a}}$ & Level $^{\mathrm{b}}$ & $\operatorname{Ref}^{c}$ \\
\hline $\begin{array}{l}\text { Diagnostic suggestions } \\
\text { Selective coronary angiography or } \\
\text { multislice CT angiography after an } \\
\text { ASO, possibly complemented by } \\
\text { myocardial perfusion imaging } \\
\text { using MRI or thallium-201 } \\
\text { scintigraphy: } \\
\text { - Is indicated in the presence of } \\
\text { electrocardiographic signs, } \\
\text { echocardiographic signs, or } \\
\text { both, that are suggestive of } \\
\text { myocardial ischaemia at any } \\
\text { time after the operation; } \\
\text { - Should be considered in the } \\
\text { presence of unusual coronary } \\
\text { patterns (single orifice, coron- } \\
\text { ary arteries coursing between } \\
\text { the great arteries) or intrao- } \\
\text { perative difficulties in coronary } \\
\text { transfer, usually during the first } \\
\text { postoperative year. }\end{array}$ & $\begin{array}{l}\text { I } \\
\text { IIa }\end{array}$ & $\begin{array}{l}\mathrm{C} \\
\mathrm{C}\end{array}$ & $\begin{array}{l}293,389 \\
293,389\end{array}$ \\
\hline Indications for late reoperation & & & \\
\hline $\begin{array}{l}\text { Reoperation is indicated in the event } \\
\text { of late coronary insufficiency } \\
\text { demonstrated with myocardial } \\
\text { imaging }\end{array}$ & I & $\mathrm{C}$ & $\begin{array}{l}390,399 \\
400\end{array}$ \\
\hline $\begin{array}{l}\text { Revascularization may be considered } \\
\text { in the absence of evident } \\
\text { myocardial ischaemia but in the } \\
\text { presence of demonstrated coronary } \\
\text { obstruction } \\
\text { Suggested treatment }\end{array}$ & IIb & $\mathrm{C}$ & 293 \\
\hline $\begin{array}{l}\text { Coronary (ostial) patch angioplasty } \\
\text { is indicated for proximal discrete } \\
\text { obstruction }\end{array}$ & I & $\mathrm{C}$ & $\begin{array}{r}293,321 \\
383,389\end{array}$ \\
\hline $\begin{array}{l}\text { Internal mammary artery grafting } \\
\text { should be considered for more } \\
\text { distal lesions, long and complete } \\
\text { occlusions of the main stem or } \\
\text { residual obstruction after primary } \\
\text { surgical arterioplasty }\end{array}$ & IIa & $\mathrm{C}$ & $\begin{array}{l}173,293 \\
354,389 \\
401\end{array}$ \\
\hline $\begin{array}{l}\text { Coronary (ostial) patch angioplasty } \\
\text { and concomitant internal } \\
\text { mammary artery grafting are not } \\
\text { indicated }\end{array}$ & III & $\mathrm{C}$ & 173,354 \\
\hline $\begin{array}{l}\text { Percutaneous transluminar coronary } \\
\text { angioplasty, with or without } \\
\text { coronary stent implantation, may } \\
\text { be considered, preferably after } \\
\text { failing primary surgical } \\
\text { arterioplasty }\end{array}$ & $\mathrm{IIb}$ & $\mathrm{C}$ & $\begin{array}{l}382,397 \\
398\end{array}$ \\
\hline
\end{tabular}

ASO: arterial switch operation; CT: computed tomography; MRI: magnetic resonance imaging.

${ }^{a}$ Class of recommendation.

${ }^{b}$ Level of evidence.

${ }^{c}$ References.

Recommendations for reoperations for residual or recurrent coronary lesions 


\subsection{Other reoperations for late complications}

8.5.1 Treatment of tracheobronchial compression. Tracheobronchial [402-404] and oesophageal [405] compression by vascular structures (aorta or pulmonary arteries) may develop after an ASO and require surgical relief.

The mechanism of 'left bronchial compression' relates to the posterior displacement of the ascending aorta behind the left pulmonary artery with either impingement of this vessel upon the left main bronchus or compression of the bronchus between the ascending and descending aorta (pincer effect) [404, 406]. Tracheography is a useful diagnostic method in cases with airway obstruction [403, 407]. Post-ASO left bronchial compression may be prevented using high transection on the great arteries and the Lecompte manoeuvre, leaving the anastomotic region above the left main bronchus level [403]. Compression of the left main bronchus by the posteriorly displaced aorta can be approached by an aortopexy procedure, through a left thoracotomy. In cases of persistent symptoms, tracheobronchomalacia must be ruled out [402].

8.5.2 Treatment of persistent pulmonary bypertension. Pulmonary vascular disease and pulmonary hypertension in TGA IVS are rare but severe [138, $316,351,408$ ] conditions that can occur even in patients undergoing an ASO before the age of 1 month [313]. Medical therapy should first be provided [409], but for the most resilient cases, surgical management may be attempted, using either blade atrial septostomy [410] or a Potts anastomosis $[293,411]$. The goal of the latter procedure is to decrease right ventricular afterload, which improves right ventricular function and potentially prevents syncope and sudden death [411].

8.5.3 Treatment of transposition of the great arteries with aortopulmonary collaterals. Aortopulmonary collaterals have long been known to coexist with TGA [412]. They present angiographically as enlarged bronchial arteries [413]. Significant collateral flow may first become manifest during surgical correction, when significant left atrial or pulmonary artery return is noticed during $\mathrm{CPB}$; intraoperative pulmonary haemorrhage has also been reported [414]. Coil embolization can be carried out either before [415] or after [413-416] an ASO, with complete occlusion of the vessels and no significant complications [413, 414, 416, 417].

8.5.4 Treatment of residual mitral regurgitation. Mitral valve reoperations are rarely necessary for ischaemic mitral regurgitation or residual mitral valve malformation (mitral cleft) [169, 293, 313].

Conflict of interest: none declared.

\section{References}

1. Sousa-Uva M, Head SJ, Thielmann M, Cardillo G, Benedetto U, Czerny M, et al. Methodology manual for European Association for Cardio-Thoracic Surgery (EACTS) clinical guidelines. Eur J Cardiothorac Surg 2015; 48: 809-816.

2. Marek J, Tomek V, Skovranek J, Povysilova V, Samanek M. Prenatal ultrasound screening of congenital heart disease in an unselected national population: a 21-year experience. Heart 2011; 97: $124-130$.

3. Fricke TA, D’Udekem Y, Richardson M, Thuys C, Dronavalli M, Ramsay JM, et al. Outcomes of the arterial switch operation for transposition of the great arteries: 25 years of experience. Ann Thorac Surg 2012; 94: 139-145.

4. Kempny A, Wustmann K, Borgia F, Dimopoulos K, Uebing A, $\mathrm{Li} \mathrm{W}$, et al. Outcome in adult patients after arterial switch operation for transposition of the great arteries. Int J Cardiol 2013; 167 : 2588-2593.

5. Lim HG, Kim WH, Lee JR, Kim YJ. Long-term results of the arterial switch operation for ventriculo-arterial discordance. Eur J Cardiothorac Surg 2013; 43: 325-334.

6. Oda S, Nakano T, Sugiura J, Fusazaki N, Ishikawa S, Kado H. Twenty-eight years' experience of arterial switch operation for transposition of the great arteries in a single institution. Eur J Cardiothorac Surg 2012; 42: 674-679.

7. Stoica S, Carpenter E, Campbell D, Mitchell M, da Cruz E, Ivy D, et al. Morbidity of the arterial switch operation. Ann Thorac Surg 2012; 93: 1977-1983.

8. Jatene AD, Fontes VF, Paulista PP, Souza LC, Neger F, Galantier $\mathrm{M}$, et al. Anatomic correction of transposition of the great vessels. J Thorac Cardiovasc Surg 1976; 72: 364-370.

9. Bonnet D, Coltri A, Butera G, Fermont L, Le Bidois J, Kachaner J, et al. Detection of transposition of the great arteries in fetuses reduces neonatal morbidity and mortality. Circulation 1999; 99: 916-918.

10. Pascal CJ, Huggon I, Sharland GK, Simpson JM. An echocardiographic study of diagnostic accuracy, prediction of surgical approach, and outcome for fetuses diagnosed with discordant ventriculo-arterial connections. Cardiol Young 2007; 17: 528-534.

11. Perolo A, Prandstraller D, Ghi T, Gargiulo G, Leone O, Bovicelli L, et al. Diagnosis and management of fetal cardiac anomalies: 10 years of experience at a single institution. Ultrasound Obstet Gynecol 2001; 18: 615-618.

12. Sivanandam S, Glickstein JS, Printz BF, Allan LD, Altmann K, Solowiejczyk DE, et al. Prenatal diagnosis of conotruncal malformations: diagnostic accuracy, outcome, chromosomal abnormalities, and extracardiac anomalies. Am J Perinatol 2006; 23: 241-245.

13. Allan LD, Sharland GK, Milburn A, Lockhart SM, Groves AM, Anderson RH, et al. Prospective diagnosis of 1006 consecutive cases of congenital heart disease in the fetus. J Am Coll Cardiol 1994; 23: 1452-1458.

14. Bull C. Current and potential impact of fetal diagnosis on prevalence and spectrum of serious congenital heart disease at term in the UK. British Paediatric Cardiac Association. Lancet 1999; 354 : 1242-1247.

15. Jaeggi ET, Sholler GF, Jones OD, Cooper SG. Comparative analysis of pattern, management and outcome of pre- versus postnatally diagnosed major congenital heart disease: a populationbased study. Ultrasound Obstet Gynecol 2001; 17: 380-385.

16. Sharland G. Routine fetal cardiac screening: what are we doing and what should we do? Prenat Diagn 2004; 24: 1123-1129.

17. Wigton TR, Sabbagha RE, Tamura RK, Cohen L, Minogue JP, Strasburger JF. Sonographic diagnosis of congenital heart disease: comparison between the four-chamber view and multiple cardiac views. Obstet Gynecol 1993; 82: 219-224.

18. Khoshnood B, Lelong N, Houyel L, Thieulin AC, Jouannic JM, Magnier S, et al. Prevalence, timing of diagnosis and mortality of 
newborns with congenital heart defects: a population-based study. Heart 2012; 98: 1667-1673.

19. Escobar-Diaz MC, Freud LR, Bueno A, Brown DW, Friedman KG, Schidlow D, et al. Prenatal diagnosis of transposition of the great arteries over a 20-year period: improved but imperfect. Ultrasound Obstet Gynecol 2015; 45: 678-682.

20. van Velzen CL, Haak MC, Reijnders G, Rijlaarsdam ME, Bax CJ, Pajkrt E, et al. Prenatal detection of transposition of the great arteries reduces mortality and morbidity. Ultrasound Obstet Gynecol 2015; 45: 320-325.

21. International Society of Ultrasound in Obstet Gynecol Education Committee. Cardiac screening examination of the fetus: guidelines for performing the 'basic' and 'extended basic' cardiac scan. Ultrasound Obstet Gynecol 2006; 27: 107-113.

22. National Institute for Health and Clinical Excellence. Antenatal Care - Routine Care for the Healthy Pregnant Woman. Clinical guideline. NICE, London: RCOG Press; 2008.

23. NHS. Fetal Anomaly Screening Programme $18+0$ to $20+6$ Weeks Fetal Anomaly Scan. National Standards and Guidance for England. London: NHS Screening Programs; 2015.

24. Hunter S, Heads A, Wyllie J, Robson S. Prenatal diagnosis of congenital heart disease in the northern region of England: benefits of a training programme for obstetric ultrasonographers. Heart 2000; 84: 294-298.

25. McBrien A, Sands A, Craig B, Dornan J, Casey F. Impact of a regional training program in fetal echocardiography for sonographers on the antenatal detection of major congenital heart disease. Ultrasound Obstet Gynecol 2010; 36: 279-284.

26. Pezard P, Bonnemains L, Boussion F, Sentilhes L, Allory P, Lepinard $\mathrm{C}$, et al. Influence of ultrasonographers training on prenatal diagnosis of congenital heart diseases: a 12 -year population-based study. Prenat Diagn 2008; 28: 1016-1022.

27. Sharland GK, Allan LD. Screening for congenital heart disease prenatally. Results of a 2 1/2-year study in the South East Thames region. Br J Obstet Gynaecol 1992; 99: 220-225.

28. Tegnander E, Eik-Nes SH. The examiner's ultrasound experience has a significant impact on the detection rate of congenital heart defects at the second-trimester fetal examination. Ultrasound Obstet Gynecol 2006; 28: 8-14.

29. British Congenital Cardiac Association. Fetal Cardiology Standards. London: British Congenital Cardiac Association; 2012.

30. Allan L, Dangel J, Fesslova V, Marek J, Mellander M, Oberhansli I, et al. Recommendations for the practice of fetal cardiology in Europe. Cardiol Young 2004; 14: 109-114.

31. Copel JA, Pilu G, Kleinman CS. Extracardiac anomalies and congenital heart disease. Semin Perinatol 1993; 17: 89-105.

32. Paladini D, Calabro R, Palmieri S, D'andrea T. Prenatal diagnosis of congenital heart disease and fetal karyotyping. Obstet Gynecol 1993; 81: 679-682.

33. Raymond FL, Simpson JM, Sharland GK, Ogilvie Mackie CM. Fetal echocardiography as a predictor of chromosomal abnormality. Lancet 1997; 350: 930.

34. Tennstedt C, Chaoui R, Korner H, Dietel M. Spectrum of congenital heart defects and extracardiac malformations associated with chromosomal abnormalities: results of a seven year necropsy study. Heart 1999; 82: 34-39.

35. Jouannic JM, Gavard L, Fermont L, Le Bidois J, Parat S, Vouhé PR, et al. Sensitivity and specificity of prenatal features of physiological shunts to predict neonatal clinical status in transposition of the great arteries. Circulation 2004; 110: 1743-1746.

36. Maeno YV, Kamenir SA, Sinclair B, van der Velde ME, Smallhorn JF, Hornberger LK. Prenatal features of ductus arteriosus constriction and restrictive foramen ovale in d-transposition of the great arteries. Circulation 1999; 99: 1209-1214.

37. Punn R, Silverman NH. Fetal predictors of urgent balloon atrial septostomy in neonates with complete transposition. J Am Soc Echocardiogr 2011; 24: 425-430.
38. Fuchs IB, Muller H, Abdul-Khaliq H, Harder T, Dudenhausen JW, Henrich W. Immediate and long-term outcomes in children with prenatal diagnosis of selected isolated congenital heart defects. Ultrasound Obstet Gynecol 2007; 29: 38-43.

39. Khoshnood B, De Vigan C, Vodovar V, Goujard J, Lhomme A, Bonnet $\mathrm{D}$, et al. Trends in prenatal diagnosis, pregnancy termination, and perinatal mortality of newborns with congenital heart disease in France, 1983-2000: a population-based evaluation. Pediatrics 2005; 115: 95-101.

40. Bartlett JM, Wypij D, Bellinger DC, Rappaport LA, Heffner LJ, Jonas RA, et al. Effect of prenatal diagnosis on outcomes in D-transposition of the great arteries. Pediatrics 2004; 113: E335-E340.

41. Kumar RK, Newburger JW, Gauvreau K, Kamenir SA, Hornberger LK. Comparison of outcome when hypoplastic left heart syndrome and transposition of the great arteries are diagnosed prenatally versus when diagnosis of these two conditions is made only postnatally. Am J Cardiol 1999; 83: 1649-1653.

42. Levey A, Glickstein JS, Kleinman CS, Levasseur SM, Chen J, Gersony WM, et al. The impact of prenatal diagnosis of complex congenital heart disease on neonatal outcomes. Pediatr Cardiol 2010; 31: 587-597.

43. Verheijen PM, Lisowski LA, Stoutenbeek P, Hitchcock JF, Bennink GB, Meijboom EJ. Lactacidosis in the neonate is minimized by prenatal detection of congenital heart disease. Ultrasound Obstet Gynecol 2002; 19: 552-555.

44. Hellstrom-Westas L, Hanseus K, Jogi P, Lundstrom NR, Svenningsen N. Long-distance transports of newborn infants with congenital heart disease. Pediatr Cardiol 2001; 22: 380-384.

45. Mirlesse V, Cruz A, Le Bidois J, Diallo P, Fermont L, Kieffer F, et al. Perinatal management of fetal cardiac anomalies in a specialized obstetric-pediatrics center. Am J Perinatol 2001; 18: 363-371.

46. Jegatheeswaran A, Oliveira C, Batsos C, Moon-Grady AJ, Silverman NH, Hornberger LK, et al. Costs of prenatal detection of congenital heart disease. Am J Cardiol 2011; 108: 1808-1814.

47. Landis BJ, Levey A, Levasseur SM, Glickstein JS, Kleinman CS, Simpson LL, et al. Prenatal diagnosis of congenital heart disease and birth outcomes. Pediatr Cardiol 2013; 34: 597-605.

48. Eckersley L, Sadler L, Parry E, Finucane K, Gentles TL. Timing of diagnosis affects mortality in critical congenital heart disease. Arch Dis Child 2016; 101: 516-520.

49. McMahon CJ, el Said HG, Feltes TF, Watrin CH, Hess BA, Fraser $\mathrm{CD} \mathrm{Jr}$. Preoperative identification of coronary arterial anatomy in complete transposition, and outcome after the arterial switch operation. Cardiol Young 2002; 12: 240-247.

50. Pasquini L, Sanders SP, Parness IA, Wernovsky G, Mayer JE Jr, Van der Velde ME, et al. Coronary echocardiography in 406 patients with d-loop transposition of the great arteries. J Am Coll Cardiol 1994; 24: 763-768.

51. Studer MA, Smith AE, Lustik MB, Carr MR. Newborn pulse oximetry screening to detect critical congenital heart disease. J Pediatr 2014; 164: 505-9.e1-2.

52. Lopes LM, Kawano C, Cristovao SA, Nagamatsu CT, Fonseca L, Furlanetto $\mathrm{BH}$, et al. Balloon atrial septostomy guided by echocardiography in a neonatal intensive care unit. Arq Bras Cardiol 2010; 95: 153-158

53. Martin AC, Rigby ML, Penny DJ, Redington AN. Bedside balloon atrial septostomy on neonatal units. Arch Dis Child Fetal Neonatal Ed 2003; 88: F339-F340.

54. Zellers TM, Dixon K, Moake L, Wright J, Ramaciotti C. Bedside balloon atrial septostomy is safe, efficacious, and cost-effective compared with septostomy performed in the cardiac catheterization laboratory. Am J Cardiol 2002; 89: 613-615.

55. Browning Carmo KA, Barr P, West M, Hopper NW, White JP, Badawi N. Transporting newborn infants with suspected duct dependent congenital heart disease on low-dose prostaglandin E1 
without routine mechanical ventilation. Arch Dis Child Fetal Neonatal Ed 2007; 92: F117-F119.

56. Meckler GD, Lowe C. To intubate or not to intubate? Transporting infants on prostaglandin E1. Pediatrics 2009; 123: E25-E30.

57. Barton KP, Munoz R, Morell VO, Chrysostomou C. Dexmedetomidine as the primary sedative during invasive procedures in infants and toddlers with congenital heart disease. Pediatr Crit Care Med 2008; 9: 612-615.

58. Finan E, Mak W, Bismilla Z, McNamara PJ. Early discontinuation of intravenous prostaglandin E1 after balloon atrial septostomy is associated with an increased risk of rebound hypoxemia. J Perinatol 2008; 28: 341-346.

59. Oxenius A, Hug MI, Dodge-Khatami A, Cavigelli-Brunner A, Bauersfeld U, Balmer C. Do predictors exist for a successful withdrawal of preoperative prostaglandin $\mathrm{E}(1)$ from neonates with d-transposition of the great arteries and intact ventricular septum? Pediatr Cardiol 2010; 31: 1198-1202.

60. Lim DS, Kulik TJ, Kim DW, Charpie JR, Crowley DC, Maher KO. Aminophylline for the prevention of apnea during prostaglandin E1 infusion. Pediatrics 2003; 112: E27-E29.

61. Roofthooft MT, Bergman KA, Waterbolk TW, Ebels T, Bartelds B, Berger RM. Persistent pulmonary hypertension of the newborn with transposition of the great arteries. Ann Thorac Surg 2007; 83: 1446-1450.

62. Newfeld EA, Paul MM, Muster AJ, Idriss FS. Pulmonary vascular disease in complete transposition of the great arteries: a study of 200 patients. Am J Cardiol 1974; 34: 75-82.

63. Fan H, Hu S, Zheng Z, Li S, Zhang Y, Pan X, et al. Do patients with complete transposition of the great arteries and severe pulmonary hypertension benefit from an arterial switch operation? Ann Thorac Surg 2011; 91: 181-186.

64. Chang AC, Wernovsky G, Kulik TJ, Jonas RA, Wessel DL. Management of the neonate with transposition of the great arteries and persistent pulmonary hypertension. Am J Cardiol 1991; 68: $1253-1255$.

65. El-Segaier M, Hellstrom-Westas L, Wettrell G. Nitric oxide in neonatal transposition of the great arteries. Acta Paediatr 2005; 94: 912-916.

66. Goissen C, Ghyselen L, Tourneux P, Krim G, Storme L, Bou P, et al. Persistent pulmonary hypertension of the newborn with transposition of the great arteries: successful treatment with bosentan. Eur J Pediatr 2008; 167: 437-440.

67. Jaillard S, Belli E, Rakza T, Larrue B, Magnenant E, Rey C, et al. Preoperative ECMO in transposition of the great arteries with persistent pulmonary hypertension. Ann Thorac Surg 2005; 79: $2155-2158$.

68. Luciani GB, Chang AC, Starnes VA. Surgical repair of transposition of the great arteries in neonates with persistent pulmonary hypertension. Ann Thorac Surg 1996; 61: 800-805.

69. Mair DD, Ritter DG. Factors influencing intercirculatory mixing in patients with complete transposition of the great arteries. Am J Cardiol 1972; 30: 653-658.

70. Shaher RM. The haemodynamics of complete transposition of the great vessels. Br Heart J 1964; 26: 343-353.

71. Shiao SY, Ou CN. Validation of oxygen saturation monitoring in neonates. Am J Crit Care 2007; 16: 168-178.

72. Marino BS, Bird GL, Wernovsky G. Diagnosis and management of the newborn with suspected congenital heart disease. Clin Perinatol 2001; 28: 91-136.

73. Howley LW, Kaufman J, Wymore E, Thureen P, Magouirk JK, McNair B, et al. Enteral feeding in neonates with prostaglandindependent congenital cardiac disease: international survey on current trends and variations in practice. Cardiol Young 2012; 22: 121-127.

74. Willis L, Thureen P, Kaufman J, Wymore E, Skillman H, da Cruz E. Enteral feeding in prostaglandin-dependent neonates: is it a safe practice? J Pediatr 2008; 153: 867-869.
75. Sables-Baus S, Kaufman J, Cook P, da Cruz EM. Oral feeding outcomes in neonates with congenital cardiac disease undergoing cardiac surgery. Cardiol Young 2012; 22: 42-48.

76. Davis D, Davis S, Cotman K, Worley S, Londrico D, Kenny D, et al. Feeding difficulties and growth delay in children with hypoplastic left heart syndrome versus d-transposition of the great arteries. Pediatr Cardiol 2008; 29: 328-333.

77. Natarajan G, Reddy Anne S, Aggarwal S. Enteral feeding of neonates with congenital heart disease. Neonatology 2010; 98: 330-336.

78. Soongswang J, Adatia I, Newman C, Smallhorn JF, Williams WG, Freedom RM. Mortality in potential arterial switch candidates with transposition of the great arteries. J Am Coll Cardiol 1998; 32: 753-757.

79. Ades A, Johnson BA, Berger S. Management of low birth weight infants with congenital heart disease. Clin Perinatol 2005; 32: 999-1015; x-xi. .

80. Hickey EJ, Nosikova Y, Zhang H, Caldarone CA, Benson L, Redington A, et al. Very low-birth-weight infants with congenital cardiac lesions: is there merit in delaying intervention to permit growth and maturation? J Thorac Cardiovasc Surg 2012; 143: 126-136.

81. Reddy VM. Low birth weight and very low birth weight neonates with congenital heart disease: timing of surgery, reasons for delaying or not delaying surgery. Semin Thorac Cardiovasc Surg Pediatr Card Surg Annu 2013; 16: 13-20.

82. Curzon CL, Milford-Beland S, Li JS, O'brien SM, Jacobs JP, Jacobs ML, et al. Cardiac surgery in infants with low birth weight is associated with increased mortality: analysis of the Society of Thoracic Surgeons Congenital Heart Database. J Thorac Cardiovasc Surg 2008; 135: 546-551.

83. Kansy A, Tobota Z, Maruszewski P, Maruszewski B. Analysis of 14,843 neonatal congenital heart surgical procedures in the European Association for Cardiothoracic Surgery Congenital Database. Ann Thorac Surg 2010; 89: 1255-1259.

84. Reddy VM, McElhinney DB, Sagrado T, Parry AJ, Teitel DF, Hanley FL. Results of 102 cases of complete repair of congenital heart defects in patients weighing 700 to 2500 grams. J Thorac Cardiovasc Surg 1999; 117: 324-331.

85. Roussin R, Belli E, Bruniaux J, Demontoux S, Touchot A, Planche $\mathrm{C}$, et al. Surgery for transposition of the great arteries in neonates weighing less than 2000 grams: a consecutive series of 25 patients. Ann Thorac Surg 2007; 83: 173-177.

86. Azakie A, Johnson NC, Anagnostopoulos PV, Egrie GD, Lavrsen MJ, Sapru A. Cardiac surgery in low birth weight infants: current outcomes. Interact CardioVasc Thorac Surg 2011; 12: 409-413.

87. Rios R, Dummer KB, Overman DM. Successful staged surgical repair using rapid pulmonary artery banding in a very-low-birthweight premature infant who had d-transposition of the great arteries with an intact ventricular septum. Pediatr Cardiol 2013; 34: 1935-1937.

88. Castaneda AR, Norwood WI, Jonas RA, Colon SD, Sanders SP, Lang $\mathrm{P}$. Transposition of the great arteries and intact ventricular septum: anatomical repair in the neonate. Ann Thorac Surg 1984; 38: 438-443.

89. Quaegebeur JM, Rohmer J, Ottenkamp J, Buis T, Kirklin JW, Blackstone EH, et al. The arterial switch operation. An eight-year experience. J Thorac Cardiovasc Surg 1986; 92: 361-384.

90. Sarris GE, Chatzis AC, Giannopoulos NM, Kirvassilis G, Berggren $\mathrm{H}$, Hazekamp M, et al. The arterial switch operation in Europe for transposition of the great arteries: a multi-institutional study from the European Congenital Heart Surgeons Association. J Thorac Cardiovasc Surg 2006; 132: 633-639.

91. Danford DA, Huhta JC, Gutgesell HP. Left ventricular wall stress and thickness in complete transposition of the great arteries. Implications for surgical intervention. J Thorac Cardiovasc Surg 1985; 89: 610-615. 
92. Rudolph AM. Myocardial growth before and after birth: clinical implications. Acta Paediatr 2000; 89: 129-133.

93. Duncan BW, Poirier NC, Mee RB, Drummond-Webb JJ, Qureshi A, Mesia CI, et al. Selective timing for the arterial switch operation. Ann Thorac Surg 2004; 77: 1691-1696.

94. Chasovskyi K, Fedevych O, Vorobiova G, Zhovnir V, Maksimenko A, Boychenko O, et al. Arterial switch operation in the first hours of life using autologous umbilical cord blood. Ann Thorac Surg 2012; 93: 1571-1576.

95. Nevvazhay T, Chernogrivov A, Biryukov E, Biktasheva L, Karchevskaya K, Sulejmanov S, et al. Arterial switch in the first hours of life: no need for Rashkind septostomy? Eur J Cardiothorac Surg 2012; 42: 520-523.

96. Bisoi AK, Sharma P, Chauhan S, Reddy SM, Das S, Saxena A, et al. Primary arterial switch operation in children presenting late with d-transposition of great arteries and intact ventricular septum. When is it too late for a primary arterial switch operation? Eur J Cardiothorac Surg 2010; 38: 707-713.

97. Davis AM, Wilkinson JL, Karl TR, Mee RB. Transposition of the great arteries with intact ventricular septum. Arterial switch repair in patients 21 days of age or older. J Thorac Cardiovasc Surg 1993; 106: 111-115.

98. Edwin F, Mamorare H, Brink J, Kinsley R. Primary arterial switch operation for transposition of the great arteries with intact ventricular septum-is it safe after three weeks of age? Interact CardioVasc Thorac Surg 2010; 11: 641-644.

99. Foran JP, Sullivan ID, Elliott MJ, de Leval MR. Primary arterial switch operation for transposition of the great arteries with intact ventricular septum in infants older than 21 days. J Am Coll Cardiol 1998; 31: 883-889.

100. Kang N, de Leval MR, Elliott M, Tsang V, Kocyildirim E, Sehic I, et al. Extending the boundaries of the primary arterial switch operation in patients with transposition of the great arteries and intact ventricular septum. Circulation 2004; 110: 123-127.

101. D'Udekem Y, Cheung M, Butt W, Shann F, Brizard CP. Transposition with intact septum diagnosed at nine months: arterial switch? Asian Cardiovasc Thorac Ann 2012; 20: 333-334.

102. Di Donato RM, Fujii AM, Jonas RA, Castaneda AR. Age-dependent ventricular response to pressure overload. Considerations for the arterial switch operation. J Thorac Cardiovasc Surg 1992; 104: 713-722.

103. Bisoi AK, Malankar D, Chauhan S, Das S, Ray R, Das P. An electron microscopic study of left ventricular regression in children with transposition of great arteries. Interact CardioVasc Thorac Surg 2010; 11: 768-772.

104. Rudolph AM. The fetal circulation and its adjustments after birth in congenital heart disease. UCLA Forum Med Sci 1970; 10: 105-118.

105. Lacour-Gayet F, Piot D, Zoghbi J, Serraf A, Gruber P, Mace L, et al. Surgical management and indication of left ventricular retraining in arterial switch for transposition of the great arteries with intact ventricular septum. Eur J Cardiothorac Surg 2001; 20: 824-829.

106. Robinson PJ, Wyse RK, Macartney FJ. Left ventricular outflow tract obstruction in complete transposition of the great arteries with intact ventricular septum. A cross sectional echocardiography study. Br Heart J 1985; 54: 201-208.

107. Bano-Rodrigo A, Quero-Jimenez M, Moreno-Granado F, Gamallo-Amat C. Wall thickness of ventricular chambers in transposition of the great arteries: surgical implications. J Thorac Cardiovasc Surg 1980; 79: 592-597.

108. Huhta JC, Edwards WD, Feldt RH, Puga FJ. Left ventricular wall thickness in complete transposition of the great arteries. J Thorac Cardiovasc Surg 1982; 84: 97-101.

109. Maroto E, Fouron JC, Douste-Blazy MY, Carceller AM, van Doesburg N, Kratz C, et al. Influence of age on wall thickness, cavity dimensions and myocardial contractility of the left ventricle in simple transposition of the great arteries. Circulation 1983; 67: 1311-1317.
110. Smith A, Wilkinson JL, Arnold R, Dickinson DF, Anderson RH. Growth and development of ventricular walls in complete transposition of the great arteries with intact septum (simple transposition). Am J Cardiol 1982; 49: 362-368.

111. Iyer KS, Sharma R, Kumar K, Bhan A, Kothari SS, Saxena A, et al. Serial echocardiography for decision making in rapid two-stage arterial switch operation. Ann Thorac Surg 1995; 60: 658-664.

112. Sidi D, Planche C, Kachaner J, Bruniaux J, Villain E, Le Bidois J, et al. Anatomic correction of simple transposition of the great arteries in 50 neonates. Circulation 1987; 75: 429-435.

113. Dabritz S, Engelhardt W, von Bernuth G, Messmer BJ. Trial of pulmonary artery banding: a diagnostic criterion for 'one-stage' arterial switch in simple transposition of the great arteries beyond the neonatal period. Eur J Cardiothorac Surg 1997; 11: 112-116.

114. Yacoub MH, Radley-Smith R, Maclaurin R. Two-stage operation for anatomical correction of transposition of the great arteries with intact interventricular septum. Lancet 1977; 1: 1275-1278.

115. Borow KM, Arensman FW, Webb C, Radley-Smith R, Yacoub $\mathrm{MH}$. Assessment of left ventricular contractile state after anatomic correction of transposition of the great arteries. Circulation 1984; 69: 106-112.

116. Sievers HH, Lange PE, Onnasch DG, Radley-Smith R, Yacoub $\mathrm{MH}$, Heintzen $\mathrm{PH}$, et al. Influence of the two-stage anatomic correction of simple transposition of the great arteries on left ventricular function. Am J Cardiol 1985; 56: 514-519.

117. Jonas RA, Giglia TM, Sanders SP, Wernovsky G, Nadal-Ginard B, Mayer JE Jr, et al. Rapid, two-stage arterial switch for transposition of the great arteries and intact ventricular septum beyond the neonatal period. Circulation 1989; 80: I203-I208.

118. Boutin C, Jonas RA, Sanders SP, Wernovsky G, Mone SM, Colan SD. Rapid two-stage arterial switch operation. Acquisition of left ventricular mass after pulmonary artery banding in infants with transposition of the great arteries. Circulation 1994; 90: 1304-1309.

119. Wernovsky G, Giglia TM, Jonas RA, Mone SM, Colan SD, Wessel DL. Course in the intensive care unit after 'preparatory' pulmonary artery banding and aortopulmonary shunt placement for transposition of the great arteries with low left ventricular pressure. Circulation 1992; 86: 133-139.

120. Parker NM, Zuhdi M, Kouatli A, Baslaim G. Late presenters with dextro-transposition of great arteries and intact ventricular septum: to train or not to train the left ventricle for arterial switch operation? Congenit Heart Dis 2009; 4: 424-432.

121. Al Qethamy HO, Aizaz K, Aboelnazar SA, Hijab S, Al Faraidi Y. Two-stage arterial switch operation: is late ever too late? Asian Cardiovasc Thorac Ann 2002; 10: 235-239.

122. Helvind MH, McCarthy JF, Imamura M, Prieto L, Sarris GE, Drummond-Webb JJ, et al. Ventriculo-arterial discordance: switching the morphologically left ventricle into the systemic circulation after 3 months of age. Eur J Cardiothorac Surg 1998; 14: $173-178$.

123. Ilbawi MN, Idriss FS, DeLeon SY, Muster AJ, Gidding SS, Duffy $\mathrm{CE}$, et al. Preparation of the left ventricle for anatomical correction in patients with simple transposition of the great arteries. Surgical guidelines. J Thorac Cardiovasc Surg 1987; 94: 87-94.

124. Bernhard A, Yacoub M, Regensburger D, Sievers HH, Smith RR, Stephan E, et al. Further experience with the two-stage anatomic correction of simple transposition of the great arteries. Thorac Cardiovasc Surg 1981; 29: 138-142.

125. Sivakumar K, Francis E, Krishnan P, Shahani J. Ductal stenting retrains the left ventricle in transposition of great arteries with intact ventricular septum. J Thorac Cardiovasc Surg 2006; 132: 1081-1086.

126. Harinck E, Van Mill GJ, Ross D, Brom AG. Anatomical correction of transposition of great arteries with persistent ductus arteriosus. One year after operation. Br Heart J 1980; 43: 95-98.

127. Boutin C, Wernovsky G, Sanders SP, Jonas RA, Castaneda AR, Colan SD. Rapid two-stage arterial switch operation. Evaluation 
of left ventricular systolic mechanics late after an acute pressure overload stimulus in infancy. Circulation 1994; 90: 1294-1303.

128. Colan SD, Boutin C, Castaneda AR, Wernovsky G. Status of the left ventricle after arterial switch operation for transposition of the great arteries. Hemodynamic and echocardiographic evaluation. J Thorac Cardiovasc Surg 1995; 109: 311-321.

129. Wernovsky G, Wypij D, Jonas RA, Mayer JE Jr, Hanley FL, Hickey PR, et al. Postoperative course and hemodynamic profile after the arterial switch operation in neonates and infants. A comparison of low-flow cardiopulmonary bypass and circulatory arrest. Circulation 1995; 92: 2226-2235.

130. Nakazawa M, Oyama K, Imai Y, Nojima K, Aotsuka H, Satomi G, et al. Criteria for two-staged arterial switch operation for simple transposition of great arteries. Circulation 1988; 78: 124-131.

131. Bellinger DC, Wypij D, duPlessis AJ, Rappaport LA, Jonas RA, Wernovsky G, et al. Neurodevelopmental status at eight years in children with dextro-transposition of the great arteries: the Boston Circulatory Arrest Trial. J Thorac Cardiovasc Surg 2003; 126: 1385-1396.

132. Karl TR, Hall S, Ford G, Kelly EA, Brizard CP, Mee RB, et al. Arterial switch with full-flow cardiopulmonary bypass and limited circulatory arrest: neurodevelopmental outcome. J Thorac Cardiovasc Surg 2004; 127: 213-222.

133. Charpie JR, Dekeon MK, Goldberg CS, Mosca RS, Bove EL, Kulik TJ. Serial blood lactate measurements predict early outcome after neonatal repair or palliation for complex congenital heart disease. J Thorac Cardiovasc Surg 2000; 120: 73-80.

134. Munoz R, Laussen PC, Palacio G, Zienko L, Piercey G, Wessel DL. Changes in whole blood lactate levels during cardiopulmonary bypass for surgery for congenital cardiac disease: an early indicator of morbidity and mortality. J Thorac Cardiovasc Surg 2000; 119: 155-162.

135. Hoffman TM, Wernovsky G, Atz AM, Kulik TJ, Nelson DP, Chang AC, et al. Efficacy and safety of milrinone in preventing low cardiac output syndrome in infants and children after corrective surgery for congenital heart disease. Circulation 2003; 107: 996-1002.

136. Bojan M, Vicca S, Boulat C, Gioanni S, Pouard P. Aprotinin, transfusions, and kidney injury in neonates and infants undergoing cardiac surgery. Br J Anaesth 2012; 108: 830-837.

137. Pasquali SK, Li JS, He X, Jacobs ML, O’brien SM, Hall M, et al. Comparative analysis of antifibrinolytic medications in pediatric heart surgery. J Thorac Cardiovasc Surg 2012; 143: 550-557.

138. Kirklin JW, Blackstone EH, Tchervenkov CI, Castaneda AR. Clinical outcomes after the arterial switch operation for transposition. Patient, support, procedural, and institutional risk factors. Congenital Heart Surgeons Society. Circulation 1992; 86: 1501-1515.

139. Prêtre R, Tamisier D, Bonhoeffer P, Mauriat P, Pouard P, Sidi D, et al. Results of the arterial switch operation in neonates with transposed great arteries. Lancet 2001; 357: 1826-1830.

140. Karamlou T, McCrindle BW, Blackstone EH, Cai S, Jonas RA, Bradley SM, et al. Lesion-specific outcomes in neonates undergoing congenital heart surgery are related predominantly to patient and management factors rather than institution or surgeon experience: a Congenital Heart Surgeons Society Study. J Thorac Cardiovasc Surg 2010; 139: 569-77.e1.

141. Khairy P, Clair M, Fernandes SM, Blume ED, Powell AJ, Newburger JW, et al. Cardiovascular outcomes after the arterial switch operation for D-transposition of the great arteries. Circulation 2013; 127: 331-339.

142. Metton O, Calvaruso D, Gaudin R, Mussa S, Raisky O, Bonnet D, et al. Intramural coronary arteries and outcome of neonatal arterial switch operation. Eur J Cardiothorac Surg 2010; 37: 1246-1253.

143. Pasquali SK, Hasselblad V, Li JS, Kong DF, Sanders SP. Coronary artery pattern and outcome of arterial switch operation for transposition of the great arteries: a meta-analysis. Circulation 2002; 106: $2575-2580$
144. Thrupp SF, Gentles TL, Kerr AR, Finucane K. Arterial switch operation: early and late outcome for intramural coronary arteries. Ann Thorac Surg 2012; 94: 2084-2090.

145. Tobler D, Williams WG, Jegatheeswaran A, Van Arsdell GS, McCrindle BW, Greutmann M, et al. Cardiac outcomes in young adult survivors of the arterial switch operation for transposition of the great arteries. J Am Coll Cardiol 2010; 56: 58-64.

146. Wong SH, Finucane K, Kerr AR, O'donnell C, West T, Gentles TL. Cardiac outcome up to 15 years after the arterial switch operation. Heart Lung Circ 2008; 17: 48-53.

147. Bove EL. Current technique of the arterial switch procedure for transposition of the great arteries. J Card Surg 1989; 4: 193-199.

148. Villafane J, Lantin-Hermoso MR, Bhatt AB, Tweddell JS, Geva T, Nathan M, et al. D-transposition of the great arteries: the current era of the arterial switch operation. J Am Coll Cardiol 2014; 64: 498-511.

149. Parry AJ, Thurm M, Hanley FL. The use of 'pericardial hoods' for maintaining exact coronary artery geometry in the arterial switch operation with complex coronary anatomy. Eur J Cardiothorac Surg 1999; 15: 159-164; discussion 64-5.

150. Tireli E, Korkut AK, Basaran M. Implantation of the coronary arteries after reconstruction of the neoaorta by using pericardial or pulmonary hood techniques. A significant impact on the outcome of arterial switch operations. J Cardiovasc Surg (Torino) 2003; 44: 173-178.

151. Yacoub MH, Radley-Smith R. Anatomy of the coronary arteries in transposition of the great arteries and methods for their transfer in anatomical correction. Thorax 1978; 33: 418-424.

152. Koshiyama H, Nagashima M, Matsumura G, Hiramatsu T, Nakanishi T, Yamazaki K. Arterial switch operation with and without coronary relocation for intramural coronary arteries. Ann Thorac Surg 2016; 102: 1353-1359.

153. Qamar ZA, Goldberg CS, Devaney EJ, Bove EL, Ohye RG. Current risk factors and outcomes for the arterial switch operation. Ann Thorac Surg 2007; 84: 871-878.

154. Planche C, Bruniaux J, Lacour-Gayet F, Kachaner J, Binet JP, Sidi D, et al. Switch operation for transposition of the great arteries in neonates. A study of 120 patients. J Thorac Cardiovasc Surg 1988; 96: 354-363.

155. Aubert J, Pannetier A, Couvelly JP, Unal D, Rouault F, Delarue A. Transposition of the great arteries. New technique for anatomical correction. Br Heart J 1978; 40: 204-208.

156. Brown EM, Salmon AP, Lamb RK. Arterial switch procedure without coronary relocation: a late complication. J Thorac Cardiovasc Surg 1996; 112: 1406-1407.

157. Suzuki T, Hotoda K, Iwazaki M, Masuoka A, Katogi T. Coronary re-implantation after completion of neo-aortic reconstruction in arterial switch operation: accurate intraoperative assessment for the optimal re-implantation site. Keio J Med 2009; 58: 227-233.

158. Takeuchi S, Katogi T. New technique for the arterial switch operation in difficult situations. Ann Thorac Surg 1990; 50: 1000 , discussion 01 .

159. Mee RBB, The Arterial Switch Operation. Surgery for Congenital Heart Defects. John Wiley \& Sons, Ltd; 2006: 471-487.

160. Asou T, Karl TR, Pawade A, Mee RB. Arterial switch: translocation of the intramural coronary artery. Ann Thorac Surg 1994; 57: 461-465.

161. Chen X, Cui H, Chen W, Yang S, Cui Y, Xia Y, et al. Early and mid-term results of the arterial switch operation in patients with intramural coronary artery. Pediatr Cardiol 2015; 36: 84-88.

162. Lecompte Y, Zannini L, Hazan E, Jarreau MM, Bex JP, Tu TV, et al. Anatomic correction of transposition of the great arteries. J Thorac Cardiovasc Surg 1981; 82: 629-631.

163. Delmo Walter EM, Miera O, Nasseri B, Huebler M, Alexi-Meskishvili V, Berger F, et al. Onset of pulmonary stenosis after arterial switch operation for transposition of great arteries with intact ventricular septum. HSR Proc Intensive Care Cardiovasc Anesth 2011; 3: 177-187. 
164. Raja S, Nayak S, Kaarne M. Arterial switch operation for simple transposition: three decades later. Intern J Thorac Cardiovasc Surg 2003; 6: 2 .

165. Swartz MF, Sena A, Atallah-Yunes N, Meagher C, Cholette JM, Gensini F, et al. Decreased incidence of supravalvar pulmonary stenosis after arterial switch operation. Circulation 2012; 126: S118-S122.

166. Ullmann MV, Gorenflo M, Bolenz C, Sebening C, Goetze M, Arnold R, et al. Late results after extended pulmonary artery reconstruction in the arterial switch operation. Ann Thorac Surg 2006; 81: 2259-2266.

167. Hutter PA, Kreb DL, Mantel SF, Hitchcock JF, Meijboom EJ, Bennink GB. Twenty-five years' experience with the arterial switch operation. J Thorac Cardiovasc Surg 2002; 124: 790-797.

168. Kawata H, Kishimoto H, Iwai S, Ishimaru K, Saito T, Kayatani F, et al. Long term outcome of arterial switch surgery for transposition of the great arteries: evaluation of the reconstruction of the pulmonary artery. Kyobu Geka 2008; 61: 303-309.

169. Raju V, Burkhart HM, Durham LA III., Eidem BW, Phillips SD, Li Z, et al. Reoperation after arterial switch: a 27-year experience. Ann Thorac Surg 2013; 95: 2105-2112.

170. Karl TR, Cochrane A, Brizard CP. Arterial switch operation. Surgical solutions to complex problems. Tex Heart Inst J 1997; 24: 322-333.

171. Lalezari S, Bruggemans EF, Blom NA, Hazekamp MG. Thirtyyear experience with the arterial switch operation. Ann Thorac Surg 2011; 92: 973-979.

172. Imoto $Y$, Kado H, Asou T, Shiokawa Y, Miyake Y, Yasuda H, et al. Postoperative pulmonary stenosis after arterial switch operation, comparison in three methods of pulmonary reconstruction: modified Pacifico, autologous pericardial patch, and equine pericardial patch. Kyobu Geka 1995; 48: 433-438; discussion 38-41.

173. Rudra HS, Mavroudis C, Backer CL, Kaushal S, Russell H, Stewart RD, et al. The arterial switch operation: 25-year experience with 258 patients. Ann Thorac Surg 2011; 92: 1742-1746.

174. Sakurai H, Maeda M, Miyahara K, Nakayama M, Murayama H, Hasegawa $\mathrm{H}$, et al. Mid-term results of the arterial switch operation for transposition of the great arteries: effect of fresh autologous pericardial patch in preventing postoperative pulmonary stenosis. Kyobu Geka 2000; 53: 807-812; discussion 13-6.

175. Arnold DM, Fergusson DA, Chan AK, Cook RJ, Fraser GA, Lim W, et al. Avoiding transfusions in children undergoing cardiac surgery: a meta-analysis of randomized trials of aprotinin. Anesth Analg 2006; 102: 731-737.

176. Fanconi S. Pulse oximetry for hypoxemia: a warning to users and manufacturers. Intensive Care Med 1989; 15: 540-542.

177. Lazzell VA, Burrows FA. Stability of the intraoperative arterial to end-tidal carbon dioxide partial pressure difference in children with congenital heart disease. Can J Anaesth 1991; 38: 859-865.

178. Stone JG, Young WL, Smith CR, Solomon RA, Wald A, Ostapkovich N, et al. Do standard monitoring sites reflect true brain temperature when profound hypothermia is rapidly induced and reversed? Anesthesiology 1995; 82: 344-351.

179. Gottlieb EA, Fraser CD Jr, Andropoulos DB, Diaz LK. Bilateral monitoring of cerebral oxygen saturation results in recognition of aortic cannula malposition during pediatric congenital heart surgery. Paediatr Anaesth 2006; 16: 787-789.

180. Tortoriello TA, Stayer SA, Mott AR, McKenzie ED, Fraser CD, Andropoulos DB, et al. A noninvasive estimation of mixed venous oxygen saturation using near-infrared spectroscopy by cerebral oximetry in pediatric cardiac surgery patients. Paediatr Anaesth 2005; 15: 495-503.

181. Andropoulos DB, Stayer SA, Diaz LK, Ramamoorthy C. Neurological monitoring for congenital heart surgery. Anesth Analg 2004; 99: 1365-1375.

182. Codaccioni JL, Velly LJ, Moubarik C, Bruder NJ, Pisano PS, Guillet BA. Sevoflurane preconditioning against focal cerebral ischemia: inhibition of apoptosis in the face of transient improvement of neurological outcome. Anesthesiology 2009; 110: 1271-1278.

183. Lee HT, Ota-Setlik A, Fu Y, Nasr SH, Emala CW. Differential protective effects of volatile anesthetics against renal ischemiareperfusion injury in vivo. Anesthesiology 2004; 101: 1313-1324.

184. Kussman BD, Zurakowski D, Sullivan L, McGowan FX, Davis PJ, Laussen PC. Evaluation of plasma fentanyl concentrations in infants during cardiopulmonary bypass with low-volume circuits. J Cardiothorac Vasc Anesth 2005; 19: 316-321.

185. Newburger JW, Jonas RA, Soul J, Kussman BD, Bellinger DC, Laussen PC, et al. Randomized trial of hematocrit $25 \%$ versus $35 \%$ during hypothermic cardiopulmonary bypass in infant heart surgery. J Thorac Cardiovasc Surg 2008; 135: 347-354.

186. Wypij D, Jonas RA, Bellinger DC, Del Nido PJ, Mayer JE Jr, Bacha EA, et al. The effect of hematocrit during hypothermic cardiopulmonary bypass in infant heart surgery: results from the combined Boston hematocrit trials. J Thorac Cardiovasc Surg 2008; 135: 355-360.

187. Sumpelmann R, Schurholz T, Thorns E, Hausdorfer J. Acid-base, electrolyte and metabolite concentrations in packed red blood cells for major transfusion in infants. Paediatr Anaesth 2001; 11: $169-173$.

188. Mou SS, Giroir BP, Molitor-Kirsch EA, Leonard SR, Nikaidoh H, Nizzi F, et al. Fresh whole blood versus reconstituted blood for pump priming in heart surgery in infants. N Engl J Med 2004; 351: $1635-1644$.

189. Pasquali SK, Hall M, Li JS, Peterson ED, Jaggers J, Lodge AJ, et al. Corticosteroids and outcome in children undergoing congenital heart surgery: analysis of the Pediatric Health Information Systems database. Circulation 2010; 122: 2123-2130.

190. Gessler P, Hohl V, Carrel T, Pfenninger J, Schmid ER, Baenziger $\mathrm{O}$, et al. Administration of steroids in pediatric cardiac surgery: impact on clinical outcome and systemic inflammatory response. Pediatr Cardiol 2005; 26: 595-600.

191. Graham EM, Atz AM, Butts RJ, Baker NL, Zyblewski SC, Deardorff RL, et al. Standardized preoperative corticosteroid treatment in neonates undergoing cardiac surgery: results from a randomized trial. J Thorac Cardiovasc Surg 2011; 142: $1523-1529$.

192. Pasquali SK, Li JS, He X, Jacobs ML, O’brien SM, Hall M, et al. Perioperative methylprednisolone and outcome in neonates undergoing heart surgery. Pediatrics 2012; 129: e385-e391.

193. Scrascia G, Rotunno C, Guida P, Amorese L, Polieri D, Codazzi $\mathrm{D}$, et al. Perioperative steroids administration in pediatric cardiac surgery: a meta-analysis of randomized controlled trials. Pediatr. Crit Care Med 2014; 15: 435-442.

194. Miyaji K, Hannan RL, Ojito J, Jacobs JP, White JA, Burke RP. Heparin-coated cardiopulmonary bypass circuit: clinical effects in pediatric cardiac surgery. J Card Surg 2000; 15: 194-198.

195. Boning A, Scheewe J, Ivers T, Friedrich C, Stieh J, Freitag S, et al. Phosphorylcholine or heparin coating for pediatric extracorporeal circulation causes similar biologic effects in neonates and infants. J Thorac Cardiovasc Surg 2004; 127: 1458-1465.

196. Finley A, Greenberg C. Review article: heparin sensitivity and resistance: management during cardiopulmonary bypass. Anesth Analg 2013; 116: 1210-1222.

197. Hickey PR, Hansen DD, Wessel DL, Lang P, Jonas RA, Elixson EM. Blunting of stress responses in the pulmonary circulation of infants by fentanyl. Anesth Analg 1985; 64: 1137-1142.

198. Liu J, Ji B, Long C, Li C, Feng Z. Comparative effectiveness of methylprednisolone and zero-balance ultrafiltration on inflammatory response after pediatric cardiopulmonary bypass. Artif Organs 2007; 31: 571-575.

199. Wypij D, Newburger JW, Rappaport LA, duPlessis AJ, Jonas RA, Wernovsky $G$, et al. The effect of duration of deep 
hypothermic circulatory arrest in infant heart surgery on late neurodevelopment: the Boston Circulatory Arrest Trial. J Thorac Cardiovasc Surg 2003; 126: 1397-1403.

200. Ballweg JA, Wernovsky G, Ittenbach RF, Bernbaum J, Gerdes M, Gallagher PR, et al. Hyperglycemia after infant cardiac surgery does not adversely impact neurodevelopmental outcome. Ann Thorac Surg 2007; 84: 2052-2058.

201. Heying R, Wehage E, Schumacher K, Tassani P, Haas F, Lange R, et al. Dexamethasone pretreatment provides antiinflammatory and myocardial protection in neonatal arterial switch operation. Ann Thorac Surg 2012; 93: 869-876.

202. Schroeder VA, Pearl JM, Schwartz SM, Shanley TP, Manning PB, Nelson DP. Combined steroid treatment for congenital heart surgery improves oxygen delivery and reduces postbypass inflammatory mediator expression. Circulation 2003; 107: 2823-2828.

203. Bergs J, Hellings J, Cleemput I, Zurel O, De Troyer V, Van Hiel $\mathrm{M}$, et al. Systematic review and meta-analysis of the effect of the World Health Organization surgical safety checklist on postoperative complications. Br J Surg 2014; 101: 150-158.

204. Boat AC, Spaeth JP. Handoff checklists improve the reliability of patient handoffs in the operating room and postanesthesia care unit. Paediatr Anaesth 2013; 23: 647-654.

205. Catchpole KR, de Leval MR, McEwan A, Pigott N, Elliott MJ, McQuillan A, et al. Patient handover from surgery to intensive care: using Formula 1 pit-stop and aviation models to improve safety and quality. Paediatr Anaesth 2007; 17: 470-478.

206. Joy BF, Elliott E, Hardy C, Sullivan C, Backer CL, Kane JM. Standardized multidisciplinary protocol improves handover of cardiac surgery patients to the intensive care unit. Pediatr Crit Care Med 2011; 12: 304-308.

207. Kaufman J, Twite M, Barrett C, Peyton C, Koehler J, Rannie M, et al. A handoff protocol from the cardiovascular operating room to cardiac ICU is associated with improvements in care beyond the immediate postoperative period. Jt Comm J Qual Patient Saf 2013; 39: 306-311.

208. Petrovic MA, Aboumatar H, Baumgartner WA, Ulatowski JA, Moyer J, Chang TY, et al. Pilot implementation of a perioperative protocol to guide operating room-to-intensive care unit patient handoffs. J Cardiothorac Vasc Anesth 2012; 26: 11-16.

209. Vergales J, Addison N, Vendittelli A, Nicholson E, Carver DJ, Stemland C, et al. Face-to-Face Handoff: Improving Transfer to the Pediatric Intensive Care Unit After Cardiac Surgery. Am J Med Qual 2015; 30: 119-125.

210. Seear MD, Scarfe JC, LeBlanc JG. Predicting major adverse events after cardiac surgery in children. Pediatr Crit Care Med 2008; 9: 606-611.

211. Bhutta AT, Ford JW, Parker JG, Prodhan P, Fontenot EE, Seib PM, et al. Noninvasive cerebral oximeter as a surrogate for mixed venous saturation in children. Pediatr Cardiol 2007; 28: 34-41.

212. Mittnacht AJ. Near infrared spectroscopy in children at high risk of low perfusion. Curr Opin Anaesthesiol 2010; 23: 342-347.

213. Holmes CL. Vasoactive drugs in the intensive care unit. Curr Opin Crit Care 2005; 11: 413-417.

214. Nissen SE. Report from the Cardiovascular and Renal Drugs Advisory Committee: US Food and Drug Administration; June 15-16, 2005; Gaithersburg, MD. Circulation 2005; 112: 2043-2046.

215. Zaritsky A, Chernow B. Use of catecholamines in pediatrics. J Pediatr 1984; 105: 341-350.

216. Deshpande S, Wolf M, Kim D, Kirshbom P. Simple transposition of the great arteries. In: Eduardo da Cruz DI, Jaggers James (eds) Pediatric and Congenital Cardiology, Cardiac Surgery and Intensive Care. London, UK: Springer-Verlag London Ltd; 2014: 1919-1940.

217. Burton GL, Kaufman J, Goot BH, da Cruz EM. The use of arginine vasopressin in neonates following the Norwood procedure. Cardiol Young 2011; 21: 536-544.
218. Decker JA, McCormack J, Cohen MI. Arrhythmia management in patients with a common arterial trunk and d-transposition of the great arteries. Cardiol Young 2012; 22: 748-754.

219. Shamszad P, Moore RA, Ghanayem N, Cooper DS. Intensive care management of neonates with d-transposition of the great arteries and common arterial trunk. Cardiol Young 2012; 22: 755-760.

220. Texter KM, Kertesz NJ, Friedman RA, Fenrich AL Jr. Atrial flutter in infants. J Am Coll Cardiol 2006; 48: 1040-1046.

221. The Esmolol Research Group. Intravenous esmolol for the treatment of supraventricular tachyarrhythmia: results of a multicenter, baseline-controlled safety and efficacy study in 160 patients. Am Heart J 1986; 112: 498-505.

222. Trippel DL, Wiest DB, Gillette PC. Cardiovascular and antiarrhythmic effects of esmolol in children. J Pediatr 1991; 119: 142-147.

223. Benson DW Jr, Dunnigan A, Green TP, Benditt DG, Schneider SP. Periodic procainamide for paroxysmal tachycardia. Circulation 1985; 72: 147-152.

224. Dubin A. Antiarrhythmic medications. In: CS Ricardo Munoz, Roth Stephen, da Cruz Eduardo (eds). Handbook of Pediatric Cardiovascular Drugs. London, UK: Springer-Verlag London Ltd; 2008: 150-189.

225. Mandapati R, Byrum CJ, Kavey RE, Smith FC, Kveselis DA, Hannan WP, et al. Procainamide for rate control of postsurgical junctional tachycardia. Pediatr Cardiol 2000; 21: 123-128.

226. Coumel P, Fidelle J. Amiodarone in the treatment of cardiac arrhythmias in children: one hundred thirty-five cases. Am Heart J 1980; 100: 1063-1069.

227. Figa FH, Gow RM, Hamilton RM, Freedom RM. Clinical efficacy and safety of intravenous Amiodarone in infants and children. Am J Cardiol 1994; 74: 573-577.

228. Perry JC, Fenrich AL, Hulse JE, Triedman JK, Friedman RA, Lamberti JJ. Pediatric use of intravenous amiodarone: efficacy and safety in critically ill patients from a multicenter protocol. J Am Coll Cardiol 1996; 27: 1246-1250.

229. Perry JC, Knilans TK, Marlow D, Denfield SW, Fenrich AL, Friedman RA. Intravenous amiodarone for life-threatening tachyarrhythmias in children and young adults. J Am Coll Cardiol 1993; 22: 95-98.

230. Maragnes P, Tipple M, Fournier A. Effectiveness of oral sotalol for treatment of pediatric arrhythmias. Am J Cardiol 1992; 69: 751-754.

231. Brugada J, Blom N, Sarquella-Brugada G, Blomstrom-Lundqvist C, Deanfield J, Janousek J. Pharmacological and nonpharmacological therapy for arrhythmias in the pediatric population: EHRA and AEPC-Arrhythmia Working Group joint consensus statement. Europace 2013; 15: 1337-1382.

232. Vernon DD, Witte MK. Effect of neuromuscular blockade on oxygen consumption and energy expenditure in sedated, mechanically ventilated children. Crit Care Med 2000; 28: 1569-1571.

233. Tibby SM, Hatherill M, Marsh MJ, Murdoch IA. Clinicians' abilities to estimate cardiac index in ventilated children and infants. Arch Dis Child 1997; 77: 516-518.

234. Bisoi AK, Ahmed T, Malankar DP, Chauhan S, Das S, Sharma P, et al. Midterm outcome of primary arterial switch operation beyond six weeks of life in children with transposition of great arteries and intact ventricular septum. World J Pediatr Congenit Heart Surg 2014; 5: 219-225.

235. Ambuel B, Hamlett KW, Marx CM, Blumer JL. Assessing distress in pediatric intensive care environments: the COMFORT scale. J Pediatr Psychol 1992; 17: 95-109.

236. Rawlinson E, Howard R. Post-operative sedation and analgesia. In: Eduardo da Cruz DI, Jaggers James (eds). Pediatric and Congenital Cardiology, Cardiac Surgery and Intensive Care. London, UK: Springer-Verlag London Ltd; 2014: 705-719.

237. Chrysostomou C, Morell VO, Wearden P, Sanchez-de-Toledo J, Jooste EH, Beerman L. Dexmedetomidine: therapeutic use for the 
termination of reentrant supraventricular tachycardia. Congenit Heart Dis 2013; 8: 48-56.

238. Hosokawa K, Shime N, Kato Y, Taniguchi A, Maeda Y, Miyazaki T, et al. Dexmedetomidine sedation in children after cardiac surgery. Pediatr Crit Care Med 2010; 11:39-43.

239. Parent BA, Munoz R, Shiderly D, Chrysostomou C. Use of dexmedetomidine in sustained ventricular tachycardia. Anaesth Intensive Care 2010; 38: 781.

240. Tobias JD, Chrysostomou C. Dexmedetomidine: antiarrhythmic effects in the pediatric cardiac patient. Pediatr Cardiol 2013; 34: 779-785.

241. Martin LD, Bratton SL, Quint P, Mayock DE. Prospective documentation of sedative, analgesic, and neuromuscular blocking agent use in infants and children in the intensive care unit: a multicenter perspective. Pediatr Crit Care Med 2001; 2: 205-210.

242. Tabarki B, Coffinieres A, Van Den Bergh P, Huault G, Landrieu P, Sebire G. Critical illness neuromuscular disease: clinical, electrophysiological, and prognostic aspects. Arch Dis Child 2002; 86: 103-107.

243. Foglia E, Meier MD, Elward A. Ventilator-associated pneumonia in neonatal and pediatric intensive care unit patients. Clin Microbiol Rev 2007; 20: 409-425.

244. Rosenthal VD, Bijie H, Maki DG, Mehta Y, Apisarnthanarak A, Medeiros EA, et al. International Nosocomial Infection Control Consortium (INICC) report, data summary of 36 countries, for 2004-2009. Am J Infect Control 2012; 40: 396-407.

245. Elward AM. Pediatric ventilator-associated pneumonia. Pediatr Infect Dis 2003; 22: 445-446.

246. Elward AM, Warren DK, Fraser VJ. Ventilator-associated pneumonia in pediatric intensive care unit patients: risk factors and outcomes. Pediatrics 2002; 109: 758-764.

247. Gil-Ruiz Gil-Esparza MA, Alcaraz Romero AJ, Romero Otero A, Gil Villanueva N, Sanavia Moran E, Rodriguez Sanchez de la Blanca A, et al. Prognostic relevance of early AKI according to pRIFLE criteria in children undergoing cardiac surgery. Pediatr Nephrol 2014; 29: 1265-1272.

248. Lex DJ, Toth R, Cserep Z, Alexander SI, Breuer T, Sapi E, et al. A comparison of the systems for the identification of postoperative acute kidney injury in pediatric cardiac patients. Ann Thorac Surg 2014; 97: 202-210.

249. Ricci Z, Di Nardo M, Iacoella C, Netto R, Picca S, Cogo P. Pediatric RIFLE for acute kidney injury diagnosis and prognosis for children undergoing cardiac surgery: a single-center prospective observational study. Pediatr Cardiol 2013; 34: 1404-1408.

250. Toth R, Breuer T, Cserep Z, Lex D, Fazekas L, Sapi E, et al. Acute kidney injury is associated with higher morbidity and resource utilization in pediatric patients undergoing heart surgery. Ann Thorac Surg 2012; 93: 1984-1990.

251. Watkins SC, Williamson K, Davidson M, Donahue BS. Longterm mortality associated with acute kidney injury in children following congenital cardiac surgery. Paediatr Anaesth 2014; 24: 919-926.

252. da Cruz E, Rimensberger P. Inotropic and vasoactive drugs. In: Ricardo Munoz CS, Roth Stephen, da Cruz Eduardo (eds). Handbook of Pediatric Cardiovascular Drugs. London, UK: Springer-Verlag London Ltd; 2008: 33-76.

253. Roth S, Munoz R, Schmitt C, da Cruz E, Kaufman J, Tissot C. Vasodilators. In: Ricardo Munoz CS, Roth Stephen, Cruz Eduardo da (eds). Handbook of Pediatric Cardiovascular Drugs. London, UK: Springer-Verlag London Ltd; 2008: 77-118.

254. Moons P, Gewillig M, Sluysmans T, Verhaaren H, Viart P, Massin $\mathrm{M}$, et al. Long term outcome up to 30 years after the Mustard or Senning operation: a nationwide multicentre study in Belgium. Heart 2004; 90: 307-313.

255. Murphy DJ Jr. Transposition of the great arteries: long-term outcome and current management. Curr Cardiol Rep 2005; 7: 299-304.
256. Puley G, Siu S, Connelly M, Harrison D, Webb G, Williams WG, et al. Arrhythmia and survival in patients $>18$ years of age after the mustard procedure for complete transposition of the great arteries. Am J Cardiol 1999; 83: 1080-1084.

257. Roos-Hesselink JW, Meijboom FJ, Spitaels SE, van Domburg R, van Rijen EH, Utens EM, et al. Decline in ventricular function and clinical condition after Mustard repair for transposition of the great arteries (a prospective study of 22-29 years). Eur Heart J 2004; 25: 1264-1270.

258. Wilson NJ, Clarkson PM, Barratt-Boyes BG, Calder AL, Whitlock RM, Easthope RN, et al. Long-term outcome after the mustard repair for simple transposition of the great arteries. 28-year follow-up. J Am Coll Cardiol 1998; 32: 758-765.

259. Birnie D, Tometzki A, Curzio J, Houston A, Hood S, Swan L, et al. Outcomes of transposition of the great arteries in the ear of atrial inflow correction. Heart 1998; 80: 170-173.

260. Sun ZH, Happonen JM, Bennhagen R, Sairanen H, Pesonen E, Toivonen L, et al. Increased QT dispersion and loss of sinus rhythm as risk factors for late sudden death after Mustard or Senning procedures for transposition of the great arteries. Am J Cardiol 2004; 94: 138-141.

261. Gewillig M, Cullen S, Mertens B, Lesaffre E, Deanfield J. Risk factors for arrhythmia and death after Mustard operation for simple transposition of the great arteries. Circulation 1991; 84: 187-192.

262. Duncan BW, Mee RB. Management of the failing systemic right ventricle. Semin Thorac Cardiovasc Surg 2005; 17: 160-169.

263. Barron DJ, Jones TJ, Brawn WJ. The Senning procedure as part of the double-switch operations for congenitally corrected transposition of the great arteries. Semin Thorac Cardiovasc Surg Pediatr Card Surg Annu 2011; 14: 109-115.

264. Mee RB. The double switch operation with accent on the Senning component. Semin Thorac Cardiovasc Surg Pediatr Card Surg Annu 2005; 8: 57-65.

265. Senning A. Surgical correction of transposition of the great vessels. Surgery 1959; 45: 966-980

266. Mustard WT. Successful two-stage correction of transposition of the great vessels. Surgery 1964; 55: 469-472.

267. Winter MM, Bouma BJ, Groenink M, Konings TC, Tijssen JG, van Veldhuisen DJ, et al. Latest insights in therapeutic options for systemic right ventricular failure: a comparison with left ventricular failure. Heart 2009; 95: 960-963.

268. Hechter SJ, Fredriksen PM, Liu P, Veldtman G, Merchant N, Freeman $\mathrm{M}$, et al. Angiotensin-converting enzyme inhibitors in adults after the Mustard procedure. Am J Cardiol 2001; 87: 660-663.

269. Gelatt M, Hamilton RM, McCrindle BW, Connelly M, Davis A, Harris L, et al. Arrhythmia and mortality after the Mustard procedure: a 30-year single-center experience. J Am Coll Cardiol 1997; 29: 194-201.

270. Diller GP, Okonko D, Uebing A, Ho SY, Gatzoulis MA. Cardiac resynchronization therapy for adult congenital heart disease patients with a systemic right ventricle: analysis of feasibility and review of early experience. Europace 2006; 8: 267-272.

271. Janousek J, Tomek V, Chaloupecky VA, Reich O, Gebauer RA, Kautzner J, et al. Cardiac resynchronization therapy: a novel adjunct to the treatment and prevention of systemic right ventricular failure. J Am Coll Cardiol 2004; 44: 1927-1931.

272. Triedman JK. Arrhythmias in adults with congenital heart disease. Heart 2002; 87: 383-389.

273. Kenleigh D, Edens RE, Bates MJ, Turek JW. Use of heart ware ventricular assist system for systemic ventricular support of a pediatric patient after Mustard procedure. World J Pediatr Congenit Heart Surg 2015; 6: 339-341.

274. Warnes CA. Transposition of the great arteries. Circulation 2006; 114: 2699-2709. 
275. van Son JA, Danielson GK, Huhta JC, Warnes CA, Edwards WD, Schaff $\mathrm{HV}$, et al. Late results of systemic atrioventricular valve replacement in corrected transposition. J Thorac Cardiovasc Surg 1995; 109: 642-652.

276. Scherptong RW, Vliegen HW, Winter MM, Holman ER, Mulder BJ, van der Wall EE, et al. Tricuspid valve surgery in adults with a dysfunctional systemic right ventricle: repair or replace? Circulation 2009; 119: 1467-1472.

277. Mavroudis C, Backer CL. Arterial switch after failed atrial baffle procedures for transposition of the great arteries. Ann Thorac Surg 2000; 69: 851-857.

278. Poirier NC, Yu JH, Brizard CP, Mee RB. Long-term results of left ventricular reconditioning and anatomic correction for systemic right ventricular dysfunction after atrial switch procedures. J Thorac Cardiovasc Surg 2004; 127: 975-981.

279. Corno AF. FloWatch device for adjustable pulmonary artery banding. J Thorac Cardiovasc Surg 2013; 145: 1144

280. Dibardino DJ, Kleeman K, Bove EL. A method of transcutaneously adjustable pulmonary artery banding for staged left ventricular retraining. J Thorac Cardiovasc Surg 2012; 144: 553-556.

281. Padalino MA, Stellin G, Brawn WJ, Fasoli G, Daliento L, Milanesi $\mathrm{O}$, et al. Arterial switch operation after left ventricular retraining in the adult. Ann Thorac Surg 2000; 70: 1753-1757.

282. Daebritz SH, Tiete AR, Sachweh JS, Engelhardt W, von Bernuth G, Messmer BJ. Systemic right ventricular failure after atrial switch operation: midterm results of conversion into an arterial switch. Ann Thorac Surg 2001; 71: 1255-1259.

283. Benzaquen BS, Webb GD, Colman JM, Therrien J. Arterial switch operation after Mustard procedures in adult patients with transposition of the great arteries: is it time to revise our strategy? Am Heart J 2004; 147: E8.

284. Mee RB. Severe right ventricular failure after Mustard or Senning operation. Two-stage repair: pulmonary artery banding and switch. J Thorac Cardiovasc Surg 1986; 92: 385-390.

285. Chang AC, Wernovsky G, Wessel DL, Freed MD, Parness IA, Perry $\mathrm{SB}$, et al. Surgical management of late right ventricular failure after Mustard or Senning repair. Circulation 1992; 86: 140-149.

286. van Son JA, Reddy VM, Silverman NH, Hanley FL. Regression of tricuspid regurgitation after two-stage arterial switch operation for failing systemic ventricle after atrial inversion operation. J Thorac Cardiovasc Surg 1996; 111: 342-347.

287. Hetzer R, Weng Y, Delmo Walter EM. State of the art in paediatric heart transplantation: the Berlin experience. Eur J Cardiothorac Surg 2013; 43: 258-267.

288. Canter CE, Shaddy RE, Bernstein D, Hsu DT, Chrisant MR, Kirklin JK, et al. Indications for heart transplantation in pediatric heart disease: a scientific statement from the American Heart Association Council on Cardiovascular Disease in the Young; the Councils on Clinical Cardiology, Cardiovascular Nursing, and Cardiovascular Surgery and Anesthesia; and the Quality of Care and Outcomes Research Interdisciplinary Working Group. Circulation 2007; 115: 658-676.

289. Kim SJ, Kim WH, Lim C, Oh SS, Kim YM. Commissural malalignment of aortic-pulmonary sinus in complete transposition of great arteries. Ann Thorac Surg 2003; 76: 1906-1910.

290. Konstantinov IE, Fricke TA, D’Udekem Y, Radford DJ. Translocation of a single coronary artery from the nonfacing sinus in the arterial switch operation: long-term patency of the interposition graft. J Thorac Cardiovasc Surg 2010; 140: 1193-1194.

291. Talwar S, Nair VV, Choudhary SK, Airan B. Atrial switch operation in the current era: modifications and pitfalls. World J Pediatr Congenit Heart Surg 2012; 3: 96-103.

292. Wernovsky G, Rome JJ, Tabbutt S, Rychik J, Cohen MS, Paridon SM, et al. Guidelines for the outpatient management of complex congenital heart disease. Congenit Heart Dis 2006; 1: 10-26.
293. Angeli E, Raisky O, Bonnet D, Sidi D, Vouhé PR. Late reoperations after neonatal arterial switch operation for transposition of the great arteries. Eur J Cardiothorac Surg 2008; 34: 32-36.

294. Valsangiacomo Buechel ER, Grosse-Wortmann L, Fratz S, Eichhorn J, Sarikouch S, Greil GF, et al. Indications for cardiovascular magnetic resonance in children with congenital and acquired heart disease: an expert consensus paper of the Imaging Working Group of the AEPC and the Cardiovascular Magnetic Resonance Section of the EACVI. Eur Heart J Cardiovasc Imaging 2015; 16: 281-297.

295. Cohen MS, Eidem BW, Cetta F, Fogel MA, Frommelt PC, Ganame J, et al. Multimodality imaging guidelines of patients with transposition of the great arteries: a report from the American Society of Echocardiography developed in collaboration with the Society for Cardiovascular Magnetic Resonance and the Society of Cardiovascular Computed Tomography. J Am Soc Echocardiogr 2016; 29: 571-621.

296. Fratz S, Chung T, Greil GF, Samyn MM, Taylor AM, Valsangiacomo Buechel ER, et al. Guidelines and protocols for cardiovascular magnetic resonance in children and adults with congenital heart disease: SCMR expert consensus group on congenital heart disease. J Cardiovasc Magn Reson 2013; 15: 51.

297. Legendre A, Losay J, Touchot-Kone A, Serraf A, Belli E, Piot JD, et al. Coronary events after arterial switch operation for transposition of the great arteries. Circulation 2003; 108 (Suppl 1): $186-190$.

298. Ou P, Khraiche D, Celermajer DS, Agnoletti G, Le Quan Sang $\mathrm{KH}$, Thalabard JC, et al. Mechanisms of coronary complications after the arterial switch for transposition of the great arteries. J Thorac Cardiovasc Surg 2013; 145: 1263-1269.

299. Cho I, Chang HJ, Shin S, Sung JM, Lin FY, et al. Incremental prognostic utility of coronary CT angiography for asymptomatic patients based upon extent and severity of coronary artery calcium: results from the COronary CT Angiography EvaluatioN For Clinical Outcomes InteRnational Multicenter (CONFIRM) study. Eur Heart J 2015; 36: 501-508.

300. Ou P, Celermajer DS, Marini D, Agnoletti G, Vouhé P, Brunelle F, et al. Safety and accuracy of 64-slice computed tomography coronary angiography in children after the arterial switch operation for transposition of the great arteries. JACC Cardiovasc Imaging 2008; 1: 331-339.

301. Tobler D, Motwani M, Wald RM, Roche SL, Verocai F, Iwanochko RM, et al. Evaluation of a comprehensive cardiovascular magnetic resonance protocol in young adults late after the arterial switch operation for d-transposition of the great arteries. J Cardiovasc Magn Reson 2014; 16: 98.

302. Buechel ER, Balmer C, Bauersfeld U, Kellenberger CJ, Schwitter J. Feasibility of perfusion cardiovascular magnetic resonance in paediatric patients. J Cardiovasc Magn Reson 2009; 11: 51 .

303. Taylor AM, Dymarkowski S, Hamaekers P, Razavi R, Gewillig $M$, Mertens L, et al. MR coronary angiography and lateenhancement myocardial MR in children who underwent arterial switch surgery for transposition of great arteries. Radiology 2005; 234: 542-547.

304. Day RW, Laks H, Drinkwater DC. The influence of coronary anatomy on the arterial switch operation in neonates. $\mathrm{J}$ Thorac Cardiovasc Surg 1992; 104: 706-712.

305. Yamaguchi M, Hosokawa Y, Imai Y, Kurosawa H, Yasui H, Yagihara T, et al. Early and midterm results of the arterial switch operation for transposition of the great arteries in Japan. J Thorac Cardiovasc Surg 1990; 100: 261-269.

306. el-Said G, Rosenberg HS, Mullins CE, Hallman GL, Cooley DA, McNamara DG. Dysrhythmias after Mustard's operation for transposition of the treat arteries. Am J Cardiol 1972; 30: 526-532. 
307. Isaacson R, Titus JL, Merideth J, Feldt RH, McGoon DC. Apparent interruption of atrial conduction pathways after surgical repair of transposition of great arteries. Am J Cardiol 1972; 30: 533-535.

308. Martin TC, Smith L, Hernandez A, Weldon CS. Dysrhythmias following the Senning operation for dextro-transposition of the great arteries. J Thorac Cardiovasc Surg 1983; 85: 928-932.

309. Hayashi G, Kurosaki K, Echigo S, Kado H, Fukushima N, Yokota M, et al. Prevalence of arrhythmias and their risk factors mid- and long-term after the arterial switch operation. Pediatr Cardiol 2006; 27: 689-694.

310. Yamazaki A, Yamamoto N, Sakamoto T, Ishihara K, Iwata Y, Matsumura $\mathrm{G}$, et al. Long-term outcomes and social independence level after arterial switch operation. Eur J Cardiothorac Surg 2008; 33: 239-243.

311. Rhodes LA, Wernovsky G, Keane JF, Mayer JE Jr, Shuren A, Dindy C, et al. Arrhythmias and intracardiac conduction after the arterial switch operation. J Thorac Cardiovasc Surg 1995; 109: 303-310.

312. Delaney JW, Moltedo JM, Dziura JD, Kopf GS, Snyder CS. Early postoperative arrhythmias after pediatric cardiac surgery. $\mathrm{J}$ Thorac Cardiovasc Surg 2006; 131: 1296-1300.

313. Losay J, Touchot A, Serraf A, Litvinova A, Lambert V, Piot JD, et al. Late outcome after arterial switch operation for transposition of the great arteries. Circulation 2001; 104: 121-126.

314. Horer J, Schreiber C, Cleuziou J, Vogt M, Prodan Z, Busch R, et al. Improvement in long-term survival after hospital discharge but not in freedom from reoperation after the change from atrial to arterial switch for transposition of the great arteries. J Thorac Cardiovasc Surg 2009; 137: 347-354.

315. Rodriguez Puras MJ, Cabeza-Letran L, Romero-Vazquianez M, Santos de Soto J, Hosseinpour R, Gil Fournier M, et al. Mid-term morbidity and mortality of patients after arterial switch operation in infancy for transposition of the great arteries. Rev Esp Cardiol (Engl Ed) 2014; 67: 181-188.

316. Haas F, Wottke M, Poppert H, Meisner H. Long-term survival and functional follow-up in patients after the arterial switch operation. Ann Thorac Surg 1999; 68: 1692-1697.

317. Freed DH, Robertson CM, Sauve RS, Joffe AR, Rebeyka IM, Ross DB, et al. Intermediate-term outcomes of the arterial switch operation for transposition of great arteries in neonates: alive but well? J Thorac Cardiovasc Surg 2006; 132: 845-852.

318. Nogi S, McCrindle BW, Boutin C, Williams WG, Freedom RM, Benson LN. Fate of the neopulmonary valve after the arterial switch operation in neonates. J Thorac Cardiovasc Surg 1998; 115: $557-562$.

319. Wernovsky G, Mayer JE Jr, Jonas RA, Hanley FL, Blackstone EH, Kirklin JW, et al. Factors influencing early and late outcome of the arterial switch operation for transposition of the great arteries. J Thorac Cardiovasc Surg 1995; 109: 289-301.

320. Williams WG, Quaegebeur JM, Kirklin JW, Blackstone EH. Outflow obstruction after the arterial switch operation: a multiinstitutional study. Congenital Heart Surgeons Society. J Thorac Cardiovasc Surg 1997; 114: 975-987.

321. Vargo P, Mavroudis C, Stewart RD, Backer CL. Late complications following the arterial switch operation. World J Pediatr Congenit Heart Surg 2011; 2: 37-42.

322. Bove T, De Meulder F, Vandenplas G, De Groote K, Panzer J, Suys B, et al. Midterm assessment of the reconstructed arteries after the arterial switch operation. Ann Thorac Surg 2008; 85: 823-830.

323. Prifti E, Crucean A, Bonacchi M, Bernabei M, Murzi B, Luisi SV, et al. Early and long term outcome of the arterial switch operation for transposition of the great arteries: predictors and functional evaluation. Eur J Cardiothorac Surg 2002; 22: 864-873.
324. Lupinetti FM, Bove EL, Minich LL, Snider AR, Callow LB, Meliones JN, et al. Intermediate-term survival and functional results after arterial repair for transposition of the great arteries. J Thorac Cardiovasc Surg 1992; 103: 421-427.

325. Paillole C, Sidi D, Kachaner J, Planche C, Belot JP, Villain E, et al. Fate of pulmonary artery after anatomic correction of simple transposition of great arteries in newborn infants. Circulation 1988; 78: 870-876.

326. Wernovsky G, Hougen TJ, Walsh EP, Sholler GF, Colan SD, Sanders SP, et al. Midterm results after the arterial switch operation for transposition of the great arteries with intact ventricular septum: clinical, hemodynamic, echocardiographic, and electrophysiologic data. Circulation 1988; 77: 1333-1344.

327. Spiegelenberg SR, Hutter PA, van de Wal HJ, Hitchcock JF, Meijboom EJ, Harinck E. Late re-interventions following arterial switch operations in transposition of the great arteries. Incidence and surgical treatment of postoperative pulmonary stenosis. Eur J Cardiothorac Surg 1995; 9: 7-10.

328. Zeevi B, Keane JF, Perry SB, Lock JE. Balloon dilation of postoperative right ventricular outflow obstructions. J Am Coll Cardiol 1989; 14: 401-408.

329. Kuroczynski W, Kampmann C, Choi YH, Hilker M, Wippermann F, David M, et al. Treatment of supravalvular pulmonary stenosis after arterial switch operations (ASO). Z Kardiol 2001; 90: 498-502.

330. Massin MM, Nitsch GB, Dabritz S, Seghaye MC, Messmer BJ, von Bernuth G. Growth of pulmonary artery after arterial switch operation for simple transposition of the great arteries. Eur J Pediatr 1998; 157: 95-100.

331. Nakanishi T, Momoi N, Satoh M, Yamada M, Terada M, Nakazawa M, et al. Growth of the neopulmonary valve annulus after arterial switch operation in transposition of the great arteries. Circulation 1996; 94: 27-31.

332. Serraf A, Bruniaux J, Lacour-Gayet F, Sidi D, Kachaner J, Bouchart F, et al. Anatomic correction of transposition of the great arteries with ventricular septal defect. Experience with 118 cases. J Thorac Cardiovasc Surg 1991; 102: 140-147.

333. Raja SG, Shauq A, Kaarne M. Outcomes after arterial switch operation for simple transposition. Asian Cardiovasc Thorac Ann 2005; 13: 190-198.

334. Santoro G, Di Carlo D, Formigari R, Ballerini L. Late onset pulmonary valvar stenosis after arterial switch operation for transposition of the great arteries. Heart 1998; 79: 311-312.

335. Formigari R, Santoro G, Guccione P, Giamberti A, Pasquini L, Grigioni $\mathrm{M}$, et al. Treatment of pulmonary artery stenosis after arterial switch operation: stent implantation vs. balloon angioplasty. Catheter Cardiovasc Interv 2000; 50: 207-211.

336. Tzifa A, Papagiannis J, Qureshi S. Iatrogenic aortopulmonary window after balloon dilation of left pulmonary artery stenosis following arterial switch operation. J Invasive Cardiol 2013; 25: E188-E190.

337. Torres A, Sanders SP, Vincent JA, El-Said HG, Leahy RA, Padera RF, et al. Iatrogenic aortopulmonary communications after transcatheter interventions on the right ventricular outflow tract or pulmonary artery: pathophysiologic, diagnostic, and management considerations. Catheter Cardiovasc Interv 2015; 86: 438-452.

338. Gleason MM, Chin AJ, Andrews BA, Barber G, Helton JG, Murphy JD, et al. Two-dimensional and Doppler echocardiographic assessment of neonatal arterial repair for transposition of the great arteries. J Am Coll Cardiol 1989; 13: 1320-1328.

339. Martin MM, Snider AR, Bove EL, Serwer GA, Rosenthal A, Peters $\mathrm{J}$, et al. Two-dimensional and Doppler echocardiographic evaluation after arterial switch repair in infancy for complete transposition of the great arteries. Am J Cardiol 1989; 63: 332-336.

340. Hovels-Gurich HH, Seghaye MC, Ma Q, Miskova M, Minkenberg R, Messmer BJ, et al. Long-term results of cardiac and general health status in children after neonatal arterial switch operation. Ann Thorac Surg 2003; 75: 935-943. 
341. Geva T. Indications for pulmonary valve replacement in repaired tetralogy of Fallot: the quest continues. Circulation 2013; 128: $1855-1857$.

342. Eicken A, Ewert P, Hager A, Peters B, Fratz S, Kuehne T, et al. Percutaneous pulmonary valve implantation: two-centre experience with more than 100 patients. Eur Heart J 2011; 32: 1260-1265.

343. Thanopoulos BV, Giannakoulas G, Arampatzis CA. Percutaneous pulmonary valve implantation in the native right ventricular outflow tract. Catheter Cardiovasc Interv 2012; 79: 427-429.

344. Biermann D, Schonebeck J, Rebel M, Weil J, Dodge-Khatami A. Left coronary artery occlusion after percutaneous pulmonary valve implantation. Ann Thorac Surg 2012; 94: E7-E9.

345. Delmo Walter EM, Huebler M, Alexi-Meshkishvili V, Sill B, Berger F, Hetzer R. Fate of the aortic valve following the arterial switch operation. J Card Surg 2010; 25: 730-736.

346. Marino BS, Wernovsky G, McElhinney DB, Jawad A, Kreb DL, Mantel SF, et al. Neo-aortic valvar function after the arterial switch. Cardiol Young 2006; 16: 481-489.

347. McMahon CJ, Ravekes WJ, Smith EO, Denfield SW, Pignatelli RH, Altman CA, et al. Risk factors for neo-aortic root enlargement and aortic regurgitation following arterial switch operation. Pediatr Cardiol 2004; 25: 329-335.

348. Schwartz ML, Gauvreau K, del Nido P, Mayer JE, Colan SD. Long-term predictors of aortic root dilation and aortic regurgitation after arterial switch operation. Circulation 2004; 110: 128-132.

349. Martin RP, Ettedgui JA, Qureshi SA, Gibbs JL, Baker EJ, Radley-Smith R, et al. A quantitative evaluation of aortic regurgitation after anatomic correction of transposition of the great arteries. J Am Coll Cardiol 1988; 12: 1281-1284.

350. Lange R, Cleuziou J, Horer J, Holper K, Vogt M, Tassani-Prell P, et al. Risk factors for aortic insufficiency and aortic valve replacement after the arterial switch operation. Eur J Cardiothorac Surg 2008; 34: 711-717.

351. Daebritz SH, Nollert G, Sachweh JS, Engelhardt W, von Bernuth $\mathrm{G}$, Messmer BJ. Anatomical risk factors for mortality and cardiac morbidity after arterial switch operation. Ann Thorac Surg 2000; 69: 1880-1886.

352. Hwang HY, Kim WH, Kwak JG, Lee JR, Kim YJ, Rho JR, et al. Mid-term follow-up of neoaortic regurgitation after the arterial switch operation for transposition of the great arteries. Eur J Cardiothorac Surg 2006; 29: 162-167.

353. Hutter PA, Thomeer BJ, Jansen P, Hitchcock JF, Faber JA, Meijboom EJ, et al. Fate of the aortic root after arterial switch operation. Eur J Cardiothorac Surg 2001; 20: 82-88.

354. Mavroudis C, Stewart RD, Backer CL, Rudra H, Vargo P, Jacobs ML. Reoperative techniques for complications after arterial switch. Ann Thorac Surg 2011; 92: 1747-1754.

355. Losay J, Touchot A, Capderou A, Piot JD, Belli E, Planche C, et al. Aortic valve regurgitation after arterial switch operation for transposition of the great arteries: incidence, risk factors, and outcome. J Am Coll Cardiol 2006; 47: 2057-2062.

356. del Nido PJ, Schwartz ML. Aortic regurgitation after arterial switch operation. J Am Coll Cardiol 2006; 47: 2063-2064.

357. Jenkins KJ, Hanley FL, Colan SD, Mayer JE Jr, Castaneda AR, Wernovsky G. Function of the anatomic pulmonary valve in the systemic circulation. Circulation 1991; 84: 173-179.

358. Lalezari S, Hazekamp MG, Bartelings MM, Schoof PH, Gittenberger-De Groot AC. Pulmonary artery remodeling in transposition of the great arteries: relevance for neoaortic root dilatation. J Thorac Cardiovasc Surg 2003; 126: 1053-1060.

359. Niwa K, Perloff JK, Bhuta SM, Laks H, Laks H, Drinkwater DC, Child JS, et al. Structural abnormalities of great arterial walls in congenital heart disease: light and electron microscopic analyses. Circulation 2001; 103: 393-400.

360. Bottio T, Thiene G, Tarzia V, Rizzoli G, Gerosa G. Arterial switch operation, aortic root dilation, and long-term aortic valve competence. Ann Thorac Surg 2008; 86: 2025-2026.
361. Co-Vu JG, Ginde S, Bartz PJ, Frommelt PC, Tweddell JS, Earing MG. Long-term outcomes of the neoaorta after arterial switch operation for transposition of the great arteries. Ann Thorac Surg 2013; 95: 1654-1659.

362. Lalezari S, Mahtab EA, Bartelings MM, Wisse LJ, Hazekamp MG, Gittenberger-de Groot AC. The outflow tract in transposition of the great arteries: an anatomic and morphologic study. Ann Thorac Surg 2009; 88: 1300-1305.

363. Michalak KW, Moll JA, Moll M, Dryzek P, Moszura T, Kopala $\mathrm{M}$, et al. The neoaortic root in children with transposition of the great arteries after an arterial switch operation. Eur J Cardiothorac Surg 2013; 43: 1101-1108.

364. Formigari R, Toscano A, Giardini A, Gargiulo G, Di Donato R, Picchio FM, et al. Prevalence and predictors of neoaortic regurgitation after arterial switch operation for transposition of the great arteries. J Thorac Cardiovasc Surg 2003; 126: 1753-1759.

365. Agnoletti G, Ou P, Celermajer DS, Boudjemline Y, Marini D, Bonnet D, et al. Acute angulation of the aortic arch predisposes a patient to ascending aortic dilatation and aortic regurgitation late after the arterial switch operation for transposition of the great arteries. J Thorac Cardiovasc Surg 2008; 135: 568-572.

366. Jhang WK, Shin HJ, Park JJ, Yun TJ, Kim YH, Ko JK, et al. The importance of neo-aortic root geometry in the arterial switch operation with the trap-door technique in the subsequent development of aortic valve regurgitation. Eur J Cardiothorac Surg 2012; 42: 794-799.

367. Murakami T, Nakazawa M, Momma K, Imai Y. Impaired distensibility of neoaorta after arterial switch procedure. Ann Thorac Surg 2000; 70: 1907-1910.

368. Fricke TA, Brizard CP, D'Udekem Y, Konstantinov IE. Aortic root and valve surgery after arterial switch operation. J Thorac Cardiovasc Surg 2012; 144: 1269-1271.

369. Marino BS, Bridges ND, Paridon SM. Aortic insufficiency: indications for surgery in children. Semin Thorac Cardiovasc Surg Pediatr Card Surg Annu 1998; 1: 147-156.

370. Imamura M, Drummond-Webb JJ, McCarthy JF, Mee RB. Aortic valve repair after arterial switch operation. Ann Thorac Surg 2000; 69: 607-608.

371. Alexi-Meskishvili V, Photiadis J, Nurnberg JH. Replacement of the aortic valve after the arterial switch operation. Cardiol Young 2003; 13: 191-193.

372. Hazekamp MG, Schoof PH, Suys BE, Hutter PA, Meijboom EJ, Ottenkamp J, et al. Switch back: using the pulmonary autograft to replace the aortic valve after arterial switch operation. J Thorac Cardiovasc Surg 1997; 114: 844-846.

373. Vicente W, Ferreira CA, Klamt JG, Manso PH, Filho OC, Carlotti AP, et al. The switch back Ross operation: report of two cases with good medium-to-long-term follow-up. World J Pediatr Congenit Heart Surg 2012; 3: 244-248.

374. Hourihan M, Colan SD, Wernovsky G, Maheswari U, Mayer JE $\mathrm{Jr}$, Sanders SP. Growth of the aortic anastomosis, annulus, and root after the arterial switch procedure performed in infancy. Circulation 1993; 88: 615-620.

375. Leobon B, Belli E, Ly M, Kortas C, Le Bret E, Sigal-Cinqualbre A, et al. Left ventricular outflow tract obstruction after arterial switch operation. Eur J Cardiothorac Surg 2008; 34: 1046-1050.

376. Kosaka Y, Kurosawa H, Nagatsu M. Konno procedure using atrioventricular groove patch plasty after arterial switch operation. Ann Thorac Surg 2004; 78: 1854-1855.

377. Tamisier D, Ouaknine R, Pouard P, Mauriat P, Lefebvre D, Sidi D, et al. Neonatal arterial switch operation: coronary artery patterns and coronary events. Eur J Cardiothorac Surg 1997; 11: 810-817.

378. Pedra SR, Pedra CA, Abizaid AA, Braga SL, Staico R, Arrieta R, et al. Intracoronary ultrasound assessment late after the arterial switch operation for transposition of the great arteries. J Am Coll Cardiol 2005; 45: 2061-2068. 
379. Bartoloni G, Bianca S, Patane L, Mignosa C. Pathology of coronary narrowing after arterial switch operation: autopsy findings in two patients who died within 3 months of surgical treatment and review of the literature. Cardiovasc Pathol 2006; 15: 49-54.

380. Bonnet D, Bonhoeffer P, Piechaud JF, Aggoun Y, Sidi D, Planche $\mathrm{C}$, et al. Long-term fate of the coronary arteries after the arterial switch operation in newborns with transposition of the great arteries. Heart 1996; 76: 274-279.

381. Tanel RE, Wernovsky G, Landzberg MJ, Perry SB, Burke RP. Coronary artery abnormalities detected at cardiac catheterization following the arterial switch operation for transposition of the great arteries. Am J Cardiol 1995; 76: 153-157.

382. Angeli E, Formigari R, Pace Napoleone C, Oppido G, Ragni L, Picchio FM, et al. Long-term coronary artery outcome after arterial switch operation for transposition of the great arteries. Eur J Cardiothorac Surg 2010; 38: 714-720.

383. Raisky O, Bergoend E, Agnoletti G, Ou P, Bonnet D, Sidi D, et al. Late coronary artery lesions after neonatal arterial switch operation: results of surgical coronary revascularization. Eur J Cardiothorac Surg 2007; 31: 894-898.

384. Bonhoeffer P, Bonnet D, Piechaud JF, Stumper O, Aggoun Y, Villain E, et al. Coronary artery obstruction after the arterial switch operation for transposition of the great arteries in newborns. J Am Coll Cardiol 1997; 29: 202-206.

385. Hutter PA, Bennink GB, Ay L, Raes IB, Hitchcock JF, Meijboom EJ. Influence of coronary anatomy and reimplantation on the longterm outcome of the arterial switch. Eur J Cardiothorac Surg 2000; 18: 207-213.

386. Angeli E, Gerelli S, Beyler C, Lamerain M, Rochas B, Bonnet D, et al. Bicuspid pulmonary valve in transposition of the great arteries: impact on outcome. Eur J Cardiothorac Surg 2012; 41: 248-255.

387. Bonnet D, Bonhoeffer P, Sidi D, Kachaner J, Acar P, Villain E, et al. Surgical angioplasty of the main coronary arteries in children. J Thorac Cardiovasc Surg 1999; 117: 352-357.

388. Raanani E, Kogan A, Shapira Y, Sagie A, Kornowsky R, Vidne BA. Surgical reconstruction of the left main coronary artery: fresh autologous pericardium or saphenous vein patch. Ann Thorac Surg 2004; 78: 1610-1613.

389. Bergoend E, Raisky O, Degandt A, Tamisier D, Sidi D, Vouhé P. Myocardial revascularization in infants and children by means of coronary artery proximal patch arterioplasty or bypass grafting: a single-institution experience. J Thorac Cardiovasc Surg 2008; 136: 298-305.

390. Prêtre R, Turina MI. Surgical angioplasty of the left main coronary artery in non-atherosclerotic lesions. Heart 2000; 83: 91-93.

391. Prifti E, Bonacchi M, Luisi SV, Vanini V. Coronary revascularization after arterial switch operation. Eur J Cardiothorac Surg 2002; 21: 111-113.

392. Jonsson A, Jensen J, Olsson A, Holm P, Liska J. Follow-up of patients operated on with arterial patch angioplasty of the left main coronary artery. Ann Thorac Surg 2006; 81: 1249-1255.

393. Dion R, Verhelst R, Matta A, Rousseau M, Goenen M, Chalant C. Surgical angioplasty of the left main coronary artery. J Thorac Cardiovasc Surg 1990; 99: 241-249.

394. Mavroudis C, Backer CL, Duffy CE, Pahl E, Wax DF. Pediatric coronary artery bypass for Kawasaki congenital, post arterial switch, and iatrogenic lesions. Ann Thorac Surg 1999; 68: 506-512.

395. Mavroudis C, Backer CL, Muster AJ, Pahl E, Sanders JH, Zales VR, et al. Expanding indications for pediatric coronary artery bypass. J Thorac Cardiovasc Surg 1996; 111: 181-189.

396. Kampmann C, Kuroczynski W, Trubel H, Knuf M, Schneider M, Heinemann MK. Late results after PTCA for coronary stenosis after the arterial switch procedure for transposition of the great arteries. Ann Thorac Surg 2005; 80: 1641-1646.

397. Abhaichand R, Morice MC, Bonnet D, Sidi D, Bonhoeffer P. Stent supported angioplasty for coronary arterial stenosis following the arterial switch operation. Catheter Cardiovasc Interv 2002; 56: 278-280.

398. El-Segaier M, Lundin A, Hochbergs P, Jogi P, Pesonen E. Late coronary complications after arterial switch operation and their treatment. Catheter Cardiovasc Interv 2010; 76: 1027-1032.

399. Agnoletti G, Bajolle F, Bonnet D, Sidi D, Vouhé P. Late coronary complications after arterial switch operation for transposition of great arteries. Clinical and therapeutic implications. Images Paediatr Cardiol 2005; 7: 1-11.

400. Sung SC, Chang YH, Lee HD, Woo JS. Left subclavian artery free graft as a salvage technique after failed coronary artery transfer in arterial switch operation. Eur J Cardiothorac Surg 2005; 27: 515-516.

401. Legendre A, Chantepie A, Belli E, Vouhé PR, Neville P, Dulac Y, et al. Outcome of coronary artery bypass grafting performed in young children. J Thorac Cardiovasc Surg 2010; 139: 349-353.

402. Robotin MC, Bruniaux J, Serraf A, Uva MS, Roussin R, LacourGayet F, et al. Unusual forms of tracheobronchial compression in infants with congenital heart disease. J Thorac Cardiovasc Surg 1996; 112: 415-423.

403. Toker A, Tireli E, Bostanci K, Ozcan V, Dayioglu E. Uncommon complication of arterial switch operation: tracheobronchial compression. Ann Thorac Surg 2000; 69: 927-929.

404. Worsey J, Pham SM, Newman B, Park SC, del Nido PJ. Left main bronchus compression after arterial switch for transposition. Ann Thorac Surg 1994; 57: 1320-1322.

405. McElhinney DB, Reddy VM, Reddy GP, Higgins CB, Hanley FL. Esophageal compression by the aorta after arterial switch. Ann Thorac Surg 1998; 65: 246-248.

406. Gandhi SK, Pigula FA, Siewers RD. Successful late reintervention after the arterial switch procedure. Ann Thorac Surg 2002; 73: 88-93.

407. Corno A, Giamberti A, Giannico S, Marino B, Rossi E, Marcelletti C, et al. Airway obstructions associated with congenital heart disease in infancy. J Thorac Cardiovasc Surg 1990; 99: 1091-1098.

408. Kumar A, Taylor GP, Sandor GG, Patterson MW. Pulmonary vascular disease in neonates with transposition of the great arteries and intact ventricular septum. Br Heart J 1993; 69: 442-445.

409. Damen J, Hitchcock JF. Reactive pulmonary hypertension after a switch operation. Successful treatment with glyceryl trinitrate. $\mathrm{Br}$ Heart J 1985; 53: 223-225.

410. Kerstein D, Levy PS, Hsu DT, Hordof AJ, Gersony WM, Barst RJ. Blade balloon atrial septostomy in patients with severe primary pulmonary hypertension. Circulation 1995; 91: 2028-2035.

411. Blanc J, Vouhé P, Bonnet D. Potts shunt in patients with pulmonary hypertension. N Engl J Med 2004; 350: 623.

412. Aziz KU, Paul MH, Rowe RD. Bronchopulmonary circulation in d-transposition of the great arteries: possible role in genesis of accelerated pulmonary vascular disease. Am J Cardiol 1977; 39: 432-438.

413. Wernovsky G, Bridges ND, Mandell VS, Castaneda AR, Perry SB. Enlarged bronchial arteries after early repair of transposition of the great arteries. J Am Coll Cardiol 1993; 21: 465-470.

414. Golej J, Trittenwein G, Marx M, Schlemmer M. Aortopulmonary collateral artery embolization during postoperative extracorporeal membrane oxygenation after arterial switch procedure. Artif Organs 1999; 23: 1038-1040.

415. Jowett V, Derrick G, Tsang V, Marek J. Coil occlusion of aortopulmonary collateral arteries before arterial switch procedure in an infant with transposition of the great arteries. Circ Cardiovasc Imaging 2008; 1: E17-E18.

416. Irving C, Chaudhari M. Enlarged bronchial collateral artery complicating recovery after arterial switch for simple transposition of the great arteries. Interact CardioVasc Thorac Surg 2008; 7: 1176-1177.

417. Santoro G, Carrozza M, Russo MG, Calabro R. Symptomatic aorto-pulmonary collaterals early after arterial switch operation. Pediatr Cardiol 2008; 29: 838-841. 